\title{
DIENSTSTELLEN DER NSDAP UND IHRER ORGANISATIONEN
}

Schriftgut der NSDAP, ihrer Gliederungen und angeschlossenen Verbände und der Vielzahl von Ämtern und Dienststellen, die von ihr nach 1933 auf allen Verwaltungsebenen errichtet wurden, ist wesentlich schlechter überliefert als die Registraturen der korrespondierenden staatlichen Einrichtungen. Nicht nur waren die Verluste durch Kriegsereignisse und Zerstörungsmaßnahmen 1945 gröBer, hinzu kommt noch, daß erhalten gebliebene Akten durch die Besatzungsmächte zersplittert wurden, um Unterlagen für die politische Säuberung zu gewinnen. Der Hauptteil der dabei gebildeten personenbezogenen Akten (biographic files), die Schriftstuicke unterschiedlicher Provenienz vereinigen, befindet sich im Berlin Document Center im Besitz der USA, u. a. in der sogenannten Parteikanzlei-Korrespondenz (PKK) über ca. 1,3 Millionen Personen; darin sind z. B. Registratursplitter von Gau- und Kreisleitungen, Karteikarten von Ortsgruppen, Erhebungsbögen der Parteistatistik 1939 und SA-Personalbögen zu finden. Kleinere dort gebildete Sammlungen von "Gaukorrespondenz" sind auch die Grundlage für einen Teil der in Staatsarchiven der Länder der ehemaligen amerikanischen Besatzungszone gesammelten NS-Überlieferung geworden. DaB Akten von Spruchkammern über einzelne Entnazifizierungsverfahren weitere Splitter enthalten, ist nicht auszuschlieBen. Bei den vom Bundesarchiv übernommenen Beständen handelt es sich dagegen um Korrespondenzund Sachakten, bei denen eine Aufteilung nach Personenbetreffen nicht möglich gewesen war oder bei denen man darauf verzichtet hat. AuBerdem entstand eine Sammlung von Einzeldokumenten und Vorgängen, die besonders interessant schienen und deshalb aus dem Registraturzusammenhang gelöst wurden (BA, Sammlung Schumacher), nach Möglichkeit bei fortschreitender ErschlieBung der Bestände aber wieder ihrer Provenienz zugeordnet werden sollen.

Unter diesen Umständen gewinnt die reichhaltige Überlieferung von gedruckten oder vervielfältigten Veröffentlichungen der NSDAP, die zum Teil nur für den Dienstgebrauch bestimmt waren, besondere Bedeutung; sie wird deshalb hier berücksichtigt. soweit sie sich - wenn auch Zeitschriften und Serien nur selten ohne Lücken - im Bundesarchiv (Best. NSD) oder (falls dort nicht vorhanden) im Institut für Zeitgeschichte (IfZ) befindet, das ein Verzeichnis demnächst veröffentlichen wird. Es ist jedoch darauf hinzuweisen, daB weitere Quellen dieser Art in vielen Bibliotheken zu ermitteln sein dürften.

Mit Unterstützung der Deutschen Forschungsgemeinschaft wurden drei Projekte durchgeführt, verlorene Akten der NSDAP aus anderen Beständen zu rekonstruieren oder dort nachzuweisen. Auf die Ergebnisse wird ebenfalls verwiesen, aber auch hier muB betont werden, daB sie nur einen beschränkten Ausschnitt bieten können und in zahlreichen weiteren Akten in staatlichen, besonders aber auch kommunalen Archiven Korrespondenz mit Dienststellen der NSDAP zu finden sein dürfte, deren eigene Akten nicht mehr vorhanden oder in personenbezogenen Dossiers verschwunden sind.

Lit: G. C. BROWDER: Problems and Potentials of the Berlin Document Center. 1972. - H. MEYER: Berlin Document Center. 1988. - H. JAEGER: Problemarik und Aussagewen überlieferungsgestöner Bestände der NS-Zeit 1975. - AKTEN der Paneikanzlei der NSDAP. 1983. - H. RUMSCHÖTTEL: Inventarisierung von Schriftgut der NSDAP und ihrer Gliederungen aus Empfängerüberlieferung [in Bayern]. 1978. - Das SCHRIFTGUT der NSDAP. ihrer Gliederungen und angęschlossenen Verbände [in Nordrhein-Westfalen]. 4 Bde. 1981 ff. 


\subsection{Reichsleitung der NSDAP}

Von den 36 unterschiedlich bezeichneten zentralen Dienststellen der Partei und ihrer Organisationen, die das „Organisationsbuch der NSDAP“ 1940 aufführe und über deren Entwicklung dessen sieben Ausgaben von 1936 bis 1943 AufschluB geben, ist relativ wenig überliefert; soweit sie für eine Gliederung oder einen angeschlossenen Verband zuständig waren, sind sie in den Abschnitten 9.3 und 9.4 behandelt. Sie hatten ihren Sitz fast sämtlich in München. der „Hauptstadt der Bewegung“. Die meisten unterstanden dem Stellvertreter des Führers oder einem der 21 Reichsleiter (mit Ausnahme von Wilhelm Grimm), von denen jedoch der Reichsorganisationsleiter als gleichzeitiger Leiter der DAF und als Aufsichtsbehörde für Reichsfrauen-, Reichsstudentenund -dozentenführung und die sieben Hauptämter für Volksgesundheit. Kriegsopfer, Beamte, Erzieher, Technik, Volkswohlfahrt und Kommunalpolitik mit den entsprechenden Verbänden eine besondere Stellung einnahm. Ihre Arbeit richtete sich nach der "Führungs- und Geschäftsordnung der NSDAP“ von 1937, die personelle Besetzung 1941 und 1943 ergibt sich aus Fernsprechverzeichnissen. Im .,Verordnungsblatt der Reichsleitung der NSDAP“ (5 Bde, 1932-1943, dazu Zusammenfassung aller gültigen Verordnungen 1937, Best. NSD 13) wurden Anweisungen und Personalnachrichten bekanntgegeben.

\subsubsection{Kanzlei des Führers der NSDAP, Berlin}

BA, Best. NS 51 ZStA, Best. $62 \mathrm{Ka} 1$

Die Überlieferung der 1934 unter dem früheren Geschäftsführer der Reichsleitung Reichsleiter Philipp Bouhler eingerichteten Kanzlei, die sich zunächst mit Eingaben aus der Bevölkerung an Hitler befassen sollte und deren Aufgaben der Präsidialkanzlei im staatlichen Bereich entsprachen, ist recht unvollständig; auch die dort bearbeitete „Sammlung der Reden, Erlasse und Verlautbarungen des Führers“ ist nur für 1943 (BA, Best. NSD 1) vorhanden.

Der Hauptteil befindet sich in Potsdam (242 Bde, 1933-1945, ab 1925/1929). Er stammt 2. T. aus der Adjutantur des Führers und der Hausintendantur und enthält Vorgänge zur Außenpolitik (16 Bde. 1935-1942), vor allem über deutsch-französische und deutsch-englische Beziehungen, Außen- und Innenpolitik Österreichs vor dem AnschluB, politische Lage in Jugoslawien und Rumänien und Berichte u. a. über den Spanischen Bürgerkrieg und die Deutsch-Südafrikanische Gesellschaft e.V. Berlin. Die Überlieferung zur Innenpolitik (20 Bde, 1934-1944) besteht vornehmlich aus Korrespondenzakten sowie zeitlich und inhaltlich unvollständigen Reihen des Reichsverfügungsblattes der NSDAP, Ausgabe A, Anordnungen, Rundschreiben des Stellvertreters des Führers, der Parteikanzlei, des Reichsschatzmeisters sowie einzelner Reichsministerien.

Einen dritten Komplex bilden Handakten (5 Bde, 1937-1943) des Reichsamtsleiters SS-Hauptsturmführer Cnyrim, Reichshauptstellenleiters Dr. Wittig, des persönlichen Adjutanten Hitlers SS-Obergruppenführer Julius Schaub und von Bouhlers Stellvertreter Albert Bormann u. a. zur wirtschaftlichen Behandlung der UdSSR, vornehmlich jedoch zu routinemäßigen Fragen der Kanzlei des Führers.

Die einzelnen Hauptämter der Kanzlei sind wie folgt vertreten (insgesamt 143 Bde): Hauptamt I - Persönliche Angelegenheiten Hitlers (42 Bde, 1925-1944).

Hauptamt II - Angelegenheiten aus Parei, Staat und Wirtschaft (9 Bde, 1932-1945). Hauptamt III - Gnadensachen (18 Bde, 1940-1945, einige Vorgänge über Einzelfälle 1944-1945 und Bericht über eine Tagung 1938 im BA-Bestand). 
Hauptamt IV - Wirtschaftliche und soziale Angelegenheiten (65 Bde, 1937-1945), einzelne Akten in Grundsatzangelegenheiten und Eingaben.

Die Koblenzer Überlieferung ist beschränkt auf einige Organisationsunterlagen (1934, 1938, ein Band betr. Zuständigkeitsabgrenzung zur Parteikanzlei, 1943-1944, auch ZStA), Vorgänge über Planungen für eine Verwaltungsvereinfachung in der Wirtschaft (1939-1941), Eingaben von Ausländern (1944-1945), Glückwünsche (1936/37) und Material zur Ahnentafel Bouhlers (3 Bde, 1935-1941); dem Bestand, der im übrigen ebenfalls einige Aktensplitter aus Bouhlers Zuständigkeit vor 1933 enthält (weitere 5 Bde vornehmlich Schriftwechsel mit Ortsgruppen und Mitgliedern sowie einzelne politische Ausarbeitungen 1928-1932 ZStA, Best. 62 Re 7), wurden auch Kopien von einzelnen Briefen aus der Korrespondenz Hitlers mit Mussolini (1931-1944, aus dem Zentralen Staatsarchiv Rom) zugewiesen.

Die Verantwortung der Dienststelle für die Ermordung der Geisteskranken ab Kriegsbeginn ergibt sich nur aus den Beweisdokumenten der Prozesse gegen die daran beteiligten Mitarbeiter und die Angestellten der Außenstelle $\mathrm{T} 4$ in der Tiergartenstraße 4: gegen Bouhlers Stellvertreter Viktor Brack im Nürnberger ÄrzteprozeB, gegen den Amtsleiter Hans Hefelmann und den T 4 - Leiter Gerhard Bohne vor dem Landgericht Limburg 1964.

Ebenfalls verloren sind die Akten der Privatkanzlei Adolf Hitler, die von Albert Bormann geleitet und 1938 in die Kanzlei des Führers eingegliedert wurde; vielleicht stammen Auszüge aus Notizbüchern des Sekretariats über Hitlers Tagesablauf (19341943) im Hauptarchiv der NSDAP (NS 26) dorther. DaB Martin Bormann, der Chef der Parteikanzlei, 1943 den zusätzlichen Titel „Sekretär des Führers" erhielt, hatte organisatorisch keine Folgen.

Ein eigener Bestand wurde in Koblenz gebildet für die formal Bouhler unterstehende, faktisch aber selbständige

Persönliche Adjutantur des Führers und Reichskanzlers BA, Best. NS 10 Die von ihr vorhandenen Akten stammen fast sämtlich aus der Zeit, in der sie von Fritz Wiedemann geleitet wurde (1934-1939, Ergänzung durch Privatkorrespondenz ab 1937 und Nachkriegsaufzeichnungen Kl. Erw. 671), während die Tätigkeit der beiden anderen Adjutanten Julius Schaub (1923-1945, Freispruch durch Landgericht München II 1949 s. JUSTIZ UND NS-VERBRECHEN Nr. 123) und Wilhelm Brückner (19301941) weniger deutlich wird. Es handelt sich überwiegend um Korrespondenzserien; Partner sind u. a. die Präsidialkanzlei (24 Bde, 1934-1941), die Reichskanzlei (5 Bde, 1938-1940), andere Reichs- und Länderministerien und die Adjutantur der Wehrmacht (22 Bde, 1933-1940, darin Berichte Papens aus Wien 1934-1938), der Stab des Stellvertreters des Führers und die Ämter der Reichsleitung (16 Bde, 1933-1940), Gau- und Kreisleitungen (6 Bde, 1933-1940). Den Hauptteil bilden private Zuschriften aus dem Inland (397 Bde, 1935-1940) und Ausland (3 Bde), z. T. mit dadurch ausgelöster weiterer Korrespondenz mit Behörden. Die wenigen Sachakten betreffen Außenpolitik (14 Bde, 1934-1940, neben wenigen Berichten der Dienststelle Ribbentrop und aus dem Ausland vor allem Pressematerial), Innen- und Kulturpolitik (12 Bde, 1934-1940, dabei Kirchenfragen und Schriftwechsel mit Künstlern), Hitlers Haushalt (8 Bde, 1932-1940), Staatsbesuche und andere Veranstaltungen (10 Bde, 1936-1941), einzelne Unterstützungs- und Gnadensachen (6 Bde) und Dienststellenverwaltung (5 Bde, u. a. Sicherheitsvorschriften, 1934-1940). 
Lit.: FINDBÜCHER zu Beständen des Bundesarchivs. Bd. 3. 1970. - F. WIEDEMANN: Der Mann, der Feldhert werden wollte. 1964. - C. SCHROEDER: Er war mein Chef. 1985. - G. ALY: Aktion T 41939 1945. 1987. - J. NOAKES: Philipp Bouhler und die Kanzlei des Führers der NSDAP. 1986. - TRIALS of War Criminals. vol. 1.

\subsubsection{Stab des Stellvertreters des Führers/Parteikanzlei}

BA, Best. NS 6

Der Bestand enthält nur wenige Akten (darunter 5 Bde aus der Adjutantur, 1924-1941) aus dem Stab des Stellvertreters des Führers, mit dem Rudolf $\mathrm{HeB}$ ab April 1933 seine Aufgabe erfüllte, die Partei ,einheitlich auszurichten und politische Richtlinien zu geben" und an allen staatlichen Maßnahmen mitzuwirken. Überwiegend stammt er aus der daraus nach HeB' Englandflug unter dem bisherigen Stabsleiter Martin Bormann hervorgegangenen Parteikanzlei. Einen Hauptbestandteil bildet die Sammlung der Rundschreiben, Anordnungen, Verfügungen (46 Bde in chronologischer Ordnung, 1933-1945 April, 7 Bde nach Sachgebieten), die neben dem "Reichsverfügungsblatt“ (1940-1945, NSD 3) und den „Vertraulichen Informationen“ (15 Bde, 1940-1945, ebda) die Tätigkeit aller Parteistellen regelten. Von besonderer Bedeutung sind Notizen und Vermerke über neun Besprechungen mit Hitler (1940, 1942, 1944, 1945) und die „Kaltenbrunner-Berichte“ nach dem 20. Juli 1944 (zusammen mit anderen Unterlagen dazu 29 Bde, 1944-1945). Sachakten sind aus folgenden Gebieten vorhanden:

- Organisation und Dienststellenverwaltung, auch der Dienststelle Berlin (54 Bde, meist 1942-1945) und der Verwaltung Obersalzberg (10 Bde. 1936-1945).

- Parteiangelegenheiten im allgemeinen (18 Bde, dabei Vorlagen an Bormann, 19381945).

- Führerkorps der NSDAP (11 Bde, 1939-1945).

- Lage- und Stimmungsberichte (29 Bde, 1935, 1943-1945, dabei der Regierungspräsidenten von NiederbayernlOberpfalz. Aurich. Schleswig und Osnabrïck und des Bremer Regierenden Bürgermeisters, „Stimmen des Auslands in Presse und Schriftum“ 1940. 1941 im IfZ).

- Mobilmachung und Reichsverteidigung (37 Bde, 1937-1945).

- Volkssturm (8 Bde, 1944-1945, dazu 10 Folgen ..Deutscher Volkssturm. - Der Dienstappell"“ in NSD 3).

- Nationalsozialistische Führung und Erziehung der Wehrmacht (49 Bde, vor allem betr. Ausbildung, Einsatz und Beurteilung von NS-Führungsoffizieren, 1944-1945).

- Maßnahmen gegen politische Gegner und Feindpropaganda (13 Bde, 1938-1945, mit Meldungen über einzelne Personen).

- Volkstum, Bevölkerungs- und Rassenpolitik (vor allem 15 Bde betr. Förderung volksdeutschen Schriftums, 1935-1941, und 11 Bde über Rassenzugehörigkeit der Bevölkerung einzelner europäischer Staaten, 1941).

- Wirtschaftspolitik (1938-1945): Außenwirtschaft (5l Bde, u. a. Devisenbewirtschaftung), gewerbliche Wirtschaft (5 Bde), Geld- und Kapitalmarkt (74 Bde), Versicherungswesen (2 Bde). Berufsbildung (2 Bde), Bauwirtschaft (35 Bde), Wohnungsbau und Siedlungswesen (ca. 200 Bde, u. a. Deutsches Wohnungshilfswerk, Eingaben und Einzelfallakten, Führerstiftung „Wohnungsbau Linz“), Ernährung und Landwirtschaft (3 Bde), ferner „Der Gauwirtschaftsberater. Mitteilungsblatt für den persönlichen Gebrauch“ (24 Bde, 1941-1943, NDS 3, „Nationalsozialistische Wirtschaftspolitik“ 1942-1944 im IfZ). - Verwaltung und Recht (19 Bde, 1935-1944). 
- Kulturpolitik: Kirchliche Angelegenheiten (5 Bde, 1937-1942), Propaganda (3 Bde, 1938-1944), Schule und Hochschule (16 Bde, 1935-1944), "Sonderauftrag Linz“ (Beschaffung von Kunstwerken für das geplante Führermuseum, 14 Bde, 1941-1945).

Im Berlin Document Center befinden sich ca. 22000 Anträge auf Verleihung von Kriegsverdienstkreuzen und -medaillen an Parteifunktionäre, die über die Gauleitungen und mit deren Stellungnahme eingereicht wurden; sie enthalten außer den Personalien der Vorgeschlagenen kurze Begründungen, z. B. „Schaffung von Unterkünften für Rüstungsarbeiter und Steigerung der Leistung von Ostarbeitern".

Im Auftrag Bormanns entstanden auch die Aufzeichnungen über Hitlers Gespräche im Führerhauptquartier (oben Abschnitt 8.1.2) durch Picker und Ministerialrat Heim (eine Aussage von ihm IfZ, Best. ZS 243). Über seine Tätigkeit beim Stellvertreter des Führers hat Willi Krämer einen Bericht vorgelegt (IfZ, ZS 1951). Ergänzungsüberlieferung enthalten die Akten des IMT-Prozesses gegen HeB und Bormann. Die im Schriftgut anderer Behörden und Dienststellen enthaltene Korrespondenz mit der Parteikanzlei ist als Mikrofiche-Edition zugänglich.

Zum Stab des Stellvertreters des Führers gehörte die in Berlin für Ribbentrop vor seiner Emennung zum Botschafter und Außenminister eingerichtete, aber auch danach fortgeführe

Dienststelle des Beauftragten für außenpolitische Fragen Von ihr ist ein kleiner Aktenbestand erhalten (86 Bde und Einzelvorgänge, meist ab 1937). Dabei handelt es sich um verschiedene Serien von vertraulichen und anderen, auch SD-Berichten (20 Bde, 1935-1944) und einige Unterlagen über Spanien (4 Bde), die Sowjetunion und den Vatikan (je $3 \mathrm{Bde}$ ), hauptsächlich aber über Beziehungen zu anderen Dienststellen und Organisationen der NSDAP (25 Bde). Hinzu kommen Vorgänge über Personal- und Organisationsangelegenheiten (4 Bde), über ausländische Presse und Journalisten (4 Bde), einzelne Persönlichkeiten (5 Bde), schließlich über Privatangelegenheiten Ribbentrops.

Von den übrigen bei der Parteikanzlei angesiedelten Ämtern sind Hauptarchiv der NSDAP, Leitung der Auslandsorganisation und Rassenpolitisches Amt unten berücksichtigt, Schriftgut des Beauftragten für alle Fragen der Technik und ihrer Organisation (Todt, bzw. Speer) und des Sachbearbeiters für alle Fragen der Volksgesundheit (Conti) dürfte mit den Registraturen der von ihnen ebenfalls geleiteten Hauptämter vereinigt gewesen sein, und dasselbe ist vom Amt für Sippenforschung anzunehmen, das mit dem Reichssippenamt (Abschnitt 2.1.1.2.2) personell verbunden war. Von Himmlers Hauptamt für Volkstumsfragen liegen nur "Mitteilungen“ (1943-1944, BA, NSD 29) vor, aus der Tätigkeit des Beauftragten für den Neubau des Reiches (Gauleiter Adolf Wagner) und des Beauftragten für Fragen der Finanz- und Steuerpolitik (Staatssekretär Fritz Reinhardt) ist nichts überliefert.

Lit: FINDBÜCHER zu Beständen des Bundesarchivs. Bd. 23. - AKTEN der Pareikanzlei der NSDAP. Microfiche-Edition. 1983. - L. BESYMENSKI: Die letzlen Notizen von Martin Bormann. 1974. - D. REBENTISCH: Reichskanzlei und Partei- Kanzlei im Staat Hiders. - SPIEGELBILD einer Verschwörung. 1984. - H. PICKER: Hitlers Tischgespräche. 2. Auf. 1965. - W. JOCHMANN: Adolf Hitler. Monologe im Führerhauptquartier. 1980. - A CATALOG of Files and Microfilms. vol. III. S. 340-343. - W. KRÄMER: Vom Stab HeB zu Dr. Goebbels. 1979. - J. v. LANG: Der Sekretär. Martin Bormann. 1977. - E. KUBIN: „Sonderauftrag Linz". 1989. - H. A. JACOBSEN: Nationalsozialistische AuBenpolitik. 1968. S. 252-318, 868-871. - C. MADAJCZYK: Das Hauptamt für Volkstumsfragen. 1986. 


\subsubsection{Reichsorganisationsleiter}

BA, Best. NS 22

Einen Querschnitt der von Robert Ley als Reichsorganisationsleiter veranlaBten Maßnahmen (zu seiner gleichzeitigen Funktion als Leiter der Deutschen Arbeitsfront unten 9.4.1) bietet eine Sammlung seiner Anordnungen, Rundschreiben und Mitteilungen (27 Bde, 1932-1943). Mit dem „Nationalsozialistischen Jahrbuch“ (18 Jahrgänge bis 1944) wandte er sich an die Öffentlichkeit, im „Schulungsbrief. Das zentrale Monatsblatt der NSDAP ab 1934 an alle Parteigenossen, der Unterrichtung der Funktionäre diente als „Verkündungsblatt für das Hauptstabsamt, das Hauptorganisationsamt, das Hauptpersonalamt und das Hauptschulungsamt“ ab 1937 „Der Hoheitsträger“.

Das überlieferte Aktenschriftgut verteilt sich, soweit es bisher erschlossen werden konnte, auf folgende Organisationseinheiten:

Hauptstabsamt unter dem Stabsleiter Heinrich Simon mit umfangreichem Schriftwechsel, von dem ein nicht unerheblicher Teil in die Zeit vor 1933 zurückreicht, mit Gauleitungen (24 Bde, 1932-1934), anderen Reichsdienststellen der NSDAP (11 Bde) und staatlichen Behörden (22 Bde, 1933-1943) sowie Sachakten über Dienststellenverwaltung (25 Bde, 1934-1943). Angelegenheiten der DAF und ihrer Organisation (36 Bde. 1933-1943) und anderer Ämter der Reichsleitung (42 Bde, 1932-1944).

Vom Hauptorganisationsamt mit dem Ausbildungsamt liegen Tageskopien der ausgegangenen Schreiben (41 Bde, 1937-1943), Tätigkeitsberichte von Gauorganisationsämtern (31 Bde im Alphabet von Hamburg bis Württemberg-Hohenzollern. 19351940) und Unterlagen über organisatorische Angelegenheiten der einzelnen Gaue vor (42 Bde, 1935-1937). Zahlreiche Organisationsübersichten und -pläne enthalten Akten über die einzelnen Dienststellen der Reichsleitung (117 Bde, 1940-1941); sie betreffen die DAF (72 Bde, 1940), die Ämter Rosenbergs (6 Bde, 1941), die NSV (7 Bde). die Reichsorganisationsleitung selbst (6 Bde), ein geplantes Oberes Amt Volksgesundheit, Rassenpolitik und Sippenkunde ( $3 \mathrm{Bde}$ ) und 18 weitere Ämter. Ein Entwurf zur „Reorganisation des Parteiapparats" 1940 (IfZ) hängt wohl damit zusammen. Andere Akten behandeln Ausbildungsfragen (u. a. Schießausbildung), Tagungen und Appelle der Politischen Leiter, Musik- und Spielmannzüge. Grundsätzliche Befehle und Vorgänge über Organisation und Personalangelegenheiten der Partei enthält auch die Sammlung Schumacher (6 Bde, 1922-1940). Die Akten werden ergänzt durch gedruckte Ausbildungsvorschriften (BA, NSD 9). Weitere Publikationen des Hauptorganisationsamtes sind Handbücher für die Arbeit der Kreis- und Ortsgruppenleitungen und Anschriftenverzeichnisse. Das Amt Statistik veröffentlichte als Ergebnis der ersten Erhebung bei sämtlichen Mitgliedern die „Parteistatistik. Stand 1. Januar 1935“ mit den vier Bänden über Mitglieder, po!itische Leiter, Gliederungen und angeschlossene Verbände. DAF.

Das Hauptschulungsamt, dem auch die Ordensburgen und Adolf-Hitler-Schulen unterstanden, ist u. a. durch eine Sammlung von Anordnungen (14 Bde, 1933-1943), von vertraulichen Informationsberichten über einzelne Länder (20 Bde, 1939-1941) und Manuskripte über „Deutsche Kultur im Ausland“ (21 Bde) sowie Material über „Große Deutsche" vertreten. Weitere Akten betreffen Lehrgänge für Südtiroler und andere Umsiedler auf Ordensburgen (7 Bde, 1940-1941) und Honorare für Beiträge zu „,Schulungsbrief" und "Hoheitsträger" (Kopien von Handakten betr. Wehrerziehung der politischen Leiter 1939-1941 im IfZ. Best. ED 27). Ergänzungsüberlieferung enthält der Nachlaß des Hauptschriftleiters des „Schulungsbriefs“, Reichsamtsleiter Woweries (WI, Abt. 1129 , mit dienstlicher Korrespondenz, Manuskripten und Unterlagen über Schulung und Propaganda bis 1945). Zahlreich sind die veröffentlichten ,Lehrstoffe“. .Mitteilungen“ und 
„Sondermitteilungen“ und Einzelschriften über weltanschauliche Fragen, die Gestaltung von Feiern und Gemeinschaftshäusern; von „Der Deutsche im Osten. Monatsschrift für Kultur, Politik und Unterhaltung“ (ab 1938) liegen nur Sonderdrucke und 3 Hefte (1944, IfZ) vor.

Die Überlieferung des Hauptpersonalamtes beschränkt sich auf Reste der Korrespondenz mit anderen Ämtern der Reichsleitung (10 Bde) und Gaupersonalämtern (8 Bde, 1936-1937), während die Organisationsleitung der Reichsparteitage mit Sachakten über alle Aspekte ihrer Planung und Durchführung (122 Bde, 1934-1940) vertreten ist, die außerdem im Hauptarchiv der NSDAP (NS 26, ca. 80 Bde, 11 weitere über die Zehnjahresfeier des Weimarer Parteitags 1936) dokumentient sind. Pläne für die Nürnberger Parteitagsbauten sind gesonder überliefert (BA, Best. Plan 1, 39, 40).

In Nürnberg selbst bestand seit $1935 \mathrm{der}$

\section{Zweckverband Reichsparteitag, Nürnberg}

Sein Schriftgut befindet sich im Stadtarchiv Nürnberg. Es handelt sich dabei um Akten über Organisation und allgemeine Verwaltung des Zweckverbandes (223 Bde, dabei 7 Bde Akten des Vorsitzenden, Reichsminister Kerrl, 1935-1941, und Niederschriften über die Sitzungen des Verwaltungsrates, 1935-1938), über die Bauverwaltung im allgemeinen (106 Bde), den Bau der KongreBhalle (314 Bde), des Märzfeldes (298 Bde, dabei Korrespondenz mit Speer und dem Bildhauer Josef Thorak, 1937-1942), des Deutschen Stadions (47 Bde), von Gästehaus, Lagern für die SA und andere Verbände und sonstige Anlagen (101 Bde), schlieBlich Sicherung und Nutzung sowie Schäden im Krieg (86 Bde).

Lit.: R. SMELSER: Roben Ley. 1989. - C. OLSCHEWSKI: Die Leitung der Politischen Organisation (PO) der NSDAP (1933/34). 1982. - M. H. KATER: The Nazi Pary. 1983. - J. HENKE: Die Reichsparteilage der NSDAP in Nürnberg 1933-1938. 1977.

\subsubsection{Reichsschatzmeister}

BA, Best. NS 1

Der Bestand enthält nur eine trümmerhafte Überlieferung aus den vielfachen Kompetenzen, die dem Reichsleiter Franz Xaver Schwarz aus seiner Verantwortung für die Finanzen der Partei gegenüber allen ihren Institutionen und Organisationen zugewachsen waren; soweit sie vom Berlin Document Center abgegeben wurden, ist mit der Entnahme personenbezogener Schriftstücke zu den dort verbliebenen biographic files zu rechnen. Sie stammt nach dem jetzigen Stand der Erschließung aus folgenden Organisationseinheiten nach dem Stand von 1940, der später mehrfach verändert wurde:

Stabsamt, ab 1942 Kanzlei mit Adjutantur, Presse- und Mob.-Abteilung: Neben persönlichen Unterlagen Schwarz', Korrespondenz mit der Parteikanzlei (überwiegend 1937-1945), Reden, Jahres- und Tätigkeitsberichten, Vorgängen über Veranstaltungen (mit 17 Bden Presseausschnitten) und organisatorische Angelegenheiten liegt eine Sammlung von Rundschreiben, Verfügungen und Bekanntmachungen vor (23 Bde, 1926-1945); für die vermögensrechtlichen Personalbestimmungen gab es daneben das „Besoldungs- und Versorgungsblatt der NSDAP“ und ebenfalls veröffentlichte „Rundschreiben“ (2 Bde, 1926-1935) und „Erlasse des Reichsschatzmeisters“ (1938-1941, z. T. nur IfZ), ferner Einzelveröffentlichungen mit Kassen- und ähnlichen Vorschriften. Eine Aktenserie enthält Verzeichnisse und andere Unterlagen über den Grundbesitz der Gaue, Kreise und Ortsgruppen, der SA, des NSKK, der HJ, der NS-Frauenschaft und des NSDStB (54 Bde, 1939-1945). Meldungen der Gauleitungen betreffen Luftangriffe und 
Fliegerschäden (17 Bde, 1940-1944 Dez.), andere Akten die Erfassung von Ausrüstungsgegenständen und ihre Abgabe an die Wehrmacht (25 Bde, 1938-1945). Auch der Einsatz des Hilfszugs Bayern zur Versorgung der Teilnehmer an Großveranstaltungen oder der Opfer von Katastrophen ist dokumentiert (8 Bde, 1935-1942).

Aus dem Reichsrechnungsamt sind Vermögensübersichten der Gaue, Kreise und Ortsgruppen überliefer (183 Bde, 1936-1938).

Die Akten des Hauptamtes Reichsfinanzverwaltung betreffen die Finanzplanung der Dienststellen der Reichsleitung (ca. 50 Bde, 1937-1944, vor allem Reichspropagandaleitung und Ämter Rosenbergs, auch Bereitstellung von Mitteln für volksdeutsche Minderheiten, Ausstellung und Errichtung von „Parteiforen“) und von Gauen, Kreisen und Ortsgruppen (29 Bde, mit Haushaltsvoranschlägen, 1941-1945). Zu den Akten der Zentral-Kassen- und Vermögensverwaltung (14 Bde, 1938-1943) gehören auch Vorgänge über Arisierungen. Von der Reichsrevisionsabteilung haben sich nur Akten über Ermittlungen gegen den Heilpraktikerbund (1934, ZStA, Best. $62 \operatorname{Re} 9$ ) erhalten.

Neben allgemeinen Akten des Reichsverwaltungsamtes (15 Bde, 1935-1944) enthält der Bestand von der zugehörigen Reichszentralstelle für Durchführung des Vierjahresplanes Unterlagen über Bewirtschaftungsmaßnahmen vor allem bei Baumaterial (28 Bde, 1937-1945).

Aus dem 1941 mit erweiterten Kompetenzen vom Reichsverwaltungsamt getrennten Zentralpersonalamt stammen Personalübersichten und -statistiken für einzelne Gaue (10 Bde, dabei Moselland, Kurhessen und Westfalen-Süd, 1939-1941), Bewerbungen (25 Bde, 1943-1944) und Akten über die Versorgung von Hinterbliebenen Gefallener (3 Bde, 1939-1945), ferner die Mitteilungen über „Personalveränderungen“ (7 Bde, März 1942-1944 Dez.); Personalakten hauptberuflicher Angestellter der NSDAP sind in die Sammlung PKK des Berlin Document Center gelangt.

Besonders umfangreich ist die Überlieferung des Rechtsamtes. Sie besteht vor allem aus Sammelakten über den Erwerb und die Zuweisung von (nicht selten enteigneten) Grundstücken im allgemeinen (23 Bde, 1934-1944), aus staats- und volksfeindlichem Vermögen in Österreich und anderen eingegliederten Gebieten (12 Bde, 1938-1944) und an die einzelnen Bedarfsträger (184 Bde, 1935-1944, u. a. „Hohe Schule“, 26 Bde an Gaue, 16 Bde an SA, 18 Bde an Allgemeine SS, 3 Bde an SD, 11 Bde an NSKK, 58 Bde an HJ, 15 Bde an NS-Frauenschaft, 5 Bde an NSV, 3 Bde an NSDStB). Weiterhin sind Stellungnahmen zu Rechtsfragen und Gesetzentwürfen und Akten über Rechtsangelegenheiten von Gauen und Organisationen (7 Bde, 1934-1938), über einzelne Zivilund andere Prozesse (12 Bde Sammelakten, 1933-1943), über Steuerprobleme (20 Bde, 1935-1944, u. a. Steuerbefreiungen für die NSDAP), Sammlungsrecht (8 Bde, 19371942) und Versicherungswesen (15 Bde, 1929-1944, zuletzt aus Hauptamt IX) vorhanden.

Zum Rechtsamt gehörte auch das Amt für Mitgliedschaftswesen mit der Reichskartei. Diese befindet sich mit 10703537 Karten (einschlieBlich einer Warnkartei über Personen, die nicht aufgenommen werden sollten) als NSDAP Master File im Document Center, das außerdem ca. 600000 Anträge auf Aufnahme in die NSDAP besitzt; die Angaben beschränken sich jedoch in beiden auf Name, Vorname, Geburtsdatum und -ort, Adresse, Beruf, Eintrittsdatum. Weitere ca. 40000 Anträge sind im Bayerischen Hauptstaatsarchiv überliefert (67 Bde, 1938). Sie stammen weit überwiegend aus Österreich und dem Sudetenland und nur aus acht Gauen im alten Reichsgebiet (dabei Schwaben, Hessen-Nassau, Weser-Ems, Westfalen-Süd, neun Berliner Kreise; sieben 
Kreise der Bayerischen Ostmark und Anträge sudetendeutscher Flüchtlinge in Württemberg, Bayern, dem Rheinland und Bremen bei den Anträgen aus dem Sudetengau). Vielfach sind ihnen als Anlage Fragebögen mit Angaben auch zu den Personalien von Eltern und Ehepartnern, Zahl der Kinder, Vorstrafen, Mitgliedschaft in anderen Organisationen, bei den Österreichern zusätzlich über Schulbildung, Berufslaufbahn, politische Betätigung vor 1938 beigefuigt, zu denen als Anlagen Stellungnahmen von Gau- und Kreisleitungen und bei den Aufnahmeanträgen von nach dem Ende ihrer Dienstzeit ausgeschiedenen Berufssoldaten, die der Partei vorher nicht hatten beitreten können, Zeugnisse ihrer Vorgesetzten gehören können. Der über einzelne Parteigenossen, vor allem über den Verlust von Mitgliedsbüchern, Beitragszahlungen, Anerkennung früherer Mitgliedschaft geführte Schriftwechsel bildet einen erheblichen Teil der PKK-files des Document Center, während der Bestand im Bundesarchiv lediglich wenige Sachakten (21 Bde, 1924-1945) enthält.

Weitere Teilbestände im Bundesarchiv stammen von der Verwaltung der Reichsparteitage (44 Bde, 1928-1944) und dem Amt für Heizung und Lüftung (24 Bde, 1935-1944, u. a. über Fernheizwerke in den $K L$ Ravensbrück und Dachau), ferner von der Hilfskasse der NSDAP (11 Bde, 1930-1943) zur Unterstützung von Parteigenossen in Notfällen (Schriftwechsel ebenfalls im DC, PKK) und der für Uniformen, Abzeichen und Ausrüstung zuständigen Reichszeugmeisterei, die auch ein eigenes ,Mitteilungsblatt" (1934-1944) veröffentlicht hat.

Als Sonderdienststelle unterstand dem Reichsschatzmeister die

\section{Bauleitung der NSDAP}

Neben einem Teilbestand im Bundesarchiv (18 Bde, 1933-1945, u. a. über Folgen von Luftangriffen) und Plänen für Bauten (vor allem der NSV, auch von Gauleitungen, SS, SA, NSKK und $H$ ) liegen von ihr mehr als 2000 Pläne und ein Rest von Akten (84 Bde, 1938-1945) im Bayerischen Hauptstaatsarchiv. AuBer Bauten in München (u. a. Braunes Haus, Parteikanzlei, Reichszeugmeisterei, Wohnung Hitlers) betreffen sie auch Parteibauten auf dem Obersalzberg, in Braunau, für den Reichssicherheitsdienst in Pullach, das SchloB in Posen, die Führerschule Bad Tölz, die Oberschule Feldafing, das Landestheater Linz und Ehrenmale für Gefallene in Frankreich.

Lit.: H. P. RASP: Eine Stadt für tausend Jahre. 1981. - D. DEGREIF: Franz Xaver Schwarz. Das Reichsschatzmeisteramt der NSDAP. 1989. - U. LÜKEMANN: Der Reichsschatzmeister der NSDAP. 1962.

\subsubsection{Reichspropagandaleitung, Berlin und München}

BA, Best. NS 18

Aus der von Goebbels in Personalunion mit dem Propagandaministerium geleiteten Zentrale für die Propaganda der Partei sind hauptsächlich Akten (ca. 850 Bde, 19391945) des Reichsrings für nationalsozialistische Propaganda und Volksaufklärung mit Sitz in Berlin, der ursprünglich die Maßnahmen der Gliederungen und Verbände koordinieren sollte, und seines Leiters Walter TieBler (Nachkriegsaufzeichnungen von ihm über seine Tätigkeit IfZ, Best. ED 58 und ZS 2327) überliefert. Sie betreffen Grundsatzfragen und Organisation (mit Aufzeichnungen über Tagungen, Rundschreiben an die Gaupropagandaleiter 1939-1942, Korrespondenz mit ihnen, u. a. Mainfranken und Württemberg-Hohenzollern 1939/40) und alle Methoden, mit denen die Bevölkerung für den Nationalsozialismus gewonnen werden sollte. Dazu gehören spezielle Kampagnen (z. B. „Mehr Höflichkeit“, „Kohlenklau“, Preisausschreiben), auch für bestimmte Ziel- 
gruppen, vor allem Landbevölkerung, Wehrmachtangehörige, Fremdarbeiter, der Einsatz von Rednern und Vortragsveranstaltungen, von Büchern und Broschüren, Film (mit Rundschreiben des Hauptamtes Film 1944) und Rundfunk, Plakaten, Mundpropaganda, Gegenpropaganda gegen Kirchen, Feindflugblätter und Auslandsrundfunk, aber auch gegen TabakmiBbrauch. Die Propaganda einzelner Organisationen, u. a. des Reichskolonialbundes, Kunst- und Kulturpflege, Musik- und Theaterveranstaltungen (z. B. Bayreuther Festspiele) sind ebenfalls dokumentiert. Ein kleiner Teilbestand stammt aus der Zeit vor 1933 (24 Bde). Gesondert überliefert sind einige Grundsatzvorgänge (Sammlung Schumacher, 3 Bde, 1932-1943) und eine Sammlung von Presseausschnitten (ZSg 118, 33 Bde) über Reden Hitlers (16 Bde, 1932-1943), Görings (4 Bde), Hans Franks. Rosenbergs, Epps, Mussolinis, Horthys und sieben anderer Politiker.

Die Überlieferung des Propagandastabs besteht dagegen nur aus wenigen Vorgängen und Berichten u. a. über das Nationalkomitee Freies Deutschland, Ereignisse am 20. Juli 1944 und die ProzeBführung Freislers gegen Beteiligte (1941-1944, ZStA, Best. $62 \operatorname{Re} 3$ ).

Mit den Monatsblättern „Unser Wille und Weg“, der „parteiamtlichen Propagandazeitschrift für die Politischen Leiter" (ab 1931), der Zeitschrift „Die Neue Gemeinschaft. Das Parteiarchiv für Nationalsozialistische Feier- und Freizeitgestaltung“ mit der Sonderausgabe „Unser Jahr“ und Einzelheften wie "Deutsche Weihnacht" ab 1935, mit dem „Kulturpolitischen Mitteilungsblatt“ ab 1941 wandte sich die Reichspropagandaleitung direkt, mit einem ,Redner-Vortragsdienst“ und Material zu Lichtbildvortägen u. a. über die Feldzüge der ersten Kriegsjahre indirekt an die Bevölkerung. Als Wandzeitungen verbreitete sie von 1936 bis 1943 die "Parole der Woche“ (ca. 400 Nrn. und weitere Plakate BA und KO). Die von ihr und den Gaupropagandaleitungen von 1937 bis 1944 außerdem herausgegebenen „Wochensprüche der NSDAP“, die in öffentlichen Gebäuden ausgehängt wurden, werden vom Institut für Kommunikationsgeschichte der FU Berlin systematisch gesammelt (bisher mehr als 550) und erschlossen.

Aus der Tätigkeit der Reichspropagandaleitung und ihres Reichsautozuges Deutschland stammen ferner 525 Platten und 43 Tonbänder, die nach dem Krieg am Tegernsee geborgen und dem Bundesarchiv als Stiftung des Hauses Bertelsmann überlassen wurden. Auf ihnen sind unveröffentlichte Reden Hitlers und anderer Parteiführer, z. T. auch Interviews, u. a. von Goebbels, Göring, Himmler, Speer, Todt und Auszüge aus den Verhandlungen gegen Beteiligte am Attentat vom 20. Juli 1944 vor dem Volksgerichtshof wiedergegeben. $\mathrm{Zu}$ den im Bundesarchiv/Filmarchiv liegenden 149 Filmen, die von der Reichspropagandaleitung und der von ihr gegründeten Deutschen Filmherstellungsund Verwertungsgesellschaft (DFG) hergestellt wurden, gehören Streifen zu den Reichstagswahlen, über die Reichsparteitage (u. a. "Triumph des Willens“, 1934) und andere Großveranstaltungen und Gedenktage und zur Werbung für den Kriegseinsatz. Weitere Filme (z. B. zur Werbung für Kraftfahrsport und HJ-Landdienst und über die NSDAP in Österreich vor 1938) befinden sich im Zentralen Filmarchiv Potsdam.

Lit.: GUDES to German Records. vol. 3, S. 16-23. - PAROLE der Woche. 1983. - H. v. KOTZE, H. KRAUSNICK: Es spricht der Führer. 1966. S. 369-379. - W. KRÄMER: Vom Stab HeB zu Dr. Goebbels. 1979. - H. BARKHAUSEN: Die NSDAP als Filmproduzentin. 1970. 


\subsubsection{Reichspressechef der NSDAP, Berlin und München}

BA, Best. NS 42

ZStA, Best. $62 \operatorname{Re} 3$

Der Koblenzer Bestand enthält lediglich Akten des Amtes Auslandspresse, vorwiegend Korrespondenz mit Personen und Institutionen in mehreren Ländern, vor allem den USA, GroBbritannien und Japan (28 Bde, 1931-1941), ferner einige Akten über ausländische Journalisten und Besucher (6 Bde, 1937-1942).

Im ZStA befinden sich (4 Bde, 1933-1944) u. a. Reden und Artikel des Reichspressechefs Otto Dietrich, der gleichzeitig seit 1937 auch Pressechef der Reichsregierung war (vgl. Abschnitt 4.1.2). Die „Tagesparolen" aus seinen Pressekonferenzen sind in beiden Beständen nur spärlich (BA, Januar bis April 1943), jedoch in den Sammlungen zur Pressepolitik (BA, ZSg. 101, 102) gut überliefert.

Die Unterrichtung der Presse wird durch folgende, für den genannten Zeitraum relativ vollständige, vorher und nachher z. T. durch einzelne Nummern repräsentierte Dienste dokumentiert (BA, NSD 13): „Nationalsozialistische Partei-Korrespondenz NSK. Pressedienst der NSDAP“, ab Oktober 1939 „Die Innere Front. Kriegssonderdienst der NSK mit Reichs-Jugend-Pressedienst, Deutsche Arbeitskorrespondenz, DAKKulturdienst und NSRL-Pressedienst“, 56 Bde, 1933-1945, 25. Februar); "Wirtschaftspolitischer Dienst. Sonderdienst der NSK“ (22 Bde, Mai 1934-1940); „Stimme der Heimat. Sonderdienst für Frontzeitungen." Hrsg. in Zusammenarbeit mit dem OKW (Folge 58 bis 322 in 8 Bden, Oktober 1940-1943); „Parteipresse-Sonderdienst“ (Prepa, nur Nr. 242/41 - 86/42); „RLD“ (Reichsleitungsdienst, 4 Bde, lückenhaft, 1940-1944) mit Sonderbeilage ,Interessantes aus der Auslandspresse“ (6 Bde, lückenhaft, März 1937-1941 November); vertrauliche „Hinweise der Reichspressestelle“ (Juni-November 1941).

Lit: GUIDES to German Records. vol 3. S. 13-15. - O. DIETRICH: Zwölf Jahre mit Hitler. 1955.

\subsubsection{Reichsleiter für die Presse}

Die Akten des Amtes, mit dem Reichsleiter Max Amann die von der Partei gegründeten oder früheren Eigentümern entzogenen Zeitungen kontrollierte, deren Zahl im ganzen Reichsgebiet von 86 im Jahre 1933 auf 200 bei Kriegsbeginn gestiegen war, sind offenbar gänzlich ebenso verloren wie das Schriftgut der Redaktionen und Verlage des „Völkischen Beobachters“ (vgl. jedoch den folgenden Abschnitt) und der übrigen NSTageszeitungen (zum „Stürmer" vgl. unten 9.2). Lediglich aus dem ebenfalls von Amann geleiteten Eher Verlag. Zentralverlag der NSDAP gibt es wenige Aktenreste (ca. 10 Bde Korrespondenz und Manuskripte, früher Library of Congress, jetzt BA, dort auch in NS 20 ein Band über die Verwaltung von Treuhandvermögen durch die Cautio, 1934-1939, und NSD 14 ein Bericht über die Entwicklung der Parteipresse bis 1936). Von seinen Tochtergesellschaften Vera-, Herold- und Phönix-Verlag befinden sich noch Akten im bayerischen Finanzministerium.

Korrespondenz über die NS-Presse und deren Auflage (1936-1939) und das Ergebnis einer Umfrage von 1937 über ca. 200 Zeitungen und Zeitschriften mit Belegstücken liegt im Hauptarchiv der NSDAP (NS 26) vor, die meisten Zeitungen selbst sind durch das Mikrofilmarchiv der deutschsprachigen Presse e. V. in Dortmund zugänglich.

Für „Verfuigungen, Erlasse, Anordnungen usw. der Parteidienststellen“ gab der Reichsleiter für die Presse das „Partei-Archiv“ heraus (im BA vorthanden 1936 bis 1943, Januar), mit einem systematischen Teil in 5 Sachgruppen und einem Sonderteil über Kriegsereignisse, ferner das „Archiv der NS-Presse“ (BA, Juni 1937-1940 August). 
In hoher Auflage erschien von 1940 bis 1945 die "Schriftenreihe der NSDAP“ mit ca. 60 Einzelheften (49 im IfZ) in den neun Gruppen „Deutsche Wehrkraft“, "Deutsche Arbeit", "Volkheit und Glaube“, „Europäische Politik“, „Das ist England“, „Erlebter Krieg", „Der Osten Europas“, „Kontinent und Übersee“, „Der Bolschewismus“.

Lit: O. J. HALE: Presse in der Zwangsjacke 1933-1945. 1964.

\subsubsection{Der Beauftragte des Führers für die Überwachung der gesamten geistigen und weltanschaulichen Schulung und Erziehung der NSDAP (DBFU), Berlin}

BA, Bestände NS 8 und NS 15

ZStA, Best. 62 Di 1

Die schriftliche Überlieferung aus den verschiedenen Funktionen, die Reichsleiter Alfred Rosenberg nacheinander oder gleichzeitig ausübte, verteilt sich auf die Akten der von ihm als Koordinierungsstelle 1934 eingerichteten Kanzlei Rosenberg (NS 8) und die Registraturen der einzelnen Ämter der NSDAP (zum AuBenpolitischen Amt unten 9.1.9) und des Reichsministeriums für die besetzten Ostgebiete.

Die - überwiegend in Korrespondenzserien geführten - Akten der Kanzlei Rosenberg enthalten einerseits persönliche Unterlagen (8 Bde biographisches Material, 1928-1944, 18 Bde Schriftwechsel, Manuskripte, Rezensionen zu Rosenbergs Publikationen, 1918 1944, 60 Bde mit Reden und Vorträgen, 1932-1943) und solche aus seiner gesamten Zuständigkeit, vor allem über organisatorische und Personalangelegenheiten (25 Bde. 1933-1944, mit Anordnungen, Rundschreiben, Besprechungsvermerken) und in Form von Schriftwechsel (auch der Adjutanten Thilo v. Trotha und Werner Koeppen) mit Privatpersonen (17 Bde, 1928-1945), Staats- und Parteidienststellen (48 Bde, 1932 1944, davon 15 Bde mit dem Stellvertreter des Führers bzw. der Parteikanzlei) sowie dem Eher-Verlag ( $3 \mathrm{Bde}$ ). Andererseits betreffen sie die einzelnen Aufgabenbereiche:

- Chefredakteur des „Völkischen Beobachters“ (23 Bde, 1924-1938, z. T. auch später, 2 Bde betr. Prozesse bis 1932).

- Leiter des Kampfbundes für deutsche Kultur (5 Bde, 1927-1936) bzw. der NSKulturgemeinde (3 Bde, 1934-1937).

- Leiter des Außenpolitischen Amtes (10 Bde, 1933-1944, vor allem betr. Nordische Gesellschaft).

- Beauftragter des Führers (27 Bde, nach den einzelnen Ämtern geordnet, 1934-1944, auBerdem 5 Bde über die Hohe Schule, 1940-1945).

- Reichsminister für die besetzten Ostgebiete (3 Bde, 1941-1945) und Leiter des Einsatzstabes Reichsleiter Rosenberg zur Ausplünderung besetzter Gebiete (5 Bde, 19401944, 2 Bde des Amtes Osten, 1941-1944, und vom Einsatzstab der Jahresbericht des Sonderkommandos Ost 1944 sowie Vorgänge über die Übernahme von Bildersammlungen von Umsiedlern 1941-1942 auch ZStA).

Ein Teilbestand aus der Kanzlei Rosenberg befindet sich im Centre de Documentation Juive Contemporaine in Paris vor allem mit Dokumenten aus den Bereichen Überwachung der weltanschaulichen Schulung (120 Dokumente, u. a. über Auseinandersetzungen über Kompetenzen), Hohe Schule und Institut zur Erforschung der Judenfrage (84 Dokumente), Wissenschaft, Kunst und Kirchen (150 Dokumente), Einsatzstab (195 Dokumente), AuBenpolitisches Amt (98 Dokumente), antisemitische Propaganda im Ausland (53 Dokumente), Ostministerium (236 Dokumente). Weitere Dokumente 
aus der Kanzlei Rosenberg wurden im Nürnberger HauptkriegsverbrecherprozeB gegen ihn herangezogen.

Aus seinem Amt als DBFU sind (BA, NS 15, ca. 320 Bde, ZStA 278 Bde, 1931/19331944) Tageskopien verschiedener Organisationseinheiten (BA, 28 Bde, 1941 JanuarOktober) und vor allem Akten folgender Organisationseinheiten vorhanden:

Zentralamt: Rundschreiben und Anordnungen (1943-1945), Personalunterlagen mit Fragebögen (1937-1945), Tageskopien (1944-1945), Reste von Akten der Dienststellenverwaltung (insgesamt ca. 35 Bde, BA), Korrespondenz des Stabsleiters Stellrecht mit Parteidienststellen (ZStA).

Amt Musik (BA, 21 Bde, u. a. über jüdische Musiker und Komponisten, 1938-1945). Amt Weltanschauliche Information, ab 1942 vereinigt mit Amt für Juden und Freimaurerfragen zum Hauptamt Überstaatliche Mächte (ZStA): Akten über Organisation und Tätigkeit (25 Bde, 1936-1945), Begutachtung von Manuskripten und Veröffentlichungen (13 Bde, 1936-1944), zahlreiche Informationen über die weltanschauliche Lage und insbesonders über Kirchen in Deutschland und im Ausland sowie zur Judenfrage.

Kulturpolitisches Archiv: Tageskopien und Schriftwechsel vornehmlich über die Beschaffung von Informationen für die dort angelegten Dossiers über ca. 60000 Wissenschaftler und Künstler und die Erteilung von Auskünften daraus an Staats- und Parteidienststellen, besonders für den Einsatz im Volksbildungswerk der DAF (BA, insgesamt ca. 135 Bde, 1935-1944).

Hauptamt Wissenschaft mit den Ämtern Wissenschaftsbeobachtung und Wissenschaftswertung: Beurteilungen von Hochschullehrern und Schriftstellern, u. a. bei der Besetzung von Lehrstühlen, und Zusammenarbeit mit dem NS-Dozentenbund und sonstigen Organisationen dabei (BA, ca. 100 Bde, 1935-1944, dabei 11 Bde Korrespondenz mit der Parteikanzlei, 8 Bde betr. Hochschulen in einzelnen Ländern), ferner Unterlagen über wissenschaftliche Gesellschaften, Vorgänge über weltanschauliche Auseinandersetzungen (,Akademikerstreit") über Probleme der Naturwissenschaften an der Universität Jena (ZStA). Ebenfalls aus diesem Amt stammen Unterlagen über 1323 Wissenschaftler und Schriftsteller, darunter Stefan George und Ludwig Klages, im YIVO Institute New York (12 Bde, Mikrofilm IfZ, MA 116, dort auch eine Untersuchung der Forschungsstelle „Weltanschauliche und praktische Lebensgestaltung", 1939).

Aus den Ämtern Schulung und Schriftum haben sich jeweils nur (ZStA) ein Band der ,Lehrplanung“ über Schulungsschriften des NS-Führungsstabes der Wehrmacht und der Reichslehrgemeinschaft Partei- und Wehrmachtsschulung (1944) bzw. über die Begutachtung von Manuskripten (1941-1943) erhalien.

Zahlreich waren die von Rosenberg und seinem Amt herausgegebenen oder geförderten Publikationen (BA, NSD 16). Zu ihnen gehörten als ,zentrale politische und kulturelle Zeitschrift der NSDAP“ seit 1931 die "Nationalsozialistischen Monatshefte“ (bis Heft 163, Juni 1944) mit der Schriftenreihe „Nationalsozialistische Wissenschaft“ (6 Hefte vor 1939). RegelmäBig wurden vertraulich die „Mitteilungen zur weltanschaulichen Lage“ (10 Bde, April 1935-1944 August) verteilt, daneben ein "PresseInformationsdienst“ (2 Bde, 1935/36). Der Verbreitung der „Weltanschauung“ dienten 9 einzelne „Reichsschulungsthemen“ (1941-1944), die „Nationalsozialistischen Schulungsschriften“ (5 Hefte ab 1939), die „Schriftenreihe zur weltanschaulichen Schulungsarbeit" (ca. 75 Hefte ab 1942 in den Teilen ,Der Schicksalskampf im Osten“, „Amerika und Europa“ und „Der Kampf als Lebensgesetz“) und ab Herbst 1943 noch 6 Folgen des „Lehrstoffs für die gesamte weltanschauliche Erziehung“ unter dem Titel „Idee 
und Tar“. Ein „Rednerdienst. Reichslehrgemeinschaft Partei- und Wehrmachtschulung“ erschien von Juli 1943 bis Januar 1945.

In Zusammenarbeit mit der Reichsstelle zur Förderung des deutschen Schriftums wurde eine "Bücherkunde“ in vier Ausgaben mit Gutachten zu einzelnen Büchern herausgegeben (11 Jahrgänge, 1933-1944, auch als „Monatshefte für das deutsche Schrifttum"), außerdem noch "Lektorenbriefe" (1938-1944) und Bücherlisten für nationalsozialistische Büchereien, Verzeichnisse jüdischer Autoren und Spezialbibliographien wie „Schriftumsbeiträge zur weltanschaulichen Schulungsarbeit“ (20 Hefte bis 1942, u. a. „Schriftum zur Judenfrage“ und „Vom Wesen und Wirken deutschen Bauerntums“). Das Amt Rosenberg war auch an der Zeitschrift „Weltanschauung und Schule“ (ab 1936, IfZ) und der Schriftenreihe „Deutsches Volkstum“ und anderen Publikationen zur Volkskunde, Vor- und Frühgeschichte beteiligt und finanzierte den „Weitdienst. Internationale Korrespondenz zur Aufklärung über die Judenfrage“ (ab 1933) mit fremdsprachigen Ausgaben.

Amtliches Organ der NS-Kulturgemeinde war zunächst eine Zeitschrift unter demselben Titel, fortgesetzt durch „Kunst und Volk“ (1935 bis 1937), diese wiederum durch „Die Kunst im Dritten Reich“ (1937-1939) und „Die Kunst im Deutschen Reich“ (bis 1944), zuletzt als Publikation der DAF wie auch „Volkstum und Heimat“ (1934-1942). Die Filmproduktion repräsentieren die Filme „Schwälmer Hochzeit“ (1934), „Das große Eis“ und „Ewiger Wald“ (1936, alle BA-Filmarchiv).

Lit.: GUIDES to German Records. vol. 28. - SCHRIFIEN ZUM STAATSAUFBAU 9. 1941. - J. BILLIG: Alfred Rosenberg dans l'action idéologique, politique et administrative du Reich hitlérien. 1963. - H.-G. SERAPHIM (Hrsg.): Das politische Tagebuch Alfred Rosenbergs aus den Jahren 1934/35 und $1939 / 40$. 1956. - R. BOLLMUS: Das Amt Rosenberg und seine Gegner. 1970. - R. HELLER: Vom faschistischen .Kampfbund für deutsche Kulsur" zur ..Nationalsozialistischen Kulturgemeinde“" 1984. - H. P. ROTHFEDER: Ami Schriftumspflege. 1981.

9.1.9 Außenpolitisches Amt, Berlin BA, Best. NS 43

Der Koblenzer Bestand enthält Korrespondenz und Redemanuskripte Reichsleiter Rosenbergs (5 Bde, 1928-1941), Rundschreiben, Aufzeichnungen und Schriftwechsel, vor allem des Amtsleiters Leibbrandt (13 Bde, 1934-1942), und vertrauliche Berichte über Italien, Großbritannien und andere Länder (3 Bde, 1933-1941). Die meisten der über 10 einzelne Länder geführten Akten (41 Bde, 1933-1943) betreffen Norwegen (22 Bde, z. $T$. über andere skandinavische Länder, 1934-1943), die Sowjetunion mit Turkestan und der Ukraine (9 Bde), Polen (4 Bde), Italien (3 Bde) und Rumänien mit Bessarabien (2 Bde). Durch Satzung, Teilnehmerverzeichnisse, Unterlagen über die Verpflichtung von Dozenten und das Vorlesungsverzeichnis für das S.S. 1938 (für W.S. 1938/39 IfZ) wird der Lehrbetrieb des Außenpolitischen Schulungshauses der NSDAP in Berlin belegt (10 Bde, 1935-1939), kaum die „Antikomintern“-Propaganda (2 Bde, 1933-1938).

Vom Presseamt sind Presseausschnitte und Akten (ZStA, 339 Bde, 1929/1933-1944) mit Berichten einzelner Mitarbeiter vorhanden; sie betreffen allgemeine und internationale Presseangelegenheiten, Politik, Wirtschaft und Kultur in den europäischen Ländern, in Nordafrika, dem Nahen und Mittleren Osten, in USA, Mittel- und Südamerika, Japan, China, Indonesien, Thailand. AuBerdem ist der ,Nur für den Dienstgebrauch“ herausgegebene „Pressebericht des AuBenpolitischen Amtes“ hieraus (28 Bde, November 1934-1942 Januar, BA, Best. NSD 15) überliefert.

Handakten des Leiters der Abteilung Außenhandel, Werner Daitz, mit Vorschlägen zur Neuordnung der Wirtschaft und für Exporte in einzelne Länder (1935) sind in dessen 
Überlieferung aus der gleichzeitigen Tätigkeit als Gesandter Lübecks in Berlin enthalten (HI).

Lit.: GUIDES to German Records. vol. 3 und 28. - A CATALOG of Files and Microfilms. vol. IIl. S. 511 . 512. - H. A. JACOBSEN: Nationalsozialistische AuBenpolitik. 1968. S. 45-89. 871. - S. KUUSISTO: Alfred Rosenberg in der nationaisozialistischen Aubenpolitik 1933-1939. 1984.

\subsubsection{Reichsamt für das Landvolk}

BA, Best. NS 35

Die Akten des in Personalunion mit dem Reichsernährungsministerium und dem Reichsnährstand (vgl. Abschnitt 6.1.5 und .6) von Darré und dann von Backe geleiteten Reichsamtes für Agrarpolitik, das 1942 umbenannt wurde, sind fast vollständig verloren, Der Rest besteht aus Anordnungen (4 Bde, 1933-1941), Organisations- und Verwaltungsunterlagen (10 Bde, 1937-1944) und Handakten des Stabsleiters Eugen Glaser (4 Bde, 1936-1942) mit Korrespondenz und Berichten über regimefeindliche Propaganda von Emigranten und aus Österreich. Von wenigen überlieferten Akten der Eigenkanzlei Darré (Best. NS 13) betreffen einige die Agrarpolitik (7 Bde, 1931-1941, dabei Korrespondenz mit Himmler, eine Denkschrift zur ,Zigeunerfrage“ 1938 und Berichte über Forschungen zur Bauernsymbolik). Handakten des Leiters der Abteilung Siedlung (1933-1938, dann im SS-Rasse- und Siedlungshauptamt) Kurt Kummer und einzelne Vorgänge und Berichte über Siedlungswesen (insgesamt 16 Bde, 1933-1942) gelangten ins Hauptarchiv der NSDAP (NS 26). Eine Rede Backes über ,Ziele und Aufgaben der Landvolkpolitik“ (Februar 1944) ist gedruckt (BA, NSD 21), ebenso „Landvolkbriefe“ (Nr. 1-3, 1943). Ab 1942 gab Backe auch die „Deutsche Agrarpolitik" neu heraus (bis Februar 1944 ebda), die schon früher unter demselben Titel als „Monatsschrift für Deutsches Bauerntum“ erschienen war.

Lit.: A. BRAMWELL: Blood and Soil. Richard Walther Darre and Hitlers .Green Party“. 1985.

\subsubsection{Kolonialpolitisches Amt}

Aus dem Amt, an dessen Spitze der bayerische Reichsstatthalter Ritter von Epp stand, blieben lediglich wenige Unterlagen mit Überlegungen zur Aufteilung des Kolonialbesitzes, zur Planung eines Reichskolonialministeriums und über Landwirtschaftsrecht (BA, NS 20, 3 Bde, 1941) sowie über Organisation und Geschäftsbetrieb (ZStA, Best. 62 Am 1, 1 Bd, 1937-1942) erhalten. Auch im NachlaB Epps (BA und M) sind nur geringe Vorgänge über Kolonialpolitik (vor allem Reden und Tagungen 1935-1939) überliefert. Tätigkeitsberichte sind vom 1. Juli 1941 und 1942 vorhanden (BA, NS 26, NSD 20), desgleichen „Richtlinien für die kolonialpolitische Schulung“ (1938-1940) und ein Bericht über eine Tagung der Kolonialschriftleiter 1942.

Publizistisch wirkte das Amt, z. T. bis 1936 gemeinsam mit der Deutschen Kolonialgesellschaft, durch die „Deutsche Kolonialzeitung“, die Ausbildungsblätter „Deutscher Kolonialdienst“, den „Kolonial-Informationsdienst“, das „Kolonial-Archiv“, das Presseartikel unter dem Titel „Kolonialpolitik in der Weltpublizistik“ wiedergab (19381943), Schulungsbriefe des Reichskolonialbundes, eine Schriftenreihe „Koloniale Politik“ (ab 1941) und ein „Koloniales Taschenbuch“ (Jahrgänge 1941 und 1942 IfZ). Ergänzungsüberlieferung bis 1936 enthalten die Akten der Deutschen Kolonialgesellschaft (ZStA). Eine „Aktuelle Kolonial-Wochenschau“ (1938/39) und Filme über die Reichstagung in Wien (1939) und Farmer in Südwest-Afrika sind im BA-Filmarchiv überliefert.

Lit.: K. HILDEBRAND: Vom Reich zum Weltreich. 1969. 


\subsubsection{Wehrpolitisches Amt}

BA - MA, Best. NS 39

Nur wenige Akten, die die Prüfung von Motoren, Geschossen und anderen Erfindungen für militärische Zwecke betreffen (12 Bde, 1932-1935), und einige Organisations- und andere Unterlagen ( $3 \mathrm{Bde}$ ) sind aus dem ebenfalls von Epp geleiteten Amt erhalten, das nur von 1932 bis 1935 bestanden hat. Epps Vertreter, Oberst a. D. Friedrich Haselmayr, äuBerte sich im Oktober 1934 über „Wehrpolitik und Wehrpolitische Erziehung“ (BA, NSD 32), der auch „Kleine Kriegshefte“ (undatierte Nr. 9 und 12 IfZ) dienten, und gab nach dem Krieg Auskunft über seine Tätigkeit (IfZ, Best. ZS 62).

Lit: W. BAUM: Die Reichswehr und das Wehrpolitische Amt. 1965.

\subsubsection{Rassenpolitisches Amt, Berlin}

Da die Akten des Amtes vollständig verloren sind, beschränkt sich die Überlieferung auf nur für den Dienstgebrauch bestimmte Ausführungen seines Reichsschulungsbeauftragten Egon Leuschner über "Nationalsozialistische Fremdvolkpolitik“ (ca. 1942, BA, NSD 17), einzelne der zusammen mit dem von ihm betreuten Reichsbund der Kinderreichen, der die „Völkische Wacht“ veröffentlichte, herausgegebenen 18 Hefte einer „Schriftenreihe“ (BA und IfZ, vor 1939), die Zeitschrift „Neues Volk“ (1933-1944 Juli) mit dem Kalender desselben Namens, den "Informationsdienst“ (1937-1944, BA) und die Korrespondenzen „KVR. Korrespondenz für Volksaufklärung und Rassenpflege“ (1933-1937. BA) und „RAK. Rassenpolitische Auslandskorrespondenz“ (1934-1941 mit englischen, spanischen, portugiesischen und schwedischen Ausgaben, BA). Im Auftrag des Amtes wurden die Filme „Das Erbe" (1935), „Erbkrank“ (1936), "Alles Leben ist Kampf“ (1937, BA-Filmarchiv), „Die Sünden der Väter" und Aufnahmen von jüdischen Geisteskranken (Zentrales Filmarchiv Potsdam) hergestellt.

Lit.: L. ROST: Propaganda zur Vernichtung .,unwerten Lebens“ durch das Rassenpolitische Amt der NSDAP. 1988. - J. STEPHENSON: „Reichsbund der Kinderreichen“. 1979. - K. H. ROTH: Filmpropaganda für die Vernichtung der Geisteskranken im .Dritten Reict”. 1986.

\subsubsection{Hauptamt für Kommunalpolitik BA, Best. NS 25}

Von allen Ämtern der Reichsleitung der NSDAP ist dieses Amt, das in Personalunion mit dem Deutschen Gemeindetag (vgl. Abschnitt 2.1.1.2.1) der Münchener Oberbürgermeister Karl Fiehler leitete, das einzige, dessen Schriftgut wohl fast völlig erhalten blieb. Es besteht aus Unterlagen über Aufbau, Organisation und Tätigkeit im allgemeinen (128 Bde, dabei 10 Bde Anordnungen, 4 Bde Auszüge aus vertraulichen Berichten, 56 Bde betr. Tagungen und Dienstbesprechungen) und umfangreichen Korrespondenzaktenserien (552 Bde, dabei 7 Bde des Stabsleiters Herbert Treff, 1933-1934, 41 Bde Tageskopien, 1941-1944, 219 Bde Korrespondenz mit den Gauämtern für Kommunalpolitik, 38 Bde mit dem Stellvertreter des Führers bzw. der Parteikanzlei, 59 Bde, 1933-1944, aus der Redaktion des "Zentralblatts für Gemeindepolitik“ mit dem Titel „Die Nationalsozialistische Gemeinde“).

Sachakten des Stabsleiters Helmuth Patutschnick betreffen seine Zusammenarbeit mit anderen Dienststellen (14 Bde, 1935-1943) und aus dem Zentralamt (202 Bde) die Dienststellen- und Personalverwaltung, auch die Schulung und publizistische Tätigkeit. Weitere Sachakten stammen aus den Zuständigkeiten für Gemeindeverfassung und -verwaltung (155 Bde), Gesundheits-, Fürsorge-, Wohnungswesen und andere Gebiete der Sozialpolitik (238 Bde), kulturelle Angelegenheiten (102 Bde), Wirtschaft (168 
Bde), Finanzen und Steuern (122 Bde). Vorgänge über die Planung für den Wohnungsbau nach dem Krieg (mit Sitzungsprotokollen, 1941-1944) sind im Hauptarchiv der NSDAP (NS 26) überliefert. Zur Unterrichtung der Kommunalpolitiker dienten außer dem Zentralblatt (mit Gau-Ausgaben und „Rechts- und Wirtschaftsberatung“, „Blättern für Sparkassenfragen") verschiedene Serien von Rundschreiben, Mitteilungen, Informationen und Berichtsauszügen (IfZ).

Lit: H. MATZERATH: Nationalsozialismus und kommunale Selbstverwaltung. 1970.

\subsubsection{Parteiamtliche Prüfungskommission zum Schutze des NS- Schriftums, Berlin BA, Best. NS 11 ZStA, Best. $62 \mathrm{Ka} 1$}

Die wenigen in Koblenz erhaltenen Akten (38 Bde) betreffen vor allem Organisation und Dienststellenverwaltung, dabei auch die Auseinandersetzung ihres Leiters, Reichsleiter Bouhler, mit Rosenberg über die Abgrenzung der Kompetenzen (13 Bde, 1937-1943), und die Gutachtertätigkeit im allgemeinen (6 Bde, 1937-1943) und in 40 Einzelfällen (8 Bde, 1937-1941). Ferner sind Transskriptionen von Reden Hitlers (1937-1939) und HeB* (1933-1937) sowie Sachaktensplitter vorhanden (u. a. über Kirchenpolitik 1937-1941). Aufgabe der Kommission war auch die Bearbeitung und Publikation der ,Nationalsozialistischen Bibliographie" (Monatshefte ab 1936, dazu "Ergänzungen" und "Beihefte" mit Spezialbibliographien, z. B. „Deutsche Rechtserneuenung“ 1939) und von „VerlegerMitteilungen" (ab 1938).

Mit der Potsdamer Überlieferung der Kanzlei des Führers (oben 9.1.1) sind auch Akten der Prüfungskommission vereinigt (59 Bde, 1928/1935-1945), überwiegend mit zur Prüfung eingereichten einzelnen Manuskripten, auch über Schulbuchherstellung und -auslieferung (2 Bde, 1944).

Lit: D. STROTHMANN: Nationalsozialistische Literaturpolitik. 1960.

\subsubsection{Oberstes Parteigericht}

BA. Best. NS 36

Der Hauptteil der Überlieferung (ca. 60000 Einzelfallakten) befindet sich im Berliner Document Center. Dabei handelt es sich hauptsächlich um Akten aus Verfahren, in denen höhere Funktionäre beschuldigt waren oder Rechtsmittel gegen Erkenntnisse von Gaugerichten eingelegt wurden oder diese überprüft wurden, weil sie von Erkenntnissen der ordentlichen Gerichtsbarkeit abwichen; z. T. sind vorgelegte Akten der Vorinstanzen noch beigefügt. Außerdem sind dort Personalakten von Vorsitzenden und Beisitzern an Gau- und Kreisgerichten mit Personalbögen überliefert, die Lebenslauf mit Angaben über Abstammung und politische Betätigung enthalten, und Bewerbungen um Anstellung in der Parteigerichtsbarkeit. Vorakten des Untersuchungs- und Schlichtungsausschusses (USchlA, 1926-1933) und einzelne Akten von Kreisgerichten aus dort schon abgeschlossenen Verfahren sind dor ebenfalls vorhanden (vgl. auch unten 9.2).

Der Bestand des Bundesarchivs umfaBt USchlA-Akten (1926-1932), einige Organisationsunterlagen und Rundschreiben des Personalamtes (1943-1944) und wenige Verfahrensakten; sie betreffen Vorwürfe wegen MiBhandlung von Häftlingen im Konzentrationslager Wuppertal-Kemna (1934-1935), Ausschreitungen beim Novemberpogrom 1938 (14 Anlagen zum Bericht des Obersten Richters, Reichsleiter Walter Buch, vom 21. Februar 1939, Nürnberger Dokument PS 3036), Amtsmißbrauch durch einen Kreisleiter (1934-1941), Beschäftigung einer Jüdin durch einen Rassenforscher (1941-1943) und gegen Gauleiter Bohle. 
Das Verfahren regelten veröffentlichte "Richtlinien und Geschäftsordnung für die Parteigerichte“ (zuletzt vom 20. 12. 1942). Der einheitlichen Rechtsprechung dienten das amtliche Mitteilungsblatt „Der Parteirichter" (1934-1943) und „Bekanntmachungen des Obersten Parteigerichts“ (ab 1936).

Lit.: D. M. McKALE: Der öffentliche Dienst und die Parteigerichtsbarkeit der NSDAP. 1986. - Ders.: The Nazi Party Courts. 1974.

\subsubsection{Chef der Auslandsorganisation (AO), Berlin $\quad$ BA. Best. NS 9}

ZStA, Best. 62 Au 1

Der Koblenzer Bestand (kleiner Teil auch im AA) enthält Reste der Korrespondenz des Gauleiters und zugleich Staatssekretärs im Auswärtigen Amt Ernst Wilhelm Bohle (4 Bde, 1936-1940) und seines Mitarbeiters Sepp Schuster (5 Bde, 1931-1942), Runderlasse und Anweisungen (28 Bde, 1937-1942) und eine Serie von Akten über einzelne Länder (56 Bde, 1937-1940). Vorhanden sind ferner Anordnungen des Stabsamtsleiters und des Organisationsleiters (1940-1943), Mitteilungen und Korrespondenz des Schatzmeisters (1937-1943), des Verbindungsreferenten in der "Stadt der Auslandsdeutschen“ (Stutgar, 1938-1939) und des Presseamtes (1936-1937). Wenige Sachakten betreffen u. a. Dienststellenverwaltung ( 9 Bde), Staatsbesuche, Zusammenarbeit mit anderen Organisationen (Deutsches Auslandinstitut, VDA), Emigranten, Reichs- und andere Tagungen. Einige Korrespondenzakten und Unterlagen über die NSDAP in Österreich vor 1938, in Italien und anderen Ländern befinden sich noch in der Sammlung Schumacher (8 Bde. 1931-1943). Listen der Parteigenossen im Ausland für 53 Länder und Kolonialgebiete stammen aus dem Document Center.

Die Tätigkeit des Rückwandereramtes, das Auslandsdeutsche nach ihrer Rückkehr nach Deutschland betreute, ist durch Korrespondenz mit ihm (6 Bde, 1937-1942) und Akten seiner Zweigstelle München (23 Bde, 1935-1943) dokumentiert, die neben allgemeinen Anordnungen und Kassenschriftgut auch Paßbücher mit Einzelangaben und Unterlagen über Spanienflüchtlinge (1936-1937) enthalten. Weitere Akten des Rückwandereramtes über einzelne Personen, u. a. Flüchtlinge aus der Tschechoslowakei 1937 und Rückkehrer aus der Schweiz 1942, mit "Fragebögen für Rückwanderer", in denen auch alle Arbeitsplätze im Ausland anzugeben waren, sind in das Berliner Document Center gelangt (ca. 16000 Einzelfälle, vermutlich aber auch aus anderen Provenienzen).

In Potsdam befinden sich neben Unterlagen über die Rückkehr von Emigranten aus der Sowjetunion (1934-1939, ehem. ZPA der SED) vor allem Akten des Außenhandelsamtes (58 Bde, 1927/1933-1942) über Entschädigung von Auslandsdeutschen (Einzelfälle). Außerdem vorhanden sind dort allgemeiner Schriftwechsel und Rundschreiben (8 Bde, 1932-1942), u. a. über Entschädigungsfragen, und Akten über die Aktivitäten in verschiedenen Ländern, vornehmlich in Österreich, in der Schweiz, in Schweden, Lettland und Ägypten (14 Bde, 1932-1942). Den Rest der Überlieferung (4 Bde) bilden Fragmente aus unterschiedlichen Tätigkeitsbereichen.

Ergänzungsüberlieferung enthalten mit dem Koblenzer Bestand vereinigte Aktenreste der Landesleitungen und einzelner Ortsgruppen der AO in Belgien, Italien, Spanien, den Niederlanden, GroBbritannien, Frankreich und Kroatien, die Akten des Nürnberger „Wilhelmstraßen“-Prozesses, in dem Bohle verurteilt wurde, und folgende von ihr herausgegebene Publikationen: „Mitteilungsblatt der Leitung der AO der NSDAP“ (19341939), „Der Auslandsdeutsche Beobachter. Parteiamtliche Monatsblätter" (ab 1932), „Deutsches Wollen. Zeitschrift der AO der NSDAP“ (1939-1940), „Jahrbuch der AO" 
(1939-1942, mit Ausgabe „für die Seeschiffahr"“), „Seefahrt ist not! Parteiamtliche Zeitschrift der AO für die deutsche Seefahr", neben denen es noch Zeitschriften von Landesleitungen gab (z. B. „Ostasiatischer Beobachter“" Schanghai 1934-1939, und „ItalienBeobachter" bis 1944). Filme liegen über die 5. und 6. Reichstagung in Stungar (1937 und 1938), eine Feier der „Wintersonnenwende“ der Landesgruppe Argentinien (1936) und unter dem Titel „Fern vom Land der Ahnen“ (1937) vor (alle BA-Filmarchiv).

Lit.: CATALOG of files and microfilms. vol. III. S. 333-339. - TRIALS OF WAR CRIMINALS. vol. "1 und 12. - SCHRIFTEN ZUM STAATSAUFBAU 13. 1937. - H.A. JACOBSEN: Nationalsozialistische AuBenpolitik. 1968. S. 90-159, 865-868.

\subsubsection{Nationalsozialistische Reichstagsfraktion}

BA, Best. NS 46

Der Bestand enthält aus der Zeit ab 1933 Akten Fricks als Fraktionsführer, die er im Reichsinnenministerium geführt hatte, und des Fraktionsgeschäftsführers, Ministerialdirigent Hans Eugen Fabricius. Sie enthalten Eingaben (1933-1937) und betreffen allgemeine Angelegenheiten (4 Bde, 1933-1940), die Wahlen, insbes. Aufstellung der Kandidatenlisten, 1933 (9 Bde) und danach (8 Bde, 1936-1940), Spenden für das WHW aus den Diäten (7 Bde, 1933-1941), DisziplinarmaBnahmen gegen Fraktionsmitglieder (5 Bde, 1938-1942, u. a. Fritz Thyssen und Gauleiter Josef Wagner) und die Reichstagsmitglieder Martin Spahn (1933-1940), Friedrich Grimm (1943) und Wehrwirtschaftsfürer Fritz Kiehn (Trossingen, 1933-1941).

\subsubsection{Hauptarchiv der NSDAP}

BA, Best. NS 26

Die Bestände des Archivs, das seit 1934 Schriftgut der zentralen Einrichtungen der Partei übernehmen, darüber hinaus aber auch Material anderer Provenienz oder aus Privatbesitz sammeln sollte, das für die Geschichte des Nationalsozialismus und seiner Gegner von Bedeutung sein konnte, sind nur zum Teil erhalten; soweit sie geschlossene Überlieferungsteile fremder Provenienz (Parteikanzlei, Deutsche Demokratische Partei, bayerische Justiz- und Polizeibehörden) enthielten, wurden sie mit der Hauptüberlieferung vereinigt. Überwiegend enthält der Bestand neben wenigen Dienstakten Registraturund Sammlungsgut aus der Zeit vor 1933 (auf Unterlagen, die möglicherweise von zentralen Parteidienststellen nach 1933 stammen, ist jeweils bei diesen verwiesen) in folgender Gliederung, wobei der Umfang der Bände zwischen wenigen Blatt und mehreren hundert Seiten liegt:

- I. Hitler persönlich (68 Bde, 1915-1941, dabei Abstammungsunterlagen, einzelne Briefe - überwiegend 1920-1926, von ihm und an ihn, Kopien von Personalakten, Reden, Aquarelle und Zeichnungen).

- II. Rätezeit (10 Bde, 1918-1924, betr. Ereignisse in München, Sachsen, Thüringen und Pommern).

- III. Die Partei (45 Bde, 1919-1935, u. a. frühe Mitteilungsblätter und Rundschreiben, Korrespondenz der DAP 1920/21).

- IV. Hitlerputsch (23 Bde, vor allem Berichte von Beteiligten).

- V. Ehrenzeichen und Medaillen (5 Bde).

- VI. Gaue, Kreise, Ortsgruppen (ca. 100 Bde, vgl. unten zu 9.2).

- VII. Untergliederungen der Partei (ca. 100 Bde, vgl. unten zu 9.3 und 9.4).

- VIII. Reichsparteitage (ca. 100 Bde, vgl. oben zu 9.1.3). 
- IX. Kirche, Religion, Freimaurer, Rassenfrage (29 Bde. 1910-1945, dabei kirchliche Rundschreiben, Unterlagen von Logen, antisemitische Propaganda und Proze $B$ gegen Streicher 1929).

- X. Erlebnisberichte aus der Kampfzeit (29 Bde, dabei auch vom Geheimen Staatspolizeiamt erfaBte Berichte der politischen Polizei u. a. aus Aachen. Berlin. Düsseldorf, Hamburg und Korrespondenz dazu).

- XI. Wahlen und Abstimmungen (58 Bde, 1920-1933, mit Wahlvorschlägen und -ergebnissen bei Reichs- und Landtagswahlen).

- XII. Prozesse (20 Bde, 1921-1934, betr. Verfahren gegen Nationalsozialisten und die NSDAP, auch Zivilverfahren mit Beteiligung führender Parteifunktionäre).

- XIII. Geschichte und Politik (16 Bde, überwiegend mit Publizistik und Kopien ab 1848/49).

- XIV. Besatzungszeit 1918-1924, Westgebiete, Danzig, Oberschlesien (9 Bde).

- XV. Österreich (23 Bde, 1886-1944).

- XVI. Deutschtum im Ausland (40 Bde Länderserie, darin Material zur Abstimmung

in Südtirol 1939, über NSB in den Niederlanden und Propaganda im Protektorat).

- XVII. Freikorps und Bünde (12 Bde, vor allem Bund Oberland 1923-1929).

- XVIIl. Einwohnerwehren (Organisation Escherich u. a. in Bayern, Berlin, Halle/Saa-

le, 9 Bde).

- XIX. Politische Parteien (ca. 35 Bde Materialsammlung über SPD und KPD).

- XX. Andere Parteien und Verbände (52 Bde Materialsammlung vor allem über deutschvölkische Organisationen).

- XXI. Kriegervereine (Deutscher Kriegerbund, Kyffhäuser-Bund, 17 Bde, z. T. mit Korrespondenz, 1903-1943).

- XXII. Gewerkschaften (10 Bde Akten des Gewerkschaftsbundes der Angestellten GDA, 1923-1934).

- XXIII. Ernährung, Landwirtschaft, Agrarpolitik (oben 9.1.10).

- XXIV. Presse, Verlag, Rundfunk (oben 9.1.7, außerdem einige Vorgänge über völkische Buchhandlungen und Verlage, Rundschreiben der Rundfunkorganisation Hamburg 1931-1933).

- (XXV. Parteikanzlei und XXVI. Stellvertreter des Führers jetzt im Best. NS 6, oben 9.1.2, XXVII. Dr. Fritz Todt s. Abschnitt 6.1.9).

- XXVIII. Sowjetrußland ( 9 Bde, u. a. betr. Volksdeutsche und Unterstützung der ukrainischen Nationalbewegung 1941).

- XXIX. Verschiedenes (ca. 200 Bde, hauptsächlich Materialsammiungen - auch Akten des Polizeipräsidiums Berlin vor 1933 - über einzelne Personen, dabei Hitlers Adjutant Wilhelm Brückner, Goebbels, Göring, Gauleiter Wilhelm Kube, Ludendorff, Hitlers Fahrer Julius Schreck, Horst Wessel, Abt Alban Schachleiter, Dietrich Eckart, Gauleiter Helmut Brückner, Walter Stennes, Gregor Straßer, Walter Buch, Dietrich Klagges, Streichers Stellvertreter Karl Holz, und Organisationen, u. a. Rotary Club, Herrenclub, ferner Polizeiberichte über Ausschreitungen der NSDAP 1927-1933).

Einen eigenen Bestand bildet die vom Hauptarchiv angelegte Sammlung von Zeitungsausschnitten (1933-1945, ZSg. 117). Sie besteht aus einem Sachteil über Innenpolitik (445 Bde, davon 67 über NSDAP und ihre Organisationen, 65 über Judentum) und Außenpolitik (54 Bde, davon 24 über Nachkriegsplanungen) und einem biographischen Teil (841 Bde, in der Regel über je eine Person, ausgenommen u. a. 55 Bde über Hitler, 11 über Roosevelt, 5 über Churchill). 
Ähnliches Material wurde vom „Archiv für Zeitgeschichte und Publizistik“ gesammelt, das der Fotograf Friedrich Joseph Rehse aufgebaut hatte und das dem Reichsschatzmeister der NSDAP unterstand. Soweit es sich dabei um publizistische Quellen handelte, wurde die "Sammlung Rehse" auf die NS-Drucksachen-Bestände des Bundesarchivs, die Bayerische Staatsbibliothek, das Bayerische Hauptstaatsarchiv und einige andere Bibliotheken und Archive aufgeteilt. Erst in den letzten Jahren von der Manuscript Division der Library of Congress zurückgegebene Akten und Dokumentationen, u. a. Zuschriften aus der Bevölkerung an Hitler, müssen noch archivisch zugeordnet werden.

Die Überlieferung der Gauarchive im späteren Gebiet der Bundesrepublik ist im folgenden Abschnitt berücksichtigt, hinzuweisen ist jedoch darauf, daB sich Bestände des Gauarchivs OstpreuBen im GStA befinden (Rep. 494, ca. 120 Bde, 1928-1940, vereinzelt bis 1944); sie enthalten auch Sammlungen von Anordnungen des Stellvertreters des Führers (5 Bde, 1931-1940), des Amtes Rosenberg (4 Bde, 1934-1939) und der Reichspropagandaleitung (5 Bde, 1930-1937).

Lit: NSDAP Hauptarchiv. Guide to the Hoover Institution Microfilm Collection. 1964. - H. BOOMS: Die .Sammiung Rehse“. 1969.

\subsubsection{Ordensburgen und andere Schulen der NSDAP}

Von den drei zur Heranbildung der künftigen Funktionäre der NSDAP errichteten Ordensburgen lagen Sonthofen (im Allgäu) und Vogelsang (in der Eifel) auf dem Gebiet der späteren Bundesrepublik. Ihre Registraturen scheinen fast vollständig vernichtet worden zu sein; nur Aktensplitter aus Sonthofen (A, 6 Bde mit Abrechnungen, 1938-1942, und Vorgängen über HJ- und BDM-Lehrgänge 1943 bzw. 1941) haben sich erha!ten, und Unterlagen aus Vogelsang befinden sich möglicherweise noch in Privatbesitz, Baupläne im BA (Best. Plan 1). Ein Schulungsplan für alle drei ist undatiert überliefert (IfZ, Best. ED 302). Ihre nach Kriegsbeginn weitgehend eingestellte Tätigkeit ist daher vor allem durch ihre eigenen Publikationen (z. B. die Kameradschaftsblätter „Der Orden“ der Ordensburg Vogelsang, 1936-1938, „Die Burggemeinschaft" der .Falkenburg am Crössinsee" in Pommern, 1940-1944) und Veröffentlichungen in der Presse dokumentiert; diese sind z. T. in einer in Sonthofen angelegten Ausschnittsammlung vorhanden (BA, Best. ZSg 119, 188 Bde, davon 12 betr. Bildungswesen, 1937-1944).

Dasselbe gilt für die Reichsschulungsburg Erwitte, in der kurzfristige Lehrgänge für Funktionäre durchgeführt wurden (einige Baupläne BA, Best. Plan 1 und 88), und für die Adolf-Hitler-Schulen, die auf den Besuch der Ordensburgen vorbereiten sollten und von denen einige am selben Ort untergebracht waren. Neben Zeitungsausschnitten der Adolf-Hitler-Schule Sonthofen (vereinigt mit ZSg 119) gehören dazu Werbeschriften (1937 und 1941, BA, Slg. Schumacher 270, und IfZ), Personalunterlagen und -listen von Mitarbeitern, Auswahlrichtlinien, einzelne Vorgänge aus den Schulen der Gaue Westmark und Köln-Aachen (alles Slg. Schumacher 270) und aus Sonthofen Stoff- und Lehrpläne für einzelne Fächer und im allgemeinen (7 Bde, 1938-1943, BA, Best. NS 22 Anh.) zusammen mit drei Dienstbüchern und einigen Reden und Berichten (ebda), ferner die Richthefte „Schüler des Führers“ (1944), ein Erziehungs- und Lehrplan (1944) sowie „Arbeitsberichte und Elternbrief“ der Adolf-Hitler-Schule Weimar (1939-1942, alle IfZ).

Auch aus der vergleichbaren Reichsschule der NSDAP Feldafing (am Starnberger See) liegen nur die Jahresberichte 1934/35 bis 1941/42, eine Werbeschrift (1937) und Unterlagen über Auswahl- und Aufnahmebedingungen (1938-1944) vor (BA, NS 20/137 
und Sammlung Schumacher), ferner eine Festschrift „10 Jahre Reichsschule Feldafing“ (1944, IfZ) und Bauzeichnungen (BA, Best. Plan 1, auch von Adolf-Hitler-Schulen).

Die Hohe Schule der NSDAP, die nach den Vorstellungen Rosenbergs die Spitze des Bildungssystems für die Parteiführer werden sollte, blieb eine Planung, über die einige Aktenvorgänge verschiedener Provenienz vorhanden sind (Sammlung Schumacher, 1938-1940); von dem aus dem Reichsinstitut für Geschichte des neuen Deutschland (vgl. Abschnitt 4.3.6.) hervorgegangenen Frankfurter Institut zur Erforschung der Judenfrage und den im Vorgriff bereits errichteten - teils mit Universitäten personell verbundenen - anderen Instituten, u. a. in Hamburg (Überseeforschung), Marburg (nationalsozialistische Volkspflege), München (indogermanische Geistesgeschichte), Kiel (germanische Forschung), Detmold bzw. Münster (deutsche Volkskunde) und Stuttgar bzw. Schelklingen/Württemberg (Biologie und Rassenlehre), ist offenbar kein Schriftgut überliefert. Das Frankfurter Institut gab ab 1941 als „wissenschaftliche Zeitschrift" die bereits seit 1926 erscheinende Monatsschrift „Der Weltkampf. Die Judenfrage in Geschichte und Gegenwart“ (bis August 1944 IfZ, mit Lücken) und vier Hefte der "Kleinen Weltkampfbücherei“" (1943, BA, NSD 16) heraus.

Lit.: H. SCHOLTZ: Die NS-Ordensburgen. 1967. - H.-D. ARNTZ: Ordensburg Vogeisang 1934-1945. 1986. - D. ORLOW: Die Adolf-Hitler-Schulen. 1965. - M. KLÜVER: Die Adolf-Hitler-Schulen. 1979. - R. BOLLMUS: Zum Projekt einer nationalsozialistischen Alternativ-Universität. 1980.

\subsection{Gauleitungen}

Im späteren Gebiet der Bundesrepublik Deutschland bestanden bei Kriegsbeginn 21 Gaue der NSDAP, deren Gebiet meistens einem Reichstagswahlkreis der Weimarer Republik entsprach, so daß es sich mit staatlichen Verwaltungsbezirken nicht immer deckte; während es z. B. in dem einen Regierungsbezirk Düsseldorf die beiden Gaue Düsseldorf und Essen gab, bildeten die beiden Regierungsbezirke Köln und Aachen einen Gau, und zum Gau Hessen-Nassau gehörte von der preußischen Provinz dieses Namens nur der Regierungsbezirk Wiesbaden zusammen mit dem Land Hessen und vier kurhessischen Kreisen, der Rest des Regierungsbezirks Kassel hingegen war mit dem Gau Kurhessen identisch.

Zur Sicherung des Parteischriftguts sollten Gau-Archive bestehen, jedoch insbesondere für die Überlieferung der Kreise und Ortsgruppen, für die Akten der Gauleitungen aber nur, soweit sie nicht vom Hauptarchiv der NSDAP beansprucht wurden, dessen Sammlungen (NS 26) daher Material zur Geschichte fast aller Gaue in unterschiedlichem Umfang enthalten, das möglicherweise - bei München-Oberbayern wohl sicher - teilweise auch aus Registraturen von Gau- und Kreisleitungen stammt (ca. 100 Bde, 1920-1944). Dazu gehören Manuskripte und Aufzeichnungen zur Frühgeschichte der Partei in Baden, Süd-Hannover-Braunschweig, Hessen-Nassau (Manuskripte und Unterlagen des Gaugeschäftsführers Adalbert Gimbel), Kurhessen, Weser-Ems und Württemberg-Hohenzollern, Unterlagen über die Leistungen im Krieg in Süd-HannoverBraunschweig, Köln-Aachen, Kurhessen, Mainfranken und Weser-Ems.

Von den bei Kriegsende vorhandenen Akten der Gauleitungen und ihrer Ämter ist nur relativ wenig in die staatlichen Archive gelangt; in den nachstehenden Bestandsbeschreibungen werden diejenigen berücksichtigt, die bei den Dienststellen für die gesamte 
Organisation entstanden sind, während die Angaben über die Überlieferung der für einzelne angeschlossene Verbände zuständigen Ämter bei diesen im übernächsten Abschnitt 9.4 folgen. Als Ergänzungsüberlieferung ist auf die Verordnungs- und Nachrichtenblätter oder -sammlungen der Gaue zu verweisen, die in regionalen Bibliotheken vorhanden sein könnten.

Lit: P. HÜTTENBERGER: Die Gauleiter. 1969. - K. HÖFFKES: Hitlers politische Generale. 1988.

Gauleitung Baden(-Elsaß), Karlsruhe (Straßburg)

KA, Best. 465 d

Der relativ umfangreiche Bestand ist wie folgt gegliedert:

Gauleitung (26 Bde, 1936-1944) mit Rundschreiben und -erlassen des Gauleiters und einzelner Ämter (7 Bde, 1939-1944), Lage- und Stimmungsberichten (5 Bde, 19421944), Akten über Luftschutz und Luftkrieg, Volkssturm und Bau von Befestigungen (1944).

Gaugeschäftsführung ( 9 Bde, 1939-1943) mit Eingaben aus der Bevölkerung (4 Bde, nur L-Z, 1939-1943), einer Personalliste (1939) und Vorgängen über Luftkriegsschäden (1943).

Gaustabsamt (16 Bde, 1941-1944) mit Lageberichten (7 Bde, 1941-1944, u. a. über die Kirchen 1943-1944, Attentat auf Hitler 1944) und Vorgängen über politische Gegner (1941-1944) und Arbeitseinsatz (1943-1944).

Gauschulungsamt (116 Bde, 1934-1944) mit Runderlassen und -schreiben (13 Bde, 1934-1944), Tätigkeitsberichten (8 Bde, 1936-1944) und Akten über Schulung im allgemeinen (6 Bde, 1936-1944), Propaganda (7 Bde, 1938-1944), Bücher, Vorträge und den „Schulungsbrief“ (25 Bde, 1936-1944), Feierstunden (5 Bde, 1941-1944), einzelne Schulungsveranstaltungen (u. a. auf der Reichsschulungsburg Erwitte und der Gauschulungsburg Frauenalb) und Einberufungen dazu (44 Bde, 1935-1945), Überwachung der Kirchen (6 Bde, 1935-1944).

Gaupersonalamt mit Rundschreiben, Anordnungen und Listen (7 Bde, 1941-1944) und den Personalakten von 577 politischen Leitern.

Gauamt für Kommunalpolitik (ca. 140 Bde) ebenfalls mit Rundschreiben ( 7 Bde, 1933-1944), Berichten aus einzelnen Gemeinden (1931-1932) und Akten u. a. über die Organisation in 24 Amtsbezirken (1933), über Beamten- und Tarifrecht (13 Bde, 19361940), Kommunalverwaltung und -wirtschaft (33 Bde, 1931-1944), Gemeindefinanzen (15 Bde, 1934-1943) und die Schulung von Bürgermeistern und Kommunalpolitikern (33 Bde, 1935-1942).

Gauarchiv (78 Bde, 1935-1943) mit Sammlungen von Rundschreiben und Erlassen der wichtigsten Ämter (19 Bde, 1937-1944), des „Nachrichtenblatts der Gauleitung“" (1934-1939, bis 1941 IfZ), des „Schulungs- und Verordnungsblatts“ (Ausgabe für das Elsaß, 1942) und des Gaudienstes „Die innere Front“ (8 Bde, 1940-1944), Akten über die Erfassung von Archivalien (8 Bde, 1935-1944, Rundschreiben des Gauarchivs 1937 1941 im IfZ) und über Evakuierungs- und RückführungsmaBnahmen vor allem im ElsaB (5 Bde, 1939-1942), über jüdisches Vermögen (1937-1942), Bauten (1939) und Luftschutzmaßnahmen (1942-1943).

Nur geringe Aktenreste sind vorhanden vom Gauinspekteur (2 Bde, 1944), Gauschatzmeister (2 Bde, 1939-1944), Gauorganisationsamt (2 Bde, u. a. Rundschreiben 1939-1944), der Gaupropagandaleitung (desgl., 1938-1941), dem Rassenpolitischen Amt (3 Bde, 1936-1944), dem Gaurechtsamt mit dem Gaugericht (8 Bde, 1934-1943, mit einzelnen Verfahrensakten 1942), Gauamt für das Landvolk (2 Bde, 1940-1944) und vom Gauwirtschaftsberater (1943-1944). 
Ein weiterer Teilbestand befindet sich im Nationalarchiv Paris (AJ 40, ca. 250 Faszikel). Dazu gehören Reste der Korrespondenz (1940-1944) des Gauleiters Robert Wagner, der 1946 von einem französischen Militärgericht zum Tode verurteilt wurde, und seines Stellvertreters Hermann Röhn, ebenfalls Rundschreiben (1939-1943) und Schriftwechsel mit dem Stellvertreter des Führers bzw. der Parteikanzlei (1937-1944). Aus dem Stabsamt sind Lageberichte der Kreisleitungen (3 Bde, 1944) und Akten über Arbeitseinsatz (8 Bde, 1943-1944) vorhanden. Die (überwiegend Korrespondenz der Mob-Abteilung) Akten des Gaugeschäftsführers (98 Bde, 1937-1944) betreffen die Heranziehung und Freistellung von Parteifunktionären und -genossen bei Einsätzen für öffenuliche Zwecke, Wehrmacht und Reichsverteidigung. Hauptsächlich Einzelfälle und außerdem die Parteistatistik für 11 badische Kreise sind in Akten der Karteiabteilung des Gauschatzmeisters dokumentiert (39 Bde, 1937-1944), die Mitgliedschaft und die Zahlung von Beiträgen in Listen und Kassenunterlagen des Opferrings (60 Bde, 1940 1944). Auf Aktensplitter beschränkt sich hier die Überlieferung des Organisationsamtes (2 Bde, 1936-1944), des Personalamtes (2 Bde, 1939-1944, mit Karteien und Beurteilungen), der Gaupropagandaleitung (5 Bde, 1938-1943, dabei Mitteilungen des Gaurings für Volksaufklärung und Propaganda), des Rassenpolitischen Amtes (8 Bde, 1939-1944, dabei Erteilung der Genehmigung zur EheschlieBung mit Ausländern, jüdische Angelegenheiten), des Schulungsamtes (7 Bde, 1935-1944, mit den Mitteilungsblättern „Grenzgau am Oberrhein“ und „Von Front zu Front“) und des Gauwirtschaftsberaters (3 Bde, 1936-1944, u. a. betr. Arisierungen).

Ergänzungsüberlieferung enthält ein Mischbestand (KA, 465 c) mit ca. 24000 Vorgängen über Parteimitglieder, die zum Teil aus dem Gaupersonalamt, überwiegend aber von nordbadischen Kreisleitungen und Ortsgruppen stammen. Rundschreiben der Gauleitung sind auch in Akten des württembergisch-badischen Ministeriums für politische Befreiung (LB, Best. EA 11/1) überliefert, Aktensplitter über LuftschutzmaBnahmen (1943-1944) und der Kreisleitungen Freiburg und Rastatt in einem südbadischen Mischbestand (FR, Best. NSDAP).

Lit.: REPERTORIEN des Badischen Generallandesarchivs: Abı. 465 d. 1974. - J. H.GRILL: The Nazi Movement in Baden 1920-1945. 1983.

\section{Gauleitung Bayerische Ostmark (ab 1943 Bayreuth), Bayreuth}

BAM, Best. M 30

Die Überlieferung besteht aus den Akten der Gauwaltung der DAF (unten Abschnitt 9.4.1.2) und aus (insgesamt ca. 400 Bden) Resten von Korrespondenz des Gauleiters Fritz Wächtler (F-Sch, 9 Bde, 1937-1942), der 1935 an die Stelle des verstorbenen Hans Schemm getreten war, aus dem ,Nachrichtenblatt“ (1932-1935) und einer Sammlung von Rundschreiben (1935-1942) der Gauleitung, des Gauschulungsamtes (1933-1938) und des Gauwirtschaftsberaters (1941-1942), Anordnungen für den Gaustab (19361939) und politischen Beurteilungen in Einzelfällen (1935-1937) sowie Lageberichten von Kreisleitungen (1938-1942). Sachakten betreffen die Gauführertagung 1937, Angelegenheiten der Gliederungen (u. a. HJ-Gebietsführung und Gebietsführerschule, 1937. 1940, NSKK-Motorstandarte 95, 1937-1945), die Errichtung der Gauwirtschafiskammer (1942) und den Gaustab des Volkssturms (5 Bde, 1944-1945). Mit einzelnen Akten sind das Gaupropagandaamt (dabei unvollständig der vom Gaupresseamt herausgegebene „NSG-Gaudienst“, 1936-1945, mit Sonderdienst „Innere Front“, 1944-1945), das Gaupersonalamt, das Organisationsamt, das Amt für Volkstumsfragen (1944) und das Gaugericht (1 Verfahren, 1937) vertreten. Im Auftrag der Gauleitung wurden Filme 
über die Eröffnung der „Arbeitsschlacht“ 1934, den Tag der HJ in Kulmbach 1933, den Empfang der siegreichen Soldaten 1940 und die Bayreuther Festspiele 1940 produzier (BA-Filmarchiv).

Eine nicht unerhebliche Ergänzung der Akten der Gauleitung bildet die Überlieferung von Kreisleitungen (BAM, Best. M 33), insbesondere der Kreisleitung Kronach (216 Bde, 1933-1945, mit Kreiswaltungen von DAF, NSV und Frauenschaft), ferner Kulmbach (46 Bde) und Cham (37 Bde, meist über einzelne Ortsgruppen) und in jeweils geringem Umfang 10 weiteren (dabei ein Kriegstagebuch 1940/41 der Kreisleitung Wegscheid). Aus Aktenresten von 22 Kreisleitungen in Niederbayern wurde ein Sammelbestand gebildet (LA, 75 Bde, 1933-1945, dabei eine Sammlung allgemeiner Erlasse). Von den Kreisleitungen Amberg (51 Bde), Regensburg (87 Bde) und acht anderen oberpfälzischen Kreisen sind ebenfalls Restakten vorhanden (AMB). Weitere Ergänzungsüberlieferung (Anordnungen und Schriftwechsel mit allen Gauämtern) konnte in Akten der Regierung von Oberfranken und Mittelfranken (BAM und N) nachgewiesen werden.

Der letzte, noch im April 1945, nachdem Wächtler von der SS erschossen worden war, ernannte Gauleiter Ludwig Ruckdeschel wurde in zwei getrennten Verfahren wegen Mitwirkung an Standgerichtsurteilen von den Landgerichten Weiden (1948) und Landshut (1949) verurteilt (JUSTIZ und NS-Verbrechen, Nr. 113).

Lit.: F. KÜHNEL: Hans Schemm. 1985.

Gauleitung Berlin

B, Rep. 244

Die Überlieferung beschränkt sich auf Berichte an Gauleiter Goebbels über Gasversorgung und Schäden in der Energiewirtschaft nach Luftangriffen (1943-1944), Schriftwechsel des Gaupropagandaamtes über Angelegenheiten der Reichskulturkammer (2 Bde, 1935-1943, u. a. mit Listen ausgeschlossener Mitglieder, Theater- und Musikveranstaltungen, Ehrengericht der DAF für kulturelle Betriebe) und Arbeitsanweisungen des Gauschulungsamtes (1937-1938, dabei Angelegenheiten der Gauschule TardorfHubertushöhe). Anweisungen wurden im Verordnungsblatt "Der Gau“ veröffentlicht (1936-1938 im IfZ). Im Document Center befinden sich ca. 220000 Fragebögen der Berliner Parteigenossen für die Parteistatistik 1939. Sie enthalten Angaben zur Person mit Konfession, Kinderzahl, Eintrittsdatum, zur beruflichen Stellung in einer von 11 vorgegebenen Gruppen und zur Mitgliedschaft in 36 vorgegebenen Organisationen, darunter „Sängerbund“ und „konfessionelle Vereine“, ferner über Funktionen in der Partei mit Nennung der Dienststelle und des Amtes, über Uniform und Ausrüstung sowie Besitz des Sportabzeichens.

Von der Hauptgeschäftsleitung der parteiamtlichen Gauzeitung ,Der Angriff، sind (ZStA, Best. 62 An 1) Reste von Schriftwechsel mit Auslandsmitarbeitern (5 Bde, 1933-1941) vorhanden.

Lit.: J. GOEBBELS: Die Tagebücher. 1987.

\section{Gauleitung Düsseldorf}

D. Best. RW 23

Vorhanden sind nur ein Informationsdienst und Rundschreiben der Gauleitung (2 Bde, 1933-1934), Rundschreiben des Gauschatzmeisters (1944) und des Gaupropagandaamtes (mit Redner-Dienst und Anweisungen für Mundpropaganda, 5 Bde, 19401945). Gauleiter Friedrich Karl Florian hat einen 1966 verfaßten ,politischen Lebenslauf 1928-1945“ und die Urteile aus den Verfahren wegen von ihm bestätigter Standgerichts- 
urteile bei Kriegsende (vgl. JUSTIZ und NS-Verbrechen Nr. 125) und als Angehörigen einer verbrecherischen Organisation hinterlassen (Best. RWN 54). Akten des Gauamtes für Kommunalpolitik sind im NachlaB des Gauamtsleiters Horst Ebel enthalten (148 Bde, 1932-1943, StadtA Düsseldorf); dazu gehören Gaubefehle und Rundschreiben der Gauleitung (1934-1940), Sitzungsprotokolle (1933-1939), Anweisungen für die Beauftragten der NSDAP bei den Gemeinden (1936-1939), Akten über Personalangelegenheiten (1932-1939), Gebiets- und Verwaltungsreform, Kulturpolitik, Siedlungswesen, Energieversorgung, ArbeitsbeschaffungsmaBnahmen, Lage der Industrie (1938-1939). Herausgabe der Zeitschrift „Das nationalsozialistische Rathaus“, Maßnahmen gegen Juden, Ausstellung „Schaffendes Volk“ (1937).

Ergänzungsüberlieferung enthalten Aktensplitter des Deutschen Volkssturms aus Düsseldorf, Mönchengladbach-Nord und Wuppertal (1945) und der Kreisleitungen Krefeld-Kempen und Mönchengladbach, sie wurde jedoch vor allem in Akten der Regierung Düsseldorf und anderer staatlicher Behörden nachgewiesen. Zeitungsausschnitte zur Geschichte der NS-Zeit im Gau Düsseldorf, u. a. über Veranstaltungen der Partei und ihrer Gliederungen, finden sich in der Sammlung Lauterbach (StadtA Köln).

Lit: SCHRIFTGUT der NSDAP. Teil I. I981. S. 8-28, 179, 181, 191, 192, 194, 199. 201, 206, $215-221$. - C. v. LOOZ-CORSWAREM, H. WEIDENHAUPT: Stadtarchiv Düsseldorf. 1987. S. 153 f. - W. FÖRST: Die theinischen Gauleiter. 1984.

\section{Gauleitung Essen}

D. Bestände RW 23 und RW 14 Von der Gauleitung unter dem Gauleiter Joseph Terboven sind nur Aktensplitter mit einem Organisationsplan und Unterlagen über den totalen Kriegseinsatz (1943-1944) vorhanden, und auch die Ersatz- und Ergänzungsüberlieferung von Kreisleitungen (nur Duisburg, Kriegschronik Juni 1942) und in staatlichen Akten ist gering.

Gut belegt wird lediglich die Tätigkeit des Gaugerichts durch Akten aus 536 Verfahren (Best. RW 14, 1935-1943). Sie wurden als Berufungsverfahren nach zuvor ergangenen Urteilen von Kreisgerichten oder erstinstanzlich gegen Mitglieder von Gliederungen geführt, die nicht zugleich Parteigenossen waren. Unter den Beschuldigten waren Fritz Thyssen (1939-1940) wegen Kritik an Hitler und der Weigerung, nach Deutschland zurückzukehren, Angehörige des öffentlichen Dienstes, die Dienstvergehen begangen hatten, Teilnehmer an Ausschreitungen am 8./9. November 1938, höhere Führer von SA und NSKK. Neben zahlreichen Fällen wegen rückständiger Beitragszahlungen wurden als Tatbestände verfolgt: Amtsanmaßung, ungerechtfertigte Bereicherung und Veruntreuung, Disziplinlosigkeit, Ehrverletzung, Diebstahl, kirchliche Bindungen (vor allem Teilnahme an Abstimmungen gegen die Gemeinschaftsschule), Schädigung des Ansehens der NSDAP, Steuerhinterziehung, Schiebungen, Umgang mit Juden, Kriegsgefangenen und Fremdarbeitern.

Lit.: SCHRIFTGUT der NSDAP. Teil 1. 1981. S. 82-95, 180, 182. 197, 234. - W. FÖRST: Die rheinischen Gauleiter. 1984.

Gauleitung Franken, Nürnberg

N, Rep. 503

Im Bestand (168 Bde, 1928-1945) ist aus der Kanzlei des Gauleiters und „Frankenführers“ Julius Streicher, der im April 1942 durch Karl Holz ersetzt wurde, nur ein Rest von Korrespondenz in Gnadensachen und Mitgliedschaftsangelegenheiten (19371944) überliefert. Für den gesamten Arbeitsbereich liegen Rundschreiben (1940-1944, Verordnungsblatt 1941-1943 im IfZ) vor. Mit Akten sind vor allem folgende Organisationseinheiten vertreten: 
Gaupersonalamt: u. a. Rundschreiben (1938-1945), Personalveränderungsmeldungen (2 Bde, 1941-1945), Korrespondenz in Mitgliedschaftsangelegenheiten mit Statistiken (9 Bde, 1937-1945).

Gauschulungsamt: u. a. Organisationsunterlagen, allgemeine Korrespondenz und Verwaltungsvorgänge (ca. 30 Bde, 1938-1944), Schulungsmaterial (10 Bde, auch über Kirchen und Juden), weltanschauliche Stimmungs- und Lageberichte aus 11 Kreisen (11 Bde, 1943-1944), Einrichtung der Gauschulungsburg Schwarzenberg (2 Bde, 1944).

Gau-Archiv: Materialsammlung zur Geschichte der NSDAP in den Kreisen (1938/39), Zeitungsausschnitte (13 Bde).

Ferner enthält der Bestand: Korrespondenz des Gauinspekteurs Glueck über Mißstände in der Partei (1933-1934), Kassen- und Rechnungsschriftgut des Gauschatzmeisters, aus dem Gaustabsamt einzelne Anordnungen und Rundschreiben und ein Vorgang über Unruhen in Absberg wegen der Ermordung der Geisteskranken (1941), aus dem Rassenpolitischen Amt Monatsberichte über Frauen- und Mädelarbeit (19411943) und Vorgänge über Arisierungen (1940-1944) und Zigeuner (1941-1942), Kreiswirtschaftsberichte und Rundschreiben des Gauwirtschaftsberaters (1944-1945), Akten über Besuche italienischer Faschistenführer und von Reichsministern ( 6 Bde, 19381942), den „Informationsdienst“ der Gauleitung (1941) und „Mitteilungen des Gaurings für Volksaufklärung und Propaganda“ (1941-1942).

Zum Bestand gehört auch eine Sammlung von Dokumenten vornehmlich aus der Zeit vor 1933 (sog. NachlaB Streicher, 148 Bde), dabei ein Terminkalender (19371939), einzelne Bände über antisemitische Propaganda (1933-1938), Zeitungsberichte über ihn, Material zur Geschichte der Partei in Franken und über Reden Streichers im Krieg.

Ergänzungsüberlieferung liegt in den Dokumenten des Verfahrens gegen Streicher vor dem Internationalen Militärtribunal in Nürnberg und in Resten von Akten der Kreisleitungen Dinkelsbühl, Eichstätt, Feuchtwangen, Hersbruck, Lauf an der Pegnitz, Fürth, Neustadt (Aisch), Nürnberg-Stadt und -Land, Rothenburg ob der Tauber und Schwabach vor (N) und ist als Korrespondenz in den Registraturen der Regierung(en) von Mittelund Oberfranken nachgewiesen.

Dieser Bestand wird durch das Archiv des von Streicher persönlich herausgegebenen antisemitischen Hetzblatts „Der Stürmer“ (Hauptteil im StadtA Nürnberg) ergänzt. Es enthält einige Akten der Redaktion (63 Bde) u. a. über sonstige Publikationen und über Prozesse und andere Auseinandersetzungen wegen Angriffen auf einzelne Firmen und Personen, besteht aber vor allem aus Zuschriften aus dem Leserkreis mit Fotos, Zeitungsausschnitten und Druckschriften, die zum Teil aus geplünderten Wohnungen von Juden stammen. Sie sind nach Reichsgebiet mit eingegliederten Gebieten (434 Bde, davon 122 Altreich, 104 Österreich, 115 Sudetenland und Protektorat), Ausland (242 Bde, davon Frankreich 65. Sowjetunion mit Baltikum 38, GroBbritannien 25) und 20 Sachgruppen (ca. 1000 Bde) geordnet; dazu gehören "Der Jude als Verbrecher" (56 Bde nach 17 Kategorien, davon 12 Bde über Wechselfälscher und Wucherer, 3 Bde über Juden in Konzentrationslagern, Gefängnissen und bei Zwangsarbeit), „Der Jude als Rassenschänder“ (33 Bde), ,in politischen Parteien“ (39 Bde), „Mischlinge“ (4 Bde), „Judenknechte“ (21 Bde, meist über Kunden jüdischer Geschäfte). Die ebenfalls vorhandene Redaktionskartei, mit der die Jahrgänge 1934 bis 1943 nach Sachen, Personen, Institutionen und Orten erschlossen wurden, ist als Microfiche-Edition zugänglich. Kleine Teile des „Stürmer-Archivs“ sind auch in das Leo-Baeck-Institut New York und das YTVO-Institut in New York gelangt. 
Lit.: GUIDES to German Records. vol 3. S. 5. 23, 70, 97. 102, 119. 137. - A. MÜLLER: Das StürmerArchiv im Stadtarchiv Nürnberg. 1984. - Die REDAKTIONSKARTEI „Der Stürmer" 1934-1943. MicroficheEdition). 1984. - F. HAHN: Lieber Stürmer! 1978. - R. L. BYTWERK: Julius Streicher. 1983. - U. GRIESER: Himmlers Mann in Nürnberg. 1974.

\section{Gauleitung Hamburg}

HH, Best. 614-2/5 (NSDAP) Erhalten blieben nur einige Organisationsunterlagen (1933-1945), Rundschreiben des Gauleiters Karl Kaufmann (3 Bde, 1930-1944) und der Kreisleitung Altona (19331944), das „Verordnungsblatt“ (1944-1945) und vom Gauamt für Kommunalpolitik ebenfalls Rundschreiben sowie Berichte und Korrespondenz mit dem Bevollmächtigten der NSDAP (7 Bde, 1935-1945), ferner einzelne Schulungsblätter. Vermutlich für die Gaupropagandaleitung wurden Filme vom Gauparteitag 1933 und vom 1. Mai 1934 produziert (BA-Filmarchiv).

Lit.: A. EBBINGHAUS. H. KAUPEN-HAAS: Heilen und Vernichten im Mustergau Hamburg. 1984.

Gauleitung Hessen-Nassau, Frankfurt

WI, Abt. 483

Der Bestand enthält einige persönliche Unterlagen des Gauleiters Jakob Sprenger (19121939), Rundschreiben von Gauleitung und einzelnen Ämtern (3 Bde, 1931-1944) und Akten vor allem folgender Organisationseinheiten:

Gaustabsamt (27 Bde): u. a. Lage- und Stimmungsberichte der Kreisleitungen (19381940, 1943-1944) und des SD-Abschnitts Frankfurt (1944).

Gauorganisationsamt (39 Bde): u. a. Akten über Organisation im allgemeinen (19341941) und einzelnen Kreisen (1938-1939), Mitgliedschaft (1929-1944, mit Statistiken), Personalangelegenheiten Politischer Leiter und Angestellter der NSDAP (1933-1943) und von Gaurednern (1931-1935) mit Beurteilungen von Absolventen der Gauführerschule Kronberg im Taunus (1933-1939) und anderer Gau- und Kreisschulen (19351939), Betreuung von Rückwanderern (1940-1943), Zahlung von Unterstützungen aus dem „Adolf-Hitler-Dank“ (1937-1944).

Gauwirtschaftsberater: $u$. a. Lage- und Stimmungsberichte, auch der Gauwirtschafiskammer (1939-1944), Akten über politische Überprüfung von Unternehmern und Rechtsanwälten, vor allem in Frankfur (1933-1944), über Bewirtschaftung und Preisbildung (1939-1943), Besetzung von Funktionen in der Rüstungswirtschaft (1941-1943).

Gaupropagandaleitung: u. a. Schriftwechsel mit dem Reichspropagandaministerium (Fernschreiben, 1943-1944), Akten über Gaukulturwoche 1937, „NS-Briefe“ (19371939) und „Rhein-mainische Zeitung“ (1943-1944), Film über "Arbeitsschlacht“ 1934 (BA-Filmarchiv).

Gau-Archiv: Einrichtung des Archivs und Bearbeitung einer Gau-Chronik (1939-1943). Gausippenamt: s. Abschnit 2.1.2.2.1.

Vorhanden sind außerdem Akten (des Gaurechtsamtes?) über die rechtliche Vertretung von Juden (1939-1943), (des Gauschatzmeisters?) über Kassen- und Buchprüfungen bei einzelnen Orsgruppen (1934-1942), über Verwertung jüdischen Vermögens (1938-1945, mit beschlagnahmter Korrespondenz des Jugendbundes „Esra“ in Wiesbaden).

Ergänzungsüberlieferung enthalten Aktenreste der Kreisleitungen Wiesbaden, Rheingau (Rüdesheim), St. Goarshausen, Hanau, Gelnhausen, Schlüchtern, GroB-Frankfurt, Maintaunus-Obertaunus (Bad Soden), Limburg-Unterlahn, Oberwesterwald (Westerburg), Oberlahn-Usingen (Weilburg), Wetzlar, Biedenkopf-Dillenburg, ferner (DA, Best. $\mathrm{N}$ 1) der Wetterau (Friedberg, $20 \mathrm{Bde}$ ), von Alsfeld-Lauterbach, Bensheim, Büdingen 
und weiteren neun im Land Hessen sowie (KO, Best. 662) St. Goarshausen und Diez und des Kreisgerichts Bingen (11 Verfahrensakten, u. a. wegen Umgangs mit Juden, 1938/39, 21 Urteile, 22 Fälle der Ablehnung der Aufnahme in die Partei).

Lit.: D. REBENTISCH: Persönlichkeitsprofil und Kartiereverlauf der nationalsozialistischen Führungskader in Hessen. 1983.

Gauleitung Köln-Aachen, Köln

D, Best. RW 23

Zum Bestand gehören nur Mitteilungsblätter (2 Bde, 1931-1936), der „NS-Gaudienst“ (1945), Rundschreiben, u. a. betr. Beitragszahlung, VerteidigungsmaBnahmen, Einsatz am Westwall, Räumung bedrohter Orte (7 Bde, 1937, 1939, 1944-1945) und des Gaupropagandaamtes (1942-1944), Vorträge (1934) und ein Register jüdischer Familiennamen des Rassepolitischen Amtes, Reste von Korrespondenz des Gauschulungsamtes (2 Bde, 1933-1935, 1939-1944, u. a. betr. Gauschule Honnef) und des Amtes fūr Volkstumsfragen (1944) sowie Akten des Gaugerichts aus einem Verfahren wegen rückständiger Beiträge (1936-1937), ferner Bilder von führenden Funktionären.

Erhebungsbögen aus der Parteistatistischen Erhebung 1939 (vgl. oben zur Gauleitung Berlin) aus den Kreisen Aachen-Stadt und -Land, Düren, Geilenkirchen, Jülich und Monschau befinden sich in Akten des Sonderbeauftragten für die Entnazifizierung im Lande Nordhein-Westfalen (D, Best. NW 1000-1129). Von den Kreisleitungen Aachen-Stadt und -Land (Stolberg, Monatsberichte 1940-1943, 22 Verfahrensakten des Kreisgerichts 1933-1942), Bergisch-Gladbach, Bonn, Euskirchen, Geilenkirchen, Jülich, Köln (10 Bde, 1940-1945) und Siegburg liegen Aktenreste als Ergänzungsüberlieferung vor, die außerdem in größerem Umfang in Registraturgut der Regierung Aachen und von Kreisbehörden nachgewiesen wird. Zeitungsausschnitte über Veranstaltungen der NSDAP und ihrer Gliederungen und über Gauleiter Josef Grohé sowie einzelne NSPublikationen enthält das 1935 bei der "Abwehrstelle“ gegen das Neuheidentum der Erzdiözese Köln eingerichtete publizistische Archiv (Sammlung Joseph Will, StadtA Köln).

Lit: SCHRIFTGUT DER NSDAP. Teil 2. S. 8-22, 115, 117, 128, 130, 132, 136, 140-150. - W. FÖRST: Die theinischen Gauleiter. 1984.

Gauleitung Koblenz-Trier (ab 1942 Moselland), Koblenz $\quad$ KO, Best. 662 Der Bestand enthält vor allem Rundschreiben (1940-1944) und Akten des Gauschatzmeisters über die Revision der Kassen bei Kreisleitungen, Ortsgruppen und Gliederungen (dabei das Reichsausbildungslager des HJ-Streifendienstes in Freusburg) und die Kreisrevisoren (42 Bde, 1934-1944), ferner Aufnahmeanträge aus 14 Koblenzer Ortsgruppen (3 Bde, 1939-1942). Beschlüsse des Gaugerichts (2 Bde, 1935-1939) werden durch Akten aus zwei Verfahren vor dem Kreisgericht Bitburg (1938 und 1940) ergänzt. Rundschreiben des Gaupropagandaamtes sind in Akten der Kreisleitungen Mayen (1944) und Luxemburg (1942-1943) überliefert, außerdem einige Unterlagen für Redner. Aktensplitter gibt es über den Volkssturm (1944-1945) und vom Beauftragten bzw. Sonderbeauftragten des Gauleiters Gustav Simon für das Wohnungshilfswerk (1944) und für Räumungsfragen (1944). Weitere Ergänzungsüberlieferung bieten vor allem Akten der Kreisleitung Trier-West-Land (308 Bde, 1933-1944, Best. 662,3).

Teilweise aus Empfängerüberlieferung stammen Rundschreiben, Mitteilungsblätter und einzelne Broschüren vor allem des Gaupropagandaamtes (19 Bde), ferner u. a. des Gaustabsamtes, des Gauamtes für Kommunalpolitik und der Gauwaltungen von 
DAF und NSV (in Best. 714). Ein Bericht der Gauleitung ,Der Grenzgau KoblenzTrier" liegt in einer ersten Ausgabe von 1936 und einer dritten von 1938 vor (IfZ).

Lit.: F. J. HEYEN: Nationalsozialismus im Alltag. - H. ROMEYK: Der Gau Moselland in der nationalsozialistischen Reichsreform. 1985.

Gauleitung Kurhessen, Kassel

WI, Abt. 483

Die wenigen Akten (15 Bde, 1932-1942) enthalten Rundschreiben (1932-1942) und betreffen die Aufnahme in die Partei und andere Mitgliedschaftsangelegenheiten (19331938), kommunalpolitische Lehrgänge an der (nach dem 1943 entlassenen und durch Karl Gerland ersetzten Gauleiter benannten) Karl-Weinrich-Gauschule in Bad SoodenAllendorf, die Ausschreitungen gegen Juden in Wolfhagen und Naumburg/Bez. Kassel im November 1938 und MiBstände im Kurbetrieb von Bad Salzschlirf. Eine Sammlung von Rundschreiben der Gauleitung, die aus Akten von Kommunalbehörden zusammengestellt wurde, befindet sich im Archiv der Forschungsgruppe Nationalsozialismus in Hessen in Kassel. Die Ersatzüberlieferung durch Akten von Kreisleitungen ist nur für Marburg (43 Bde, 1935-1945, mit Rundschreiben des Gauschatzmeisters, 1937-1942, Teilbestand auch WI) und Hünfeld (ca. 100 Bde, meist politische Beurteilungen, 19361944, beide MR, Best. 327/1), außerdem für Fritzlar-Homberg, Wolfhagen, Eschwege und Frankenberg/Eder (alle WI) relativ umfangreich, für Fulda, Melsungen, Hofgeismar, Gelnhausen, Kassel, Rotenburg/Fulda, Witzenhausen, Wolfhagen und Ziegenhain splitterhaft.

Gauleitung Mainfranken, Würzburg

WÜ, Best. III 8.0.1 Der Bestand vereinigt Aktenreste (vor allem Korrespondenz mit Ortsgruppen) und -splitter der meisten Ämter der Gauleitung (insgesamt 126 Bde, 1929-1945). Von Gauleiter Hellmuth, seinem Stellvertreter, dem Gaugeschäftsführer und dem Organisationsamt (insgesamt 13 Bde) stammen einzelne Anordnungen, Organisationsunterlagen, Berichte der Kreisleitungen und anderer über die Stimmung (1938-1942), die Wirtschaftslage (1939) und Folgen von Luftangriffen (1943-1944) sowie Vorgänge über UkStellungen (1939). Vertreten sind ferner der Gauinspekteur (4 Bde, dabei Berichte über einzelne Geistliche 1936-1942), das Gaupersonalamt ( 9 Bde betr. Politische Leiter, auch Denunziation von Beamten als Kunden von Juden 1938), das Gauschulungsamt (mit Manuskripten von Vorträgen) mit dem Gauausbildungsleiter, der Gauschatzmeister (5 Bde), Gaupropagandaleitung und Gaupresseamt (10 Bde, dabei „NS-Gaudienst" 1936-1938, Rednerinformationen), das Gaugericht (Teil einer Strafkartei) und das Gauarchiv ( 2 Bde, dabei Beiträge zu einer Chronik). Etwas umfangreicher ( $38 \mathrm{Bde}$ ) sind die Akten des Gauwirtschaftsberaters mit Berichten der Kreisleitungen (12 Bde, 1939 1943), des Führungsstabs Wirtschaft im Wehrwirtschaftsbezirk XIII (1939-1941) und Vorgängen u. a. über Arisierungen (1938-1941), Betriebsstillegungen (1940), Ansiedlung in Polen.

Ersatzüberlieferung bieten Aktenreste der Kreisleitungen Aschaffenburg-Alzenau, Brückenau-Hammelburg, Ebern, Haßfurt, Bad Kissingen-Münnerstadt, KitzingenGerolzhofen, Königshofen-Hofheim, Lohr-Gemünden, Marktheidenfeld-Karlstadt, Miltenberg-Obernburg, Neustadt-Mellrichstadt, Ochsenfurt, Schweinfurt und Würzburg (die Vorgänge der Kreisleitung Würzburg-Land über kirchliche Angelegenheiten und einzelne Geistliche 1936-1941 im Diözesanarchiv), und Korrespondenz wurde im Registraturgut der Landratsämter des Regierungsbezirks nachgewiesen.

Lit: S. WENISCH: Quellen zur Zeitgeschichte im Staatsarchiv Würzburg. 1980. 
Der Bestand enthält Ortsgruppen- und andere Anschriftenverzeichnisse (6 Bde, o. D. und 1939-1941), Korrespondenz des Gauleiters Paul Giesler (17 Bde, vor allem Gesuche, 1943-1945), der 1943 auf den verstorbenen Gauleiter Adolf Wagner (NachlaB im StadtA Burghausen, darin Diensttagebücher 1936, 1939, 1941/42) folgte, Rundschreiben und Aufrufe der Gauleitung und einzelner Ämter (5 Bde, 1936-1939, 1944-1945) und Sachakten aus folgenden Gebieten: Personalangelegenheiten im öffentlichen Dienst (4 Bde, 1930-1945), Arisierungen (2 Bde, 1938-1943), Kassen- und Rechnungswesen (4 Bde, 1933-1939). Reichsverteidigungsangelegenheiten (33 Bde, 1937-1945, mit Stimmungsberichten 1944), Statsbesuche und Großveranstaltungen, insbes. am 9. November (19 Bde, 1935-1942), Reichsparteitage (18 Bde, 1933-1938), Wahlen und Volksabstimmungen (2 Bde, 1934-1938), Propaganda (3 Bde, 1935-1944), Angelegenheiten der Reichsschule Bernau/Chiemsee, der Gauschule Niedernfels u. a. Parteischulen (3 Bde, 1935-1936, 1943).

Neben einer Korrespondenzaktenserie (8 Bde, 1934-1944), die vor allem Schriftwechsel mit der Reichsleitung und Behörden enthält, sind Korrespondenzakten aus dem Gaupersonal- und dem Gauorganisationsamt vorhanden (70 Bde, 1933-1944, dabei Beurteilungen, 7 bzw. 21 Bde Schriftwechsel mit dem Reichsorganisationsleiter und Kreisleitungen). Aus denselben Ämtern stammen Rundschreiben (7 Bde, 1934-1944) und Sachakten über Personalveränderungen und andere Personalangelegenheiten (u. a. Religionszugehörigkeit, Wehrdienst) politischer Leiter (14 Bde, 1934-1944), Dienstauszeichnungen und Medaillen (13 Bde, 1938-1943), Organisation und Dienstbetrieb (6 Bde, 1934-1942), Musikzüge, Sport und Rohstoffsammlungen (je 2 Bde). Aus dem Rassepolitischen Amt (8 Bde, 1934-1945) sind Schriftwechsel mit dem Reichsbund Deutsche Familie (u. a. über Ehevermittlung), Tätigkeitsberichte (1940-1941) und Vorgänge über das Erbgesundheitsgesetz vorhanden.

Von den periodischen Veröffentlichungen der Gauleitung liegen im Bestand das „Gaumitteilungsblatt“ (1934-1936) vor, ab 1937 unter dem Titel „Der Traditionsgau. Die Gauleitung München-Oberbayern ordnet an" (1937-1944, lückenhaft, weitere Teile im IfZ), der "Informationsdienst für Hoheitsträger und Redner“ (11 von 12 Nummern, 1939-1940) und der ,NS-Gaudienst“ (1942-1943, 1945, unvollständig), im IfZ der „Kriegsinformationsdienst“ (1939-1940) und - ebenfalls unvollständig - „Die Parole. Monatsdienst der Gaupropagandaleitung“ (1942-1944) und das "Mitteilungsblatt des NS-Gaurings für Volksaufklärung und Propaganda" (1942-1943).

Von den einzelnen Kreisleitungen sind wenige Stimmungs- und Tätigkeitsberichte bei der Gauleitung überliefert (1938-1939, Wasserburg 1934-1936), eigenes Schriftgut vor allem von Berchtesgaden-Laufen (149 Bde) und Rosenheim (49 Bde), im übrigen mit jeweils mehr als einem Band nur von Altötting (5 Bde), Dachau (2 Bde), Ebersberg (4 Bde), Freising (4 Bde), Fürstenfeldbruck (Haushaltskartei), Ingolstadt (15 Bde), Landsberg/Lech (4 Bde), Mühldorf (9 Bde), München (9 Bde), Schongau (14 Bde), Starnberg (5 Bde), Traunstein (8 Bde), Wasserburg ( 8 Bde) und Weilheim (41 Bde). Die im Hauptarchiv der NSDAP (BA, Best. NS 26) über den Gau angelegten Akten (ca. 60 Bde, meist vor 1933, dabei eine Sammlung des Ortsgruppenleiters von Ottobrunn, Weinbeer, 1925-1938) enthalten vor allem Material über einzelne Ortsgruppen. Ein Film über die Eröffnung des bayerischen Landtags 1933 wurde ebenfalls für das Hauptarchiv, ein anderer über die Gedenkfeiern am 9. November 1933 von der Gauleitung produziert (beide Zentrales Filmarchiv Potsdam). 
Lit: WIDERSTAND UND VERFOLGUNG in Bayern. Bd. 2. 1975. S. 1-93, 159.

Gauleitung Ost-Hannover, Lüneburg

H, Best. Hann. $310 \mathrm{I} / \mathrm{K}$

Aus den Akten dieser Gauleitung, an deren Spitze von 1925 bis zuletzt der sonst kaum hervorgetretene Ono Telchow stand, sind nur wenige Schriftstücke überliefer. Es handelt sich um Unterlagen über Betriebsappelle der DAF in Harburg (1935-1937), Schulungs- und Propagandamaterial (2 Bde, 1943-1944), Arbeitspläne des Volksbildungswerks (1942/43), Vorgänge über den Volkssturm (1944-1945) und einzeine Rundschreiben (1945).

\section{Gauleitung Saarpfalz (ab 1942 Westmark), Neustadt/Weinstraße}

Die Restüberlieferung ist geteilt zwischen den Archiven in Saarbrücken, Metz und Speyer. Der Saarbruickener Bestand enthält Rundschreiben $(4 \mathrm{Bde})$ und Akten über einzeine Baumaßnahmen (4 Bde) und Arbeitskräfteeinsatz (9 Bde) des Gauorganisationsleiters für den Stellungsbau (1944), ferner Rundschreiben und Drucksachen der Gaupropagandaleitung (5 Bde, 1929-1944) und Aktensplitter des Kommandostabs Volkssturm und des Gaugerichts (1942-1944).

In Metz (21 Bde, 1928-1944) befinden sich Reste von Korrespondenz und Manuskripte aus dem Büro des Gauleiters Bürckel, auf den 1944 Stöhr folgte, und Berichte der Kreisleiter (1936-1941).

Die Speyerer Überliefenung (Best. T 65) beschränkt sich auf wenige Schriftstücke über das Gauarchiv, die Saar-Volksabstimmung und Veranstaltungen (1934-1940).

Lit.: D. WOLFANGER: Ernst Ludwig Leyser. Stellvertretender Gauleiter der NSDAP in der Saapfalz 1988. - G. PAUL: Die NSDAP des Saargebietes. 1987.

Gauleitung Schleswig-Holstein, Kiel

SL, Abt. 454

Der Bestand ( 40 Bde, jedoch $z$. T. nur aus einzelnen Schriftstücken) umfaBt Rundschreiben (1944-1945, weitere von 1934-1937 HH, in Best. 614-2/5 NSDAP, auBerdem aus der Kreisleitung Eutin in SL, Abt. 456/1), einzelne Wochenberichte an die Parteikanzlei und Lageberichte von Kreisleitungen (1941, 1944-1945), Akten über einzelne Personen (10 Bde, 1937-1942, dabei politische Überprüfungen und Parteigerichtsverfahren, auch über Kreisleiter und Landräte, Erfassung von NS-Funktionären durch die Gestapo 1938-1939), über HJ-Führer und Verpflichtung der Jugend (4 Bde, 1937-1943), Verhältnis zur Kriegsmarine (1939) und Wirtschaftsangelegenheiten (6 Bde, 1938-1939). Die publizistische Tätigkeit der NSDAP ist in einer Sammlung von Drucksachen (700 Bde) im NachlaB des Reichstagsmitglieds und Kreisbauernführers Hans Beeck dokumentiert. Die Akten über das Spruchgerichtsverfahren gegen Gauleiter Hinrich Lohse als Angehörigen einer in Nürnberg für verbrecherisch erklärten Organisation befinden sich im BA (Best. Z 42 II).

Gauleitung Schwaben, Augsburg

Aus der Dienststellenleitung (103, z. T. nur wenige Blatt umfassende Bde überwiegend aus den letzten Kriegsjahren) enthält der Bestand das Verordnungsblatt „Der politische Soldat" (1941-1944, einzelne Nummern auch 1938-1940), Stimmungs- und Lageberichte der Kreisleitung Augsburg-Stadt (1939-1942), den Tätigkeitsbericht des Bundes der Schweizer in Großdeutschland für 1943, Akten über Reichsverteidigungsmaßnahmen (15 Bde, 1943-1945, dabei Korrespondenz von Gauleiter Wahl mit der Parteikanzlei, u. a. über Bildung einer Heimatschutztruppe, Rundsprüche zum Freikorps „Adolf Hitler“ 
1945), über Einzelfälle gegnerischer Äußerungen ( 9 Vorgänge), vor allem aber über Personalangelegenheiten politischer Leiter (35 Bde mit Listen, Beurteilungen, Meldung von Verwundeten und Beschwerden) und über soziale HilfsmaBnahmen (17 Bde, u. a. aus Mitteln der Karl-Wahl-Stiftung).

Aus der Gaupropagandaleitung (60 Bde, 1931-1944) stammen u. a. Stimmungsund Tätigkeitsberichte von 12 Kreisleitungen (1940-1944), Rednerlisten und -ausweise (17 Bde, 1934-1940), andere Personalvorgänge (12 Bde, 1938-1943), einige Unterlagen über Organisationsangelegenheiten (9 Bde, 1931-1944) und das Verhältnis zu den Kirchen (4 Bde, 1934-1936, 1943). Das Gauorganisationsamt (27 Bde, 1937, 1941 1945 ) ist vor allem durch Karteien über Kriegsteilnehmer und Kriegsopfer (22 Bde), ferner durch einige Statistiken vertreten, der Gauschatzmeister durch Unterlagen über Kassenrevision bei Ortsgruppen und der NS-Frauenschaft (13 Bde, 1935-1941). Nur Aktenfragmente liegen vom Gaukulturamt (5 Bde), vom Gauschulungsamt (zusätzlich Lehrgangsunterlagen der Gauschulungsburg Bachhagel/Krs. Dillingen, 1937-1939) und Gaupresseamt vor, vom Gaugericht sind sieben Verfahren durch einzelne Schriftstücke (1941-1944) dokumentiert. Im Bestand befinden sich ferner Unterlagen der DeutschItalienischen Gesellschaft (9 Bde, 1938-1944) mit dem Jahresbericht des Gauamtsleiters Josef Sewald (1943), von dem außerdem - wie auch vom Augsburger Bürgermeister Mathias Kellner - einige private Papiere (1933-1943) die NSDAP-Überlieferung ergänzen.

Weitere Ergänzungsüberlieferung ist in Akten der Kreisleitungen Memmingen (ca. 1150 Bde, mit Unterlagen von Vorgliederungen, 1928-1944), Augsburg, Günzburg, Marktoberdorf, Nördlingen, Sonthofen und in geringerem Umfang von 13 weiteren Kreisleitungen enthalten.

Lit.: K. WAHL: Patrioten oder Verbrecher. 1975.

Gauleitung Süd-Hannover-Braunschweig, Hannover H, Best. Hann. 310 I Überliefert sind vor allem Akten und Materialsammlungen, die vom Archiv für Zeitgeschehen des Gaus und später vom Gau-Archiv übernommen und angelegt worden waren, mit einem relativ hohen Anteil von Schriftgut (auch der Nationalsozialistischen Freiheitsbewegung von 1924) vor 1933. Dazu gehören zahlreiche Korrespondenz- (u. a. mit der Reichsleitung und anderen Gauleitungen) und wenige Sachakten, u. a. über Parteimuseum Niedersachsen e. $V$., Wahlen, Versammlungen, Rechtsschutzangelegenheiten, MiBbrauch von Parteisymbolen (insgesamt 130 Bde, 1925-1944). Weitere Akten enthalten Schriftwechsel der Gaupropagandaleitung (64 Bde, 1928-1939) über Rednereinsatz und -kameradschaften (1937-1939), Kundgebungen und Versammlungen, Tätigkeit der Lügenabwehrstelle, Reichstagswahl 1936 und Propagandaberichte sowie den Informationsdienst des Amtes Rosenberg (1935-1936).

Nachrichten über Gegner der NSDAP stammen vor allem aus der Zeit vor 1933 (36 Bde, 1927-1934), ebenso Manuskripte für den „Niedersächsischen Beobachter" und Drucksachen, während das Verordnungsblatt bis 1937 reicht (6 Bde mit Rundschreiben der Gauleitung und verschiedener Ämter, 1934-1936, 1941, in Akten der Ortsgruppe Northeim). Die Sammlungen des Gauarchivs (28 Bde) enthalten Material über andere Parteien vor 1933, Flugblätter, Feldpostbriefe an eingezogene Parteigenossen, den „NS-Gaudienst“ (1944), Informationen über Opfer politischer Auseinandersetzungen und über Gauleiter Hartmann Lauterbacher, der 1940 auf Rust folgte, und betreffen NSBO, NSLB und den Luftangriff auf Hannover im Oktober 1943. Angaben zur Frühgeschichte der Partei machen die Erinnerungen des Gaupropagandaleiters und späteren 
Staatssekretärs Leopold Gutterer (Manuskript WF, Best. $250 \mathrm{~N}$ ). Von sechs Heften einer Schriftenreihe des Rassepolitischen Amtes sind zwei vorhanden (1941-1942, IfZ). Die vom Gauarchivar Gustav Lauterbach angelegte Sammlung von Zeitungsausschnitten (BA, Best. ZSg 103) besteht zwar zur Hälfte aus Meldungen und Artikeln von Regionalzeitungen, ist jedoch nicht nach regionalen Betreffen geordnet und berücksichtigt vor allem außenpolitische und militärische Ereignisse.

Ergänzungsüberlieferung gibt es in Akten der Kreisleitungen Göttingen (133 Bde), Braunschweig- Stadt und -Land (Mitgliederkartei 1936-1942) und sieben weiterer sowie mehrerer Ortsgruppen.

Gauleitung Weser-Ems, Oldenburg

OL, Best. 320 Überliefert sind lediglich (insgesamt 12 Bde) Unterlagen über Gauleiter Carl Röver (mit Kopie seiner Denkschrift über die Lage der Partei 1942), dem 1942 Paul Wegener folgte, Handakten des Gauinspekteurs Erich Drescher (mit Reden und Veröffentlichungen 1939-1944, Berichten über den Kreis Wilhelmshaven 1938-1940, Vorgängen über einzelne Personen 1934-1944 und das Verhältnis von NSDAP und Verwaltung 1933-1945), ferner einzelne Rundschreiben. Weitere Rundschreiben (1934-1937), auch des Gauorganisationsleiters, „Informationsdienst“ (1940-1942) und „Sonderinformationen" (1943-1944) der Gaupropagandaleitung und Erhebungsbögen der Parteistatistik 1939 (14 Bde, vgl. oben zu Gauleitung Berlin) befinden sich im Staatsarchiv Bremen (Best. 7, 1066), ergänzt durch Akten der Kreisleitungen Bremen (mit Kreisgericht) und Wesermünde (künftig im Stadtarchiv Bremerhaven). Von den „vertraulichen Mitteilungs- und Führungsblättern“ unter dem Titel „Der Berichterstatter” ist eine Folge von 1943 im Hauptarchiv der NSDAP erhalten (BA, NS 26).

\section{Gauleitung Westfalen-Nord, Münster}

Aus der Dienststellenleitung sind Glückwunschschreiben von höheren Funktionären an Gauleiter Alfred Meyer, Lageberichte der Kreisleitungen (28 Bde, 1937-1940) und über die kirchliche Lage (1934-1936), Rundschreiben (1939-1944) und Akten über Organisation (1922-1938), Ausbildung (1936) und Ermittlungen der Gauinspekteure (1933) vorhanden. Im übrigen enthält der Bestand Schriftgut folgender Provenienzen:

Gauschulungsamt (259 Bde): Rundschreiben (20 Bde, 1932-1944), Lage- und Stimmungsberichte vor allem der Kreisschulungsämter (1934-1945), Schulungsmaterial (36 Bde, 1935-1943), Unterlagen über politische Gegner (1934-1937), „Gau-Nachrichten“ (12 Bde, 1938-1942), Akten über die Durchführung von Lehrgängen in den Kreisen (40 Bde, 1934-1945) und durch DAF, KdF und Deutsches Volksbildungswerk (45 Bde), über Personalangelegenheiten (40 Bde, 1933-1944), Errichtung und Zuständigkeit des Gauarchivs (ca. 50 Bde, mit Sammlungen zur Geschichte der Partei in Westfalen, einzelnen Kreisen und Orten 1922-1939).

Gauschatzamt (279 Bde): Akten über die Verleihung des Goldenen Parteiabzeichens (1934-1943) und Personalakten.

Gaukulturamt (5 Bde, 1933-1938, u. a. betr. Landes- und Volkskunde, Vor- und Frühgeschichte, Planung eines Schlageter-Denkmals, Familienforschung).

Gauamt für Volkstumsfragen (18 Bde, nur Zeitungsausschnitte über Auslandsdeutschtum, 1939-1944, zur unterstellten Forschungsstelle Westfalen in aller Welt s. Abschnitt 2.4.3).

Gaugericht (6 Bde aus vier einzelnen Verfahren, 1935-1944). 
Ein bei der politischen Säuberung nach 1945 zufallig gebildeter Teilbestand ( 83 Bde) aus verschiedenen Organisationseinheiten befindet sich im Stadtarchiv Bielefeld. Schwerpunkte bilden darin Akten und Einzelvorgänge über allgemeine Organisationsund Personalangelegenheiten (5 Bde, 1933-1939), Parteigerichtsverfahren und Ermittlungen dafür, meist aus politischen Gründen (19 Bde, 1933-1942), Maßnahmen gegen Geisteskranke (2 Bde, 1935-1939), Juden (1932-1943), Kirchen (3 Bde, 1931-1942), Kulturpolitik (3 Bde, 1933-1944) und über einzelne Kreise und Ortsgruppen (insgesamt 28 Bde), vor allem über Geschichte und Organisation sowie Disziplinarangelegenheiten in Bielefeld (22 Bde, 1923-1941).

Der Gau war in mehrere Bezirke unter Gauinspekteuren eingeteilt, aus deren Tätigkeit folgende Bestände vorhanden sind:

Gauinspektion für die Kreise Beckum, Borken-Bocholt, Coesfeld, Lüdinghausen, Recklinghausen-Land (106 Bde, 1933-1939): Rundschreiben der Gauleitung und anderer Dienststellen (15 Bde, 1934-1939), Lageberichte der Kreisleitungen (1934-1937), hauptsächlich Akten über Stellenbesetzung, Beschwerden und Untersuchungen (19331939), auch über Parteitage (1934-1939), SA (1934-1938), Kommunalpolitik (19341937), Wirtschaft (1933-1938).

Gauinspektion für die Kreise Münster-Stadt und -Land, Steinfurt, Tecklenburg und Warendorf (5 Bde, 1934-1935, betr. Beschwerden und Untersuchungen).

Gauinspektion für die Kreise Bielefeld-Stadt und -Land, Büren, Halle, Herford, Lübbecke, Minden, Paderborn und Wiedenbrūck (DT, in Best. M 15, 32 Bde, 19241939, meist bis 1934): Schriftwechsel u. a. mit der Gauleitung, Arbeitspläne, Mitgliederlisten, Unterlagen über Parteitage und Propaganda.

Ergärzungsüberlieferung bieten Akten der Gaukulturfachberaterin in Bielefeld (DT, in Best. M 15, 55 Bde, 1932-1936, mit Unterlagen über die Tätigkeit von Fachberaterinnen in der Kulturarbeit von 51 einzelnen Ortsgruppen) und des Reichsredners Leopold Bolwin (MS, 9 Bde über Einsatz auf Kundgebungen, 1929-1936), die Nachlässe von Gauleiter Meyer (DT, Best. D 72, vor allem Mappen mit Bildern aus seinen amtlichen und Parteifunktionen, auch in den besetzten Ostgebieten, einige Manuskripte und Entwürfe für Reden 1930-1940), des Gauamtsleiters Walter Steinecke (ebda, mit persönlichen Erinnerungen) und des Gauinspekteurs Erich Hartmann (ebda). Der Gauwirtschaftsberater wurde 1948 vom Landgericht Paderborn als Denunziant verurteilt (JUSTIZ UND NS-VERBRECHEN, Nr. 094).

Von folgenden Kreisleitungen sind - meist nur ganz wenige - Akten vorhanden: in Münster Borken-Bocholt, Lippstadt, Lüdinghausen, Münster-Warendorf (9 Bde), in Detmold Detmold-Lemgo (mit Berichten des Gauleiters 1936 und 1940, der DAF- und NSV-Kreiswaltung und umfangreichen Karteien), Herford (22 Bde, dabei Arbeitsberichte des Gauamtes für Agrarpolitik 1940-1941) und Höxter-Warburg. In Akten des Sonderbeaufuragten für die Entnazifizierung im Lande Nordrhein-Westfalen (D, Best. NW 1000-1129) sind Unterlagen aus 32 Verfahren (1933-1941) des Kreisgerichts Paderborn erhalten. Schriftwechsel mit der Gauleitung ist aus Akten des Reichsstatthalters und der Landesregierung von Lippe nachgewiesen.

Lit.: Das SCHRIFTGUT der NSDAP. Teil 4. 1983. S. 23-66.

Gauleitung Westfalen-Süd, Bochum

Aus der Tätigkeit der Gauleiter Josef Wagner (bis 1941), Paul Giesler (1941-1943) und Albert Hoffmann (bis Kriegsende) und der zentralen Ämter ist nur wenig überliefert (23 
Bde. 1931-1945); hauptsächlich handelt es sich um Akten über den Einsatz bei Schanzarbeiten im Westen (14 Bde, 1944-1945), ferner über Evakuierungsmaßnahmen (1943) und Einberufung politischer Leiter (1940-1941), auch um Bilder der Reichsschulungsburg Erwitte (1935), von Hoffmann liegen jedoch „Erinnerungen“ aus dem Jahr 1950 vor (BA, Kl. Erw. 854).

Um so umfangreicher ist das Schriftgut des Gauwirtschaftsberaters, des Direktors der Reichswerke „Hermann Göring“ und Vorsitzenden der Reichsvereinigung Kohle (vgl. Abschnitt 6.2.1.10), Paul Pleiger (mit 4 Bden Handakten, 1935-1937), der vielfach vom Hauptgeschäftsführer der Wirtschaftskammer Westfalen-Lippe in Dortmund, Heinrich Bornemann, vertreten wurde, vor allem aus folgenden Sachgebieten ( 779 Bde, 1934-1944):

- Organisation der Wirtschaft mit Rundschreiben (7 Bde, 1935-1943), Aufzeichnungen über Tagungen der Gau- (5 Bde, 1935-1941) und Kreiswirtschaftsberater (11 Bde, 1937 1940) und Akten über Wirtschafts- und Gauwirschaftskammern (9 Bde, 1938-1943).

- Arisierung von Betrieben und Grundbesitz im allgemeinen (52 Bde, 1935-1939), in den 19 einzelnen Kreisen (ca. 340 Bde, 1936-1940) und außerhalb des Gaues (18 Bde).

- ErschlieBung von Bodenschätzen im Vierjahresplan im allgemeinen (13 Bde, 1935 1938) und in 12 Kreisen (ca. 130 Bde, 1935-1939).

- RationalisierungsmaBnahmen und Betriebsstillegungen im allgemeinen (14 Bde, 1940-1943) und in 21 einzelnen Wirtschaftszweigen (ca. 100 Bde, 1940-1943).

Andere Akten betreffen Energiewirtschaft (8 Bde, 1935-1939), die Reichswerke (3 Bde, 1940-1941), NS-Musterbetriebe (1937), Verstöße gegen Devisen- (5 Bde, 19351938) und Preisvorschriften (9 Bde, 1936-1943), Bekämpfung von Ratenkreditverkäufen (4 Bde, 1937-1939) und politische Beurteilungen (12 Bde, 1936-1939).

Ergänzungsüberlieferung ist in den Dokumenten aus dem Verfahren gegen Pleiger im Nürnberger Wilhelmstraßenprozeß vor dem US-Militärgerichtshof enthalten, zur gesamten Zuständigkeit der Gauleitung in Akten der Kreisleitungen Herne-Castrop-Rauxel (65 Bde), Bochum (12 Bde) und (nur Splitter) Ennepe-Ruhr.

Lit.: TRIALS of War Criminals. vol. 12. 13. - G. KRATZSCH: Der Gauwirtschaftsapparat der NSDAP. 1989.

Gauleitung Württemberg-Hohenzollern, Stuttgart

LB, Best. PL 501 Im Bestand befinden sich relativ zahlreiche (ca. 200 Bde, 1924-1945), jedoch in der Regel nur wenig umfangreiche Reste von Akten. Sie betreffen u. a. Vorbereitung des Reichsparteitags 1939, den „Bund der Schweizer in GroBdeutschland“ (1942), die Reichsbewegung Deutsche Christen (1936-1938) und enthalten auch Schulungsmaterial (1939-1942). Folgende Organisationseinheiten sind vor allem vertreten:

Gauorganisationsamt (52 Bde, 1924-1942, mit Korrespondenz mit Kreisleitungen und Ortsgruppen vor 1933, ferner Vorgängen über unzulässige Verwendung nationalsozialistischer Bezeichnungen durch andere Organisationen).

Gaugeschäftsführer (5 Bde).

Gauschatzmeister (12 Bde).

Gaupersonalamt (17 Bde, 1928-1944, und 28 Bde Einzel-Personalunterlagen mit Beurteilungen, Ermittlungen).

Gaupropagandaamt (29 Bde).

Gaupresseamt (8 Bde, meist dessen „Informationen“).

Gauamt für Volksgesundheit (15 Bde, auch in Best. PL 514,12, u. a. Rundschreiben des Hauptamtes Volksgesundheit 1935-1938). 
Rassepolitisches Amt (3 Bde, dabei Erfassung .Andersrassiger").

Außerdem sind Anordnungen des Gauleiters Murr und Rundschreiben aller genannten Ämter sowie des Amtes Ausbildungswesen, Gauschulungsamtes, Gaugerichts, Gauwirtschaftsberaters und der Gauämter für Kommunalpolitik, für Technik, für Agrarpolitik und für Volkstumsfragen und eine Materialsammlung, vielleicht des Gauarchivs, zur Geschichte der NSDAP vor 1933 (speziell in Ulm) vorhanden. Weitere Rundschreiben sind in Akten des württembergisch-badischen Ministeriums für politische Befreiung (Best. EA 11/1) überliefert, ein „Bericht zur weltanschaulichen Lage“ der Gauleitung für die Zeit von Juli 1943 bis August 1944 im IfZ (ED 7la).

Von der in Personalunion mit der Kreisleitung Ulm verbundenen Gauinspektion II sind vor allem Akten über einzelne Disziplinarverfahren und über die Überwachung kirchlicher Tätigkeit vorhanden (24 Bde, 1933-1940, in PL 502/32).

Als Ergänzungsüberlieferung kommen Akten von Kreisleitungen in Betracht, unter denen diejenigen von Aalen, Backnang, Böblingen, Esslingen, Göppingen, Heilbronn, Ludwigsburg, Öhringen-Künzelsau, Ulm und Vaihingen größeren Umfang haben, acht weitere geringeren (Best. PL 501). Zusätzlich sind Verfahrensakten der Kreisgerichte Aalen, Crailsheim, Ehingen, Heidenheim, Öhringen-Künzelsau, Ulm und Waiblingen vorhanden (Best. PL 503), die jedoch überwiegend kriminelle Delikte betreffen.

\subsection{Gliederungen der NSDAP}

Das NS-Regime unterschied (Verordnung vom 29. März 1935) zwischen Gliederungen ohne eigene Rechtspersönlichkeit und Vermögen und angeschlossenen Verbänden (vgl. folgenden Abschnitt), die eigene Rechtspersönlichkeit besitzen konnten und deren Vermögen nur der Aufsicht der NSDAP unterworfen war. Zu den sechs Gliederungen gehörte außer den nachstehend behandelten die SS (vgl. Abschnitt 2.2), eine Mittelstellung zwischen Staat und Partei nahm seit 1935 der Reichsarbeitsdienst ein (vgl. Abschnitt 7.2), und das NS-Fliegerkorps (unten) unterstand dem Reichsminister der Luftfahrt, Reichsarbeitsführer und Korpsführer des NSFK waren aber auch Reichsleiter der NSDAP.

\subsubsection{SA (Sturmabteilungen der NSDAP)}

\subsubsection{Oberste SA-Führung (OSAF)}

BA, Best. NS 23

ZStA, Best. 62 Sa 1

Neben einer Sammlung von Befehlen (17 Bde, 1927-1940), Manuskripten, Reden und Unterlagen des Stabschefs und Nachfolgers von Ernst Röhm, Victor Lutze, für Besprechungen mit Hitler (1936), der das Amt des Obersten SA-Führers für sich selbst in Anspruch nahm, bilden vor allem die Verfügungen (ca. 30 Bde, 1931-1945 April), Korrespondenz- und einige Sachakten des Hauptamtes Verwaltung (190 Bde, 19311945) den Koblenzer Bestand. Sie betreffen u. a. Personalangelegenheiten und Besoldung. Ausrüstung, Ausbildung - insbesondere Schießausbildung und Wehrerziehung der SA und ihrer Wehrmannschaft, Pionier-, Sanitäts- und Nachrichteneinheiten, ferner die Verwaltung von Grundbesitz. 
Akten des Rechtsamtes (24 Bde) betreffen u. a. Amnestien, Beleidigung der SA, Ehrenangelegenheiten, das Verhältnis zu den Kirchen und die "Röhm-Revolte" (mit Liste der Opfer). Nur wenig ist über Propaganda und Presse (15 Bde) und SAWachmannschaften in Konzentrationslagern (4 Bde, 1933-1934, 1937, 1939) vorhanden. Noch im Bestand enthaltenes Schriftgut regionaler Dienststellen ist im folgenden Abschnitt berücksichtigt.

Akten des Chefs des Ausbildungswesens (Chef AW) und seiner Abwicklungsstelle über Personal- und Ausbildungsfragen bilden den Potsdamer Bestand (15 Bde, 1931/33-1935). Der für seine Aufgaben produzierte Film „Laufendes, marschierendes Volk" (1934) ist wie zwei SA-Filme über Arbeitseinsatz (1933 oder 1934) und die Wehrmannschaft (1940) überliefert (BA-Filmarchiv).

Das Hauptarchiv der NSDAP (NS 26) enthält neben Berichten und anderen Quellen aus der Zeit vor 1933 eine Sammlung von Befehlen (1933-1937) und einige Unterlagen über den „Röhmputsch“ (1934). Material zur Geschichte der SA, ihre Organisation, Personalangelegenheiten, Gnaden- und Rechtssachen befindet sich in der Sammlung Schumacher (20 Bde, 1921-1944, dabei einzelne Briefe Röhms, 4 Bde mit Berichten aus dem In- und Ausland 1933/34 aus seinem Ministeramt, Vorgänge über die Sonderbevollmächtigten in Bayern, die Auflösung des „Stahlhelm“ 1935/36 und die Standarte „Feldherrnhalle“ 1935-1944).

Die im Berlin Document Center verwahrten Personalunterlagen der SA über 437459 Personen (mit einem unbekannten Anteil von NSKK- und NSFK-Mitgliedern) sind verschiedener Herkunft. Den größten Teil bilden fragmentarische Vorgänge (4 074 Bde), die nur zum kleineren Teil bei der Obersten SA-Führung, überwiegend aber bei SA-Gruppen in Bayern und Hessen und ihren Standarten (insbesondere in Ansbach und Regensburg) entstanden sind. Nur zum Teil enthalten sie Führerfragebögen (1933-1934) und Personalfragebögen (1937) mit Angaben über Tätigkeiten und Funktionen im Staatsdienst und in der Partei. Vollständige Personalakten der Obersten SA-Führung und der Gruppen Bayerische Ostmark, Franken und Hochland und Einzelfallakten des Sondergerichts der Obersten SA-Führung (1934-1935) bzw. des Disziplinargerichts der Obersten SA-Führung (1935-1944) sind im anderen Teil vereinigt (776 Bde Sammelakten). Dazu kommen Karteikarten zum "Warnungsbuch", das die ausgeschlossenen SA-Mitglieder verzeichnete, mit Angabe des Ausschlußgrundes und eine Kartei über Angehörige der kasernierten SA-Standarte „Feldherrnhalle“.

Befehle und Anweisungen wurden im Verordnungsblatt der Obersten SA-Führung (1931-1944), außerdem in .Stabs“- bzw. "Personalstabsbefehlen“ (ab 1935), in „Führungsbefehlen der Obersten SA-Führung“ (1942-1944), dem „Mitteilungsblatt des Personalhauptamtes" (1942) und „Verwaltungs-Mitteilungen“" (1942-1944) veröffentlicht (alle teils BA, teils IfZ). Außerdem erschienen die Zeitschriften "Der SA-Mann" ab 1928, „Der SA-Führer" (1936-1944, August), „Die SA“ (1940-1941, mit Sonderdruck „Geschichte der SA“, 1941), „Der Appell“ der Abteilung Weltanschauung und kulturelle Dienstgestaltung (Nr. 1-14, 1937-1939, IfZ), „Führerbefehle“ (82 Nrn, 1931-1943. IfZ), „Führungshefte“ (2 Nrn, 1944), „Kampfschriften“ (14 Nrn, 1937-1939, IfZ) und zahlreiche Einzelpublikationen über Dienstgestaltung, Uniformen. Spor und Gesundheitswesen.

Nachdem die SA in Nürnberg von der Anklage als verbrecherische Organisation freigesprochen worden war und auch Lutzes Nachfolger Schepmann erreicht hatte, daB ein Verfahren gegen ihn vor einem Spruchgericht (Akten im BA, Best. Z 42 II) eingestellt 
wurde, war die Beteiligung einzelner SA-Leute an Verbrechen unmittelbar nach dem 30. Januar 1933 und am Novemberpogrom 1938 mehrfach Gegenstand von Strafverfahren, so gegen einen SA-Brigadeführer aus Wiesbaden (Landgericht Marburg 1961), gegen einen SA-Oberführer und Angehörige der Stabswache Nürnberg (Landgericht Nürnberg 1948).

Lit: SCHRIFTEN ZUM STAATSAUFBAU 21. 1938. - M. JAMIN: Zwischen den Klassen. 1984. - P. LONGERICH: Die braunen Bataillone. 1989.

\subsubsection{SA-Gruppenführungen}

Die SA war regional in Gruppen geglieder, deren Gebiet sich in der Regel mit staatlichen Verwaltungsbezirken (Ländern oder Regierungsbezirken) oder Gauen deckte, in Einzelfällen jedoch auch davon abwich. Im späteren Gebiet der Bundesrepublik Deutschland gab es 1940 vierzehn Gruppen, die jeweils aus mehreren Brigaden, diese wiederum aus Standarten in Regimentsstärke bestanden, deren Untergliederungen (Sturmbanne und Stürme) auf mehrere Standorte verteilt sein konnten. Von folgenden Gruppen und den ihnen zugehörigen Verbänden ist - überwiegend splitterhaftes, Personalangelegenheiten betreffendes - Schriftgut überliefert, während es aus den Gruppen Berlin-Brandenburg und Nordmark völlig fehlt:

\section{SA-Gruppe Bayerische Ostmark, Bayreuth}

Ein Mischbestand (BAM, M 31, 68 Bde, 1933-1945) enthält Sammlungen von Befehlen der Gruppe und der Brigade 80 (Passau), besteht jedoch hauptsächlich aus Akten über Organisation, Tätigkeit und Personal der Standarte 5 (Bamberg), außerdem 7 (Bayreuth), 28 (Hof) und 32 (Zwiesel). Schriftwechsel der Standarte 10 (Ingolstadt) liegt im StA München (5 Bde, 1931-1940), ein Sammelband mit Stammrollen und Listen verschiedener niederbayerischer Standarten im StA Landshut. Korrespondenz ist in Registraturgut der Regierung von Ober- und Mittelfranken nachgewiesen.

Lit.: WIDERSTAND UND VERFOLGUNG in Bayern. Bd. 2. 1975. S. 106.

\section{SA-Gruppe Franken, Nürnberg}

Die Überlieferung (WÜ, in Best. III 8.0.1) besteht lediglich in Aktenresten (1932-1940) der Brigade 79 (Würzburg) und 11 mainfränkischer Standarten (darunter eine Reiterund eine Jägerstandarte). Relativ umfangreiche Korrespondenz, auch der Sonderkommissare und -beauftragten der OSAF bei den Regierungen und Bezirksämtern, ist jedoch in Registraturgut der Regierung von Ober- und Mittelfranken und der unterfränkischen Landratsämter nachgewiesen.

Lit.: E. G. REICHE: From .spontaneous““ to legal terror. 1979.

\section{SA-Gruppe Hansa, Hamburg}

Ein Mischbestand, in dem Teilprovenienzen nicht ausgewiesen sind (HH, in Best. 614 2/5 NSDAP, 269 Bde, 1924-1940, z. T. 1943), enthält Akten der SA (auch von SAMarine-, -Reiter-, -Nachrichten- und Sanitätsformationen) in Hamburg. Dabei befinden sich OSAF-, Gruppen-, Brigade- und Standarenbefehle (1933-1940), unvollständige Handakten des Vorsitzenden des Sondergerichts der OSAF, Gruppenführer Böckenhauer (1934-1935), und Akten u. a. über Organisation, Rechtsangelegenheiten, Verhältnis zu Wehrverbänden, Beschaffungswesen, Disziplinarverfahren, Fürsorgemaßnahmen, Auszeichnungen, Ausbildung, Sport. Wehrertüchtigung, weltanschauliche Schulung, 
Kundgebungen und Aufmärsche, Kampf gegen politische Gegner. Ein weiterer Teilbestand (72 Bde) mit Befehlen, Dienstplänen, Organisations-, Ausbildungs- und Personalunterlagen befindet sich noch im BA (in Best. NS 23).

\section{SA-Gruppe Hessen, Frankfurt}

Der Hauptbestand (WI, in Abt. 483, 190 Bde, 1931-1941) enthält das „Nachrichtenblatt" (1941-1942, März 1944), Befehle und Rundschreiben der OSAF und der Gruppe (25 Bde, 1933-1940), Stärkemeldungen, Schulungsmaterial, Stammrollen und vor allem Personal- und Besoldungsakten und Schriftwechsel in Personalangelegenheiten mit Einzelfällen von Ausschlüssen (25 Bde, 1932-1945, u. a. wegen Ausschreitungen, konfessioneller Bindungen), Beurteilungen, Verleihung von Kriegsverdienstkreuzen, Bewerbungen für Neubauernstellen im Osten, auBerdem Akten der Brigaden 46 (Fulda, 7 Bde betr. Entlassungen, 1934-1936), 49 (Frankfurt, 37 Bde. 1933-1943, Befehle, Personalakten, Stärkemeldungen) und 146 (Melsungen, 3 Bde, 1934-1935). In einem Teilbestand (MR, Best. 327/1, 5 Bde) befinden sich Rundschreiben und Schriftwechsel mit der Brigade 48 (Marburg), auch über Einsatz beim Volkssturm (1944-1945).

\section{SA-Gruppe Hochland, München}

Im StA München sind Rundschreiben und Schriftwechsel u. a. über Personalangelegenheiten, Ausbildung, Besichtigungen, Machtergreifung 1933 (7 Bde, 1927-1944), Personalakten von 27 Führern und Unterführern vorhanden sowie Aktenreste (insgesamt 52 Bde, 1931-1945, meist vor 1939) der Brigaden 84 (Chiemgau) und 85 (München) und ihrer Einheiten, vor allem der Jägerstandarten 3 (Traunstein) und 5 (Garching) und der Standarte 25 (Garching), Akten über Lehrgänge noch im BA (in Best. NS 23, 7 Bde). Ein Bestand im StA Augsburg stammt von der Brigade 87 bzw. 86 (Schwaben, 28 Bde) mit Befehlen über Organisation, Personal und Ausrüstung (1935-1939), Korrespondenz mit der Gruppe und einzelnen Standarten (1933-1939), Personalunterlagen (1936-1939), den SA-Sonderbeauftragten für Füssen und Krumbach (1933-1934) und Einheiten in Augsburg, Kempten, Mindelheim und Sonthofen.

Lit.: WIDERSTAND UND VERFOLGUNG in Bayern. Bd. 2. 1975. S. 95-105.

\section{SA-Gruppe Kurpfalz, Mannheim}

Der gröBte Teilbestand (89 Bde, 1933-1944) mit Lageberichten und Akten über Personalangelegenheiten und Besoldung, Ausbildung, Lehrgänge und Kriegseinsatz befindet sich noch im BA (in Best. NS 23). Vorhanden sind ferner (KA, in Best. 465 d, 13 Bde, 1934-1943) Tätigkeitsberichte (1934, 1939-1940), Tagesbefehle, Stärkemeldungen, Schriftwechsel mit Standarten, Vorgänge über Beschwerden (1934) und Personalunterlagen auch der Brigaden 53 (Schwarzwald-Nord, 38 Bde) und 153 (Heidelberg) und (insgesamt 65 Bde) Tagesbefehle, Personalunterlagen und Reste von Sachakten der Standarten 109 (Karlsruhe), 110 und 153 (Heidelberg), 111 (Rastatt), 112 (Eberbach) und 250 (Bruchsal). Weitere Befehle der Gruppe (1934-1936), die Schrift „Kurpfälzer SA“ sind mit Schriftgut der Brigade 50 (Starkenburg), u. a. Brigadebefehle (1934), Personalunterlagen (33 Bde) und einzelne Sachakten, sowie der Reiterstandarte 50 und der Standarten 115, 145, 168, 221, 222 (Friedberg, 200 Bde, OSAF-Verfügungen, Strafsachen, Dienstpläne) und 390 überliefert (DA Best. N 1, 5 Bde mit Einzelfällen von Entlassung, 1933-1943, auch WI, in Abt. 483).

Lil: REPERTORIEN des Badischen Generallandesarchivs. Best. 465 d. 1974. S. 92-100. 
SA-Gruppe Mittelrhein (bis 1941 Westmark), Koblenz

Außer Aktenresten über Einzelfälle von AusschluB aus der SA (WI, in Abt. 483, 7 Bde, 1934-1944) sind nur Gruppenbefehle (KO, Best. 662,5, 3 Bde, 1935-1936) und Personalbefehle (1941-1943, BA, in Best. NS 23) überliefert.

\section{SA-Gruppe Niederrhein, Düsseldorf}

Vorhanden sind nur (D, in Best. RW 23) Nachrichtenblatt und Personalvorgänge (2 Bde, 1934-1944) und Aktenreste (12 Bde) von den Standarten 16 (Köln), 25 (Aachen), 53 (Solingen), 136 (Köln), 160 (Bonn), 161 (Düren), J 8 (Würselen). Ersatzüberlieferung (vor allem für die Brigaden 72, 73, 74, 75 und 76) ist in Registraturgut der Regierungen Aachen und Düsseldorf und anderer Verwaltungsbehörden nachgewiesen.

Lit:: SCHRIFTGUT DER NSDAP. Teil 1. S. 139-151. Teil 2. S. 80-91.

\section{SA-Gruppe Niedersachsen, Hannover}

Die Überlieferung ( $\mathrm{H}$, in Best. Hann. $310 \mathrm{I}$ ) ist auf wenige Akten der Gruppenfühnung (5 Bde, 1938-1943, u. a. OSAF-Rundschreiben 1940, Vorgänge über Veranstaltungen und Einsatz bei Luftangriffen), der Brigaden 59 (Harz) und 61 (Hannover) sowie der Standarten 17 (Helmstedt), 79 (Hildesheim), 82 (Göttingen, zusammen 9 Bde, 19321941) beschränkt.

\section{SA-Gruppe Nordsee, Bremen}

Ein kleiner Bestand (HB, in Best. 1066, 10 Bde, 1934-1937, Ergänzung in Akten der Senatskanzlei) enthält Vorgänge über Personal, Gliederung, Aufmärsche und Einberufungen in das Hilfswerklager.

\section{SA-Gruppe Südwest, Stuttgart}

Überliefert sind nur (LB, Best. PL 505/0I, 66 Bde, z. T. Einzelblätter) Befehle der Obersten SA-Führung (1937-1939), Gruppenbefehle (1933-1939) und Mitteilungen über Personalveränderungen, Schulungsmaterial, Vorgänge über Ausrüstung, über die Sonderbevollmächtigten der SA und Verfahren vor SA-Gerichten. Weitere Akten stammen von den Brigaden 55 (Stuttgart, 20 Bde) und 56 (Schwäbisch Hall, 17 Bde) sowie den Standarten 119, 121, 123, 247 und 248 und der Reiterstandarten 55 und 155, ferner unverzeichnetes Schriftgut (KA, in Best. $465 \mathrm{c}$ ) von den badischen Brigaden 110, 153 und 169 (ab 1942 zur Gruppe Oberrhein).

\section{SA-Gruppe Westfalen, Dortmund}

In einem Mischbestand (MS, 55 Bde, 1929-1945) ist Schriftgut der Gruppenführung (8 Bde betr. Organisation und Personal, 1929, 1934-1945), der Gruppenschule Fredeburg (Ausbildungsplan, Beurteilungen 1943) und der Standarten 15 (Bottrop, 12 Bde, mit Fotoalben), 130 (Siegen), 143 (Recklinghausen, Stimmungsberichte 1943/44), 457 (Herne) und 471 (Dülmen, 28 Bde) vereinigt. Korrespondenz mit der Brigade 65 (Detmold) und ihren Einheiten ist in Akten des Reichsstatthalters und der Landesregierung von Lippe nachgewiesen. 


\subsubsection{Nationalsozialistisches Kraftfahr-Korps (NSKK)}

\subsubsection{Korpsführung}

BA, Best. NS 24

Aus der Dienststellenleitung sind Verfügungen (ca. 20 Bde, 1935-1941), persönliche Korrespondenz des Korpsführers Erwin Kraus, der 1942 dem verstorbenen Korpsführer Adolf Hühnlein folgte, auch aus seiner vorherigen Stellung als Inspekteur für technische Ausbildung und Geräte (19 Bde, 1934-1943), und Organisationsunterlagen des Chefstabsführers (4 Bde, 1937-1944) überliefert. Den Hauptteil des Bestandes bilden Korrespondenz- und einzelne Sachakten der Dienststelle des Inspekteurs für technische Ausbildung und Geräte (ca. 200 Bde, 1935-1942), u. a. mit einzelnen Ämtern der Korpsführung, Obergruppen und Gruppen und über Rennsport, Versuchsfahrten mit heimischen Treibstoffen (6 Bde, 1935-1936), Beschaffungswesen, Lehrgänge der Technischen Führerschule München (22 Bde, 1935-1939). AuBerdem sind Aktenreste des Amtes Technik (8 Bde, 1931-1935) und des Personalhauptamtes (1933-1935, einzelne Personalvorgänge im Berlin Document Center) vorhanden.

Als Ergänzung liegen das „Verordnungsblatt der Korpsführung“ (1934-1944, IfZ) und (BA, Best. NSD 42) mehrere gedruckte Serien von „Führerbefehlen“ (1934-1943). „Korpsfuhrer-Befehlen“ (19341944) und ,Korpsbefehlen“ (1934-1937) vor, ferner einzelne Nummern des „Mitteilungsblatts des NSKK“ (1939), der „Kraftfahrtechnischen Mitteilungen“ (Jg. 1 und 2, 1943-1944), der „Deutschen Kraftfahrt“ (1933-1944, im Krieg mit anderen Kraftfahrzeitschriften vereinigt) und der wöchentlichen „Kampfschrift des NSKK“ (ab 1938) „Der NSKK-Mann“. Aus der Werbe- und Lehrfilmproduktion gibt es vier Streifen (BA-Filmarchiv), darunter über einen Appell der Führerschule des motorisierten Feldjägerkorps (1933 oder 1934).

Lit.: SCHRIFTEN ZUM STAATSAUFBAU 34. 1939. - F. W. SEIDLER: Das Nationalsozialistische Kraftfahrkorps und die Organisation Todt im Zweiten Weltkrieg. 1984.

\subsubsection{Regionale Gliederungen und Einheiten des NSKK}

Im späteren Gebiet der Bundesrepublik gliederte sich das NSKK 1940 in die Motorobergruppen Nord, Mitte und Süd, die Motorgruppen Nordmark, Nordsee. Niedersachsen, Franken, Hochland, Hessen, Kurpfalz-Saar, Niederrhein, Westfalen, Westmark und Südwest und die Motorbrigade Bayerische Ostmark. Von ihnen allen wie auch von der Motorgruppe Berlin und von den Motorbrigaden und -standarten und von den 12 Motorsportschulen sind nur geringe Schriftgutreste erhalten geblieben. Sie stammen von der

Motorgruppe Hochland, München (MSt, 16 Bde, 1931-1941, dabei Rundschreiben der Korpsführung 1936-1938, Korrespondenz des Gruppenführers Erwin Kraus 1931-1934. Vierteljahresberichte 1935, auch der Motorbrigaden Kurpfalz-Saar, Südwest, Franken und Bayerische Ostmark, Akten über Erfassung von Fahrzeugen 1943, technische Prüfungen, Verkehrserziehung, Motorsportschule Bayreuth-Saas). Korrespondenz der Obergruppe Süd mit der Motorgruppe „Adolf Hühnlein“ (2 Bde, 1943) befindet sich noch im BA (in Best. NS 24).

Motorgruppe Hessen, Frankfurt (WI, in Abt. 483, nur Gruppenbefehle 1938-1942). Motorgruppe Südwest, Stuttgart (LB, Best. PL 508, nur Aktensplitter über Personalangelegenheiten und Aufgaben im Krieg, 1932-1939). 
Motorbrigade Kurpfalz-Saar, Kaiserslautern (SP, Best. T 65, 242 Bde, auch und vor allem der Motorstandarten 162, 163 und 164, 1935-1944, meist ab 1939) mit Befehlen, Rundschreiben und Berichten, Dienstplänen, Abrechnungsunterlagen und Akten über Organisation, Werbung, Personalangelegenheiten, Lehrgänge, Aufbau des NSKK in Lothringen, Verhältnis zur HJ, Ausbildung von Frauen, Ausstattung mit Fahrzeugen.

Weitere Aktenreste sind von den Motorstandarten 46 (Hanau, WI), 48 (Marburg, 16 Bde Personalangelegenheiten, 1934-1944, MR, Best. 327/1), 49 (Frankfurt, WI), 55 (Ludwigsburg, LB), 86 (München, MSt), 87 (Augsburg, A), 155 (Heilbronn, LB), 62 (Bremen, 27 Bde, HB), 148 (Wiesbaden, WI), 152 (Trier, 5 Bde, BA, in Best. NS 24), 181 (Bayerischer Wald, LA) und 187 (Kempten, A) in die Archive gelangt. Im Registraturgut theinischer, lippischer und fränkischer Verwaltungsbehörden konnte Schriftwechsel mit NSKK-Dienststellen nur in geringem Umfang nachgewiesen werden.

Lit.: SCHRIFTGUT der NSDAP. Teil 1, S. 152; Teil 2, S. 92-94; Teil 4, S. 262-263.

\subsubsection{Nationalsozialistisches Fliegerkorps (NSFK)}

Schriftgut der NSFK-Korpsfühnung unter den Luftwaffengeneralen Friedrich Christiansen (bis 1943) und Alfred Keller und der für das spätere Gebiet der Bundesrepublik zuständigen neun NSFK-Gruppen ist bis auf eine unbekannte Anzahl von Personalvorgängen im Berlin Document Center fast nicht überliefert. Gedruckt liegen Stellenpläne und Stärkenachweisungen für die Rechnungsjahre 1938 bis 1941, die Beförderungsordnung, einzelne Vorschriften und Dienstanweisungen, das Bildwerk „Wir fliegen in Wind und Wolken“ (1942), das „NSFK-Verordnungsblatt“ (1937-1944) und Nummern der Zeitschrift „Das NS-Fliegerkorps. Ausgabe B der Luftwelt" (1939-1944, alles im BA, Best. NSD 44) vor, dazu kommen (im IfZ) eine Schrift zum einjährigen Bestehen 1938, ein Anschriftenverzeichnis 1940 und Heft 1 einer "Luftfahrtkunde“ von 1943.

$\mathrm{Zu}$ ermitteln waren sonst lediglich Aktenreste der Gruppe 15 (WürttembergHohenzollern) mit Nachrichtenblatt und Organisations-, Ausbildungs-, Personal- und Veranstaltungsunterlagen (LB, Best. PL 507, 20 Bde, 1937-1944) und der unterstellten Standarten 102 (Heilbronn) und 103 (Kirchheim) und aus dem Bereich der späteren Gruppe 16 (StraBburg) vom 6. Sturm (Karlsruhe) der Standarte 80 (KA, in Best. 465c, 80 Bde mit Personalunterlagen, auch Flugdienstmeldungen) und vom 1. Sturm (Rastatt) der Standarte 82 (FR, in Best. NSDAP, 36 Bde, 1939-1944) mit Gruppenbefehlen (7 Nummern ihres Verordnungsblatts 1942 BA, in NSD 42) und Unterlagen über Wettbewerbe, Lehrgänge, Modellfluggruppen an Schulen, ferner von drei Stürmen der Augsburger Standarte 96 (A, 3 Bde betr. Ausbildung und Spenden, 1938-1944).

Der Werbung und Ausbildung dienten sechs von und für das NSFK hergestellte Filme, z. B. „Flieger über Deutschland“ und „Sturmdienst am Gerät“ (1938-1942, BAFilmarchiv).

Lit.: SCHRIFTEN ZUM STAATSAUFBAU 24. 1938.

\subsubsection{Hitlerjugend (HJ)}

\subsubsection{Reichsjugendführung}


und Bund Deutscher Mädel (BDM) mit Jungmädelbund (JM) und BDM-Werk „Glaube und Schönheit" ist fast völlig verloren. Nur einzelne Bände sind in Potsdam überliefert (27 Bde, 1933-1944). Sie enthalten allgemeine Vorgänge (2 Bde, 1933-1939), den Geschäftsverteilungsplan von 1939, Akten des HJ-Obergerichts (1 Bd, 1938-1940), des Personalamtes mit einem Bericht über die bündische Jugend (nach 1934), des Kulturamtes über Kultur- und Theaterpolitik (2 Bde, 1937-1939) und Rundfunkfragen (1 Bd, 1936-1937), des Rundfunkamtes über die Gestaltung von Rundfunksendungen vor allem für die weibliche Jugend und die Rundfunkarbeit in den Gauen (4 Bde, 1936-1939) und des Auslands- und Volkstumsamtes u. a. über Verbindung zu einzelnen Landesjugendführungen, die Kulturkundgebung der europäischen Jugend Weimar-Florenz 1942, den Europäischen Jugendverband, Wehrertüchtigungslager und über den Besuch des rumänischen Staatsjugendführers General Iliescu (16 Bde, 1940-1944).

Der Koblenzer Bestand vereinigt nur wenige Geheimrundschreiben (5 Bde, 19391940) und Fragmente von Personalvorgängen mit Akten der Befehlsstelle Ostland für die besetzten baltischen Länder (29 Bde, 1943-1944). Die Überlieferung im Berlin Document Center beschränkt sich auf eine Kartei über ca. 2800 aus der $\mathrm{HJ}$ ausgeschlossene Mitglieder mit Angaben über Wohnort, Konfession, Beruf, Datum und Grund des Ausschlusses (z. B. dauernde Disziplinlosigkeit, homosexuelles Verhalten).

Unter den vom Hauptarchiv der NSDAP (Best. NS 26) gesammelten Unterlagen befinden sich Reden des Reichsjugendführers (bis 1940) Baldur von Schirach, Unterlagen aus dem Presse- und Propagandaamt (1934-1944) und ein Bericht der Gebietsführung Saarpfalz über Verwahrlosungserscheinungen (1935). Weitere Ersatzüberlieferung liegt in Dokumenten des Verfahrens gegen Schirach als Hauptkriegsverbrecher in Nürnberg und in einer Materialsammlung der ehemaligen BDM-Reichsreferentin Jutta Rüdiger (BA, Best. NS 20/138, zum Thema Kriegsbetreuungsdienst auch IfZ, ZS 1609) vor. Über ,Musik und Musikerziehung in der HJ 1933-1945“ gibt es eine Dokumentation im BA (Kl. Erw. 872, 24 Bde). Material über die Überführung der im Bund Großdeutscher Jugend vereinigten bündischen Jugendgruppen in die HJ 1933 enthält der NachlaB seines Bundesführers und Ehrenführers der Marine-HJ Admiral von Trotha (SHG, Dep. 18).

Eine wesentliche Ergänzung bieten die Publikationen der $\mathrm{HJ}$, die z. T. in parallelen Ausgaben für die einzelnen Gliederungen mit alters- und geschlechtsbedingten Unterschieden vorliegen (BA, Best. NSD 43 und IfZ). Dazu gehören: „Verordnungsblatt der Reichsjugendführung der NSDAP“, ab 1937 „Amtliches Nachrichtenblatt des Jugendführers des Deutschen Reiches und des Reichsjugendführers der NSDAP“ (19331944); „Das Junge Deutschland. Amtliches Mitteilungsblatt (ab 1936: Organ) des Jugendführers des Deutschen Reiches. Sozialpolitische Zeitschrift der deutschen Jugend“ (ab 1933); „Die HJ. Das Kampfblatt der Hitler-Jugend“ (1935-März 1939), fortgesetzt als „Junge Welt. Die Reichszeitschrift der Hitler-Jugend“ (1939-1943); „Wille und Macht. Führer-Organ der nationalsozialistischen Jugend“ (1933-1944); „Reichsbefehl. Befehle und Mitteilungen für die Führer und Führerinnen der Hitler-Jugend“" (1936-1945); ,Rundschreiben der NSDAP/Reichsjugendführung“ (1940-1944); „ReichsJugend-Pressedienst. Amtlicher Pressedienst des Jugendführers des Deutschen Reiches“ (1934-1939); ,Zucht und Ehre. Mitteilungs- und Schulungsblatt für die Dienststrafvor-

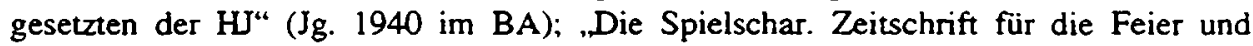
Freizeitgestaltung“ (1936-1943); „Das Deutsche Mädel. Die Zeitschrift des BDM in der HJ“ (1935-1943) und die Jungvolk-Zeitschrift „Der Pimpf“; „Blätter für Heimatabendgestaltung" (1935-1939) in den Ausgaben „Die Jungenschaft“, „Die Kameradschafi“, „Die 
Jungmädelschaft“. „Die Mädelschaft". Dazu kommen das „Jungvolk-Jahrbuch“ (19361937) und zwischen 1937 und 1944 weitere, nicht sämtlich überlieferte Jahrbücher (.Jungen - eure Welt", "Mädel - eure Welt“, „Wir schaffen"), ein „Schulungsdienst der Hitler-Jugend“ (1939-1943), „Material für die Kulturarbeit im Kriege“ (IfZ), Dienst- und Ausbildungshandbücher (,HJ im Dienst“, „Pimpf im Dienst") und -vorschriften (u. a. über Schießdienst), „Heereshefte“ (1944, BA) und eine Fülle von Einzelschriften über Heime, Landdienst, Streifendienst, Sport und Spiele, den „Adolf-Hitler-Marsch“ zum Reichsparteitag, Zeltlager, Luftschutz. Speziell für die KLV bestimmt waren "Mitteilungsblätter" (1940-1943) und „Rundschreiben“ (1940-1945, BA) der Dienststelle Kinderlandverschickung sowie „Unser Lager. Richtblätter für die Dienstgestaltung“ (19411945, IfZ), an Gehörlose und Blinde wandten sich "Die Quelle" bzw. "Der Weckruf".

Von den Propagandafilmen, die für die Reichsjugendführung hergestellt wurden oder für die $\mathrm{HJ}$ werben sollten, sind sieben Folgen der ,HJ-Monatsschau“ "Junges Europa“ (Juni 1942-Mai 1944) und 24 einzelne Filme u. a. über Lager und Heime, den Landdienst, die „Hochland“-HJ in den Alpen, KLV und vormilitärische Ausbildung überliefer (BA-Filmarchiv, 1933-1944). SchlieBlich gibt es noch 50 Plakate der Reichsjugendführung und von $\mathrm{HJ}$ und BDM (BA).

LiL: SCHRIFTEN ZUM STAATSAUFBAU 16, 22/23. 1937, 1938. - JUGEND im NS-Staat. 1979. - B. v. SCHIRACH: Ich glaubte an Hitler. 1967. - G. GRIESMAYR. O. WÜRSCHINGER: Idee und Gestalt der Hitlerjugend. 1980. - J.RÜDIGER: Die Hitlerjugend und ihr Selbstverständnis. 1983. - Dies.: Der Bund Deutscher Mädel. 1984. - M. KLAUS: Mädchen im Dritten Reich. 1983. - M. v. HELLFELD. A. KLÖNNE: Die betrogene Generation. 1985. - M. H. KATER: Hitlerjugend und Schule im Dritten Reich. 1979. - M. BUDDRUS: Zur Geschichte der Hitlerjugend (1922-1939). 1989. - J. v. LANG: Der Hitler-Junge. 1988. - J. SCHULTZ: Die Akademie für Jugendführung der $\mathrm{HJ}$ in Braunschweig. 1978.

\subsubsection{HJ-Gebietsführungen}

Jeweils einem oder zwei NSDAP-Gauen in der späteren Bundesrepublik entsprach ein Gebiet der HJ, dessen Führer auch den Befehl über die Untergliederungen führte, wobei jedoch der BDM-Bereich als Obergau bezeichnet wurde. Vom Schriftgut der Gebietsführungen wie auch von ihren Publikationen (z. B. "Nordmarkjugend" für Nordmark, „Unsere Fahne“ für Westfalen, „Niederrheinische Fanfare“ für Ruhr-Niederrhein und „Reichssturmfahne" für Württemberg) ist ebenfalls wenig erhalten. Es fehlt völlig von den Gebieten Berlin (bis auf einzelne Nummern des „Führerinnendienstes“ ab 1939 im IfZ), Bayerische Ostmark, Franken, Hamburg, Hochland (nur Gebietsbefehle 1938 im IfZ, jedoch "Erinnerungen“ des Obergebietsführers Emil Klein von 1985 im BA, Kl. Erw. 832), Nordmark, Nordsee, Moselland und Ruhr-Niederrhein. Der Rest verteilt sich auf folgende Bestände, die auch Aktenreste zugehöriger Einheiten enthalten:

Gebietsführung Baden (21), Karlsruhe

Lediglich in den Sammlungen des Gauarchivs sind Obergaubefehle (1939-1944), der "Führerinnendienst" (1942-1943) und Bannbefehle des Banns 172 (Pforzheim, 1939) überliefert (KA, in Best. $465 \mathrm{~d}$ ).

\section{Gebietsführung Düsseldorf (34)}

Überliefert ist ein einziger Band über MaBnahmen bei Kriegsausbruch (D, in Best. RW 23), und auch in Registraturgut staatlicher Behörden wurde Korrespondenz (auch mit dem Gebiet Ruhr-Niederrhein) nur in geringem Umfang ermittelt. 


\section{Gebietsführung Hessen-Nassau (13), Wiesbaden}

Die Aktenreste betreffen das Landjahr (1935-1939), Uniformbeschaffung, Haushalt und Besoldung (5 Bde, 1938-1943) und enthalten BDM-Stammrollen (WI, in Abt. 483, einzelne Nummern des „Führerinnendienstes“ im IfZ). Weitere Akten stammen von den Bannen 81 (Frankfurt, 9 Bde, 1936-1943), 253 (Limburg), 303 (Herborn) und 392 (Gelnhausen, alle WI) und 116 (GieBen) und 287 (Offenbach, beide DA).

\section{Gebietsführung Köln-Aachen (11), Köln}

Die Bestände (D, in Best. RW 23, insgesamt 23 Bde, 1941-1943) enthalten Berichte und Unterlagen über Beziehungen zu anderen Organisationen, Dichterlesungen und andere kulturelle Veranstaitungen (6 Bde), Spielscharen (2 Bde), Marine-HJ, vom BDMObergau Akten betr. kulturelle Veranstaltungen (6 Bde, 1936-1943) sowie Aktenreste der Banne 160 (Bonn, 3 Bde) und 161 (Düren) und Befehle des Jungbanns 161 (19351937). Korrespondenz ist in Akten der Regierung Aachen nachgewiesen.

Lit.: SCHRIFTGUT der NSDAP. Teil 2. 1981. S. 99-114.

\section{Gebietsführung Kurhessen (14), Kassel}

Gebietsbefehle (1941/42) sind in Akten des Banns 304 (Alsfeld-Lauterbach) enthalten (DA), Personalbögen von Führern und Führerinnen vom Bann 762 (Ziegenhain) vorhanden (WI, in Abt. 483).

\section{Gebietsführung Mainfranken (39), Würzburg}

AuBer einem Band aus der Gebietsführung (1942-1944) sind Aktenreste der Bannführungen für Würzburg-Stadt und -Land, Aschaffenburg, Schweinfurt, Neustadt/Saale, Karlstadt-Marktheidenfeld, Kitzingen-Gerolzhofen, Haßfur, Lohr und Bad Kissingen erhalten (WÜ, in Best. III 8.0.1). Korrespondenz mit der Gebietsführung (auch des Gebiets Franken, zu dem Mainfranken bis 1940 gehörte) ist in Registraturgut der Regienung von Mittel- und Oberfranken und der unterfränkischen Landratsämter nachgewiesen.

\section{Gebietsführung Niedersachsen (8), Hannover}

Die Überlieferung $(\mathrm{H})$ ist auf Drucksachen betr. Landdienst, Elternabende, Führerthing (1935-1944) und Korrespondenz des Gebietsführers Lauterbacher (1930) beschränkt.

Gebietsführung Saar-Pfalz (25), später Westmark, Neustadt/W.

Die Überlieferung (4 Bde, SB) besteht aus einzelnen Drucksachen (1934 und 1936) und einer Befehlssammlung (1944) sowie (KO Best. 662,5) Vorgängen über BDMKriegseinsatz im Obergau (1938-1941), Schulungsdienst 1944, Musikerziehung 1941, Einziehung von Geheimakten der Banne (1941).

\section{Gebietsführung Schwaben (36), Augsburg}

Der einzige relativ umfangreiche Bestand (197 Bde, meist 1939-1945, A) enthält Rundschreiben und Runderlasse (23 Bde, 1939-1944, in chronologischen und Betreffserien, z. B. KLV, Einsatz nach Luftangriffen), Akten über den $\mathrm{HJ}-S t r e i f e n d i e n s t$ im allgemeinen und einzelnen Bannen (39 Bde, 1939-1944), über Wehrertüchtigung (auch einzelne WE-Lager) und Werbung von Freiwilligen für die Wehrmacht (65 Bde, meist ab 1943), Luftwaffenhelfer (9 Bde), Nachrichten-, Motor- und Flieger-HJ (22 Bde), bergsteigerische Ausbildung (6 Bde, 1943), ferner über Heime, Sport, KLV und Personalangelegenheiten. Die Obergauführung ist mit Runderlassen (16 Bde) und Akten über Sport (4 
Bde), Jungmädelbund (3 Bde) und Personalvorgängen sowie (IfZ) 8 Heften des „Führerinnendienstes“ vertreten. Ergänzende Unterlagen im insgesamt etwa demselben Umfang sind von den Bann- (z. T. auch Untergau-)führungen Allgäu, Augsburg-Stadt und -Land, Donauwörth, Günzburg, Memmingen, Neuburg, Nördlingen und Wertach vorhanden.

\section{Gebietsführung Westfalen (9), Münster}

Nur Gebietsbefehle (1935-1938) und vom Führerinnendienst einzelne Nummern (IfZ), ein Führerverzeichnis (1939) und Akten des Jungbanns 138 (Siegen, 6 Bde betr. Organisation 1941-1945) sind vorhanden (MS). Korrespondenz ist in Akten des Reichsstatthalters und der Landesregierung Lippe nachgewiesen.

Lit.: SCHRIFTGUT der NSDAP. Teil 4. 1983. S. 265-286.

Gebietsführung Württemberg (20), Stuttgart

Die Akten (LB, Best. PL 509 und 510) der Gebiets- (19 Bde, 1934-1944) und der Obergauführung (7 Bde, 1936-1940) betreffen Organisation (5 Bde, 1937-1942, mit Rundschreiben, ca. 60 weitere Gebietsbefehle und -rundschreiben, 1933-1938, IfZ), Personalund Besoldungsangelegenheiten (11 Bde HJ, 7 Bde BDM), Gesundheitswesen (3 Bde, 1937-1944). AuBerdem sind die Akten über die Lehrgänge der Gebietsführerschule „Wilhelm Neth" auf der Solitude (35 Bde, 1935-1937) und Aktenreste der Bannfuhrungen 119 (mit Untergauführung), 122 und 364 (mit Untergauführung) und Papiere des Oberbannführers Oskar Riegraf (Best. PL 704) vorhanden.

\subsubsection{NS-Frauenschaft und Deutsches Frauenwerk}

\subsubsection{Reichsfrauenführung/Reichsgeschäftsstelle}

BA, Best. NS 44 ZStA, Best. 62 Re 1

Die Dienststelle der Reichsfrauenführerin Gertrud Scholtz-Klink war sowohl für die Parteigliederung NS-Frauenschaft als auch für das Deutsche Frauenwerk zuständig, das unter Führung der Mitglieder der Frauenschaft alle Frauen erfassen sollte. Aus ihrer Tätigkeit sind im Koblenzer Bestand nur eine sehr unvollständige Sammlung von Anordnungen und Rundschreiben verschiedener Abteilungen (15 Bde, 1934-1942) und vermischte Aktenreste (8 Bde, 1925-1945, dabei Jahresberichte 1938-1939, Rundschreiben der Auslandsdeutschen Frauenschaft 1937-1940, Unterlagen über Kinder- und Jugendgruppen) vorhanden. Den Hauptteil des Bestandes bilden Beurteilungsbögen mit Lebensläufen von ca. 900 Kreisfrauenschaftsleiterinnen (31 Bde, 1934-1938), die an Kursen der Reichsschule I der NS-Frauenschaft in Coburg teilgenommen haben.

In Potsdam sind Reste von Schriftwechsel, Berichte und allgemeine Unterlagen überliefert (9 Bde, 1934-1944), Berichte über verschiedene Gaue und Kreise (1931-1936 im Hauptarchiv der NSDAP (BA, Best. NS 26)), ferner Berichte der Leiterin über die Aufgaben der Abteilung Volkswirtschaft/Hauswirtschaft im Deutschen Frauenwerk (BA, Kl. Erw. 771, und IfZ, Ms. 335). Die Sammlung von Anträgen auf Mitgliedschaft in der NSDAP im Berlin Document Center umfaBt auch an die Reichsgeschäftsstelle gerichtete Anträge für die Frauenschaft.

Von beiden Organisationen gingen zahlreiche Publikationen aus: „NS-Frauenwarte. Zeitschrift der NS-Frauenschaft“ (1932-1945), „Frauenkultur. Zeitschrift des Deutschen Frauenwerks“. - „Nachrichtendienst der Reichsfrauenführung“ (1932-1944, ab 1939 der Reichsfrauenführerin). - „Nationalsozialistische Frauenkorrespondenz“ (ab 1932). 
- Jahrbücher (1936-1941) ..Deutsches Frauenschaffen“ bzw. „Deutsches Frauenschaffen im Kriege“ und andere Jahresberichte. - „Die Heimleiterin. Schulungshefte für den Dienstgebrauch der Führerinnen der Wehrmacht und die Heimleiterinnen der Frauenwohnheime" (1944). - Schriftenreihen „Von An und Brauch" und "Jugend und Elternhaus. Beiträge zur Jugenderziehung in unserer Zeit“ (1944). - „Arbeitsblätter für die Jugendgruppen" (nur 1 Heft von 1943 im IfZ). Von den von ihnen oder für sie produzierten Filmen sind sechs vorhanden, darunter über Mütterdienst, Jugendgruppen, "Altstoff - Rohstoff" und "Frauen danken der Front" (BA-Filmarchiv).

Lit.: SCHRIFTEN ZUM STAATSAUFBAU 15. 1937. - G. SCHOLTZ-KLINK: Die Frau im Dritten Reich. 1978. - S. DAMMER: Kinder, Küche, Kriegsarbeit 1981. - J. STEPHENSON: ., VerantwortungsbewuBisein“. 1980.

\subsubsection{Gaufrauenschaftsleitungen}

Vom Schriftgut der bei jeder Gauleitung eingerichteten Dienststellen der Gaufrauenschaftsleiterinnen wie auch von ihren Untergliederungen ist nur wenig in die Archive gelangt. Es handelt sich dabei um Vorschriften für die Frauenschaft in Baden (1940. 1942, KA, in Best. 465 d), eine Stellenkartei des Kreises Hersfeld von Kurhessen (1934-1943, MR, Best. 327/1), einige Akten der Gaufrauenschaftsleitung Mainfranken (9 Bde, 1936-1945, mit Berichten über Tätigkeit im Krieg, Vorgängen über Ausschließungsverfahren. rassenpolitische Erziehung, Kindergruppen, ergänzt durch Aktenreste von 12 Kreisfrauenschaftsleitungen, WÜ, in Best. III 8.0.1), ebenso der Gaufrauenschaftsleitung Württemberg-Hohenzollern (LB, Best. PL 511, zusammen mit Akten der Kreisfrauenschaftsleitungen Stuttgart und Ludwigsburg, u. a. betr. Schulungsangelegenheiten, 1938-1944) und um Aktenreste der Gaufrauenschaftsleitung Schwaben und der Frauenschaftsleitungen der Kreise Augsburg, Donauwörth, Kempten, Krumbach, Marktoberdorf, Memmingen, Neuburg, Neu-Ulm. Nördlingen und Sonthofen (A), vor allem aber um den umfangreichen Bestand

Gaufrauenschaftsleitung Westfalen-Nord, Münster MS Er enthält allgemeine Rundschreiben (22 Bde, 1932-1939), Monatsstatistiken der Ortsgruppen (39 Bde, 1933-1935) und Akten aus folgenden Sachgebieten:

Organisation und Dienstbetrieb (43 Bde, 1930-1940) - Personalangelegenheiten (ca. 30 Bde, 1934-1936) - Zusammenarbeit mit der NSV (ca. 40 Bde, 1933-1935) - Betreuung sudetendeutscher Füchtlinge (1938) - Kinder- und Müttererholung (6 Bde, 1933 1934) - Angelegenheiten der NS-Schwesternschaft (1934-1935), des Frauenarbeitsdienstes (1935-1936), des Vaterländischen Frauenvereins und anderer Frauenorganisationen (25 Bde, 1933-1937), der Kinder- (,Kinderschar") und Jugendgruppen (8 Bde, 19341940) und der Abteilung Volkswirtschaft, Hauswirtschaft des Deutschen Frauenwerks (14 Bde, 1933-1936) - Soziale Betriebsarbeit (2 Bde, 1933-1934) - Ernährungswesen (3 Bde, 1933-1936) - Grenz- und Auslandstätigkeit (6 Bde, 1935) - Kulturarbeit (ca. 170 Bde, 1933-1935) - Schulung und Schulungskurse (18 Bde, 1933-1938) - Tagungen und Propaganda (25 Bde, 1933-1939).

Ergänzungsüberlieferung bieten die Akten der Gaufrauenschaftsschule Haus Botzlar in Selm-Beifang (MS, 84 Bde betr. Dienststellenverwaltung und Lehrgänge, 19341939) und der Kreiswaltung Herford (DT, in Best. M 15, 68 Bde, 1938-1945, mit Gaurundschreiben 1942, Monatsberichten) sowie der Frauenschule "Haus der Frau" in Bad Oeynhausen (ebda). 


\subsubsection{NS-Studentenbund (NSDStB)}

\subsubsection{Reichsstudentenführung}

BA, Best. NS 38

WÜ, Best. III 8.0.3

Eine Unterscheidung zwischen Schriftgut der Reichsstudentenführung, der Zentraldienststelle der als betreute Organisation gleichgeschalteten Deutschen Studentenschaft (DSt, Akten bis 1933 mit einzelnen Nachakten im BA, Best. R 129), der alle Studenten über die Studentenschaften ihrer Hochschulen angehörten, und des NSDStB (mit dem NS-Altherrenbund fur die ehemaligen Mitglieder auch studentischer Korporationen) als Parteigliederung ist schwer möglich, da nicht nur die Spitze mit dem Reichsstudentenfuihrer Gustav Adolf Scheel, sondern auch fast alle Ämter seit 1936 in Personalund Realunion besetzt waren. Die dort gefühten Akten gelangten zum gröBten Teil über das 1939 dort eröffnete Institut für deutsche Studentengeschichte nach Würzburg (früher Universitätsbibliothek, jetzt StA WÜ), zum kleineren über das amerikanische Nationalarchiv und die Library of Congress nach Koblenz.

Der Bestand im BA enthält vor allem Korrespondenzakten, vielfach in Form von Tageskopien. Sie stammen bei der Reichsstudentenführung vom Adjutanten (3 Bde, 1933-1936), dem Stabsamt (1938-1939), dem Sekretariat (3 Bde, 1937), dem Beauftragten für die Fachschulen (4 Bde, 1935-1936), den Ämtern Politische Erziehung (1937-1938), Wissenschaft und Facherziehung (4 Bde, 1936-1942, dabei Reichsreferent Kirchliche Fragen, 1936-1938, ein weiterer Bd. betr. Bildungsangelegenheiten, 1933-1938, ZStA, Best. 62 Re 11), Presse und Propaganda (9 Bde, 1936-1939) und dem Wirtschafts- und Sozialamt (2 Bde, 1938).

Der NSDStB ist durch den Stabsleiter (4 Bde, 1933-1936), die Organisationsabteilung (2 Bde, 1934-1936), die Ämter Kameradschaftserziehung (1934) und für Studentenkampfhilfe (2 Bde, 1936), den Referenten für Hochschulpolitik (3 Bde, 19311933) und die Beauftragten für Verbändefragen (1933, dazu Gegenüberlieferung in Akten der Gemeinschaft Studentischer Verbände, BA, Best. R 128) und für Disziplinarund Ehrensachen (1934-1936) vertreten.

Hinzu kommen Befehle des Stabsamtes der Reichsstudentenführung (1938), an diese gerichtete Arbeitsberichte der Bereichsführer (1937-1938) und dort erstellte einzelne Gutachten über Hochschullehrer (A-M. 1936-1942), vom NSDStB Rundschreiben (3 Bde, 1933-1936), Schulungsmaterial (4 Bde, 1933-1935) und vor allem Personalakten von 344 Teilnehmem am Langemarck-Studium ohne Reifeprüfung (1938-1942) und über dafür in Heidelberg durchgeführte Lehrgänge ( 5 Bde), schlieBlich noch eine Materialsammlung zur Geschichte der nationalsozialistischen Studenten (2 Bde, 1929-1939). Akten des Japanreferats des Außenamtes der Reichsstudentenführung (1939-1942) sind bei der Deutsch-japanischen Gesellschaft überliefert (BA, Best. R 64 IV). Die Akten des Reichsstudentenwerks (Best. R 149) enthalten einige Nachakten über die soziale Betreuung von Studenten, vor allem durch Verpflegung in einer Mensa und Wohnheime, über Maßnahmen für arbeitslose Jungakademiker und Studium im Ausland (ca. 40 Bde, 1932-1937, mit Rundschreiben und Berichten aus einzelnen Hochschulen).

Auch die früher in der Library of Congress aufbewahrten Akten bestehen hauptsächlich aus Korrespondenz (mit privatem Schriftwechsel). Sie wurde vom Vertreter Scheels und Leiter des Amtes für Wissenschaft und Facherziehung Dr. Fritz Kubach (1934-1943, dabei auch Tagebücher, Redemanuskripte) und von Dr. Erich Otto, Reichsfachgruppenleiter Volksgesundheit (1934-1940, u. a. über Rassenkunde, Finanzangelegenheiten, 
Medizinerausbildung, mit Berichten) geführt. Rundschreiben und „Kriegsbriefe“ (19391944) sowie Berichte über die Entstehung des NSDStB sind auch im Hauptarchiv der NSDAP (NS 26) gesammelt.

In Würzburg befinden sich in einem Teilbestand DSt und Reichsstudentenführung Sachakten und Korrespondenzserien, Rundschreiben, Reden, Vorgänge über einzelne Hochschullehrer; sie beginnen vor 1933, entstanden meist zwischen 1933 und 1937 und reichen bis 1939. Sie stammen von Hauptämtern, Ämtern und anderen Organisationseinheiten für Wissenschaft, Fachschulen, Presse und Propaganda, Auslandsbeziehungen (mit Grenzlandamt und Ostmarkenamt), Leibesübungen, politische Erziehung, Förderung und Wirtschaftsfragen (mit Reichsstudentenwerk), Arbeitsdienst, Landdienst und Studentinnen. Sie betreffen vor allem die Gleichschaltung der Korporationen, den Aufbau der Kameradschaftserziehung, die studentische Arbeitsdienstpflicht, die Gleichschaltung der Universitäten und Auseinandersetzungen zwischen Deutscher Studentenschaft und NSDStB bis zur Vereinigung unter der Reichsstudentenführung.

Der Teilbestand NSDStB umfaßt eine Sammlung zur Geschichte des Bundes vor und nach 1933 (47 Bde, z. T. nach Orten, 1926-1939) und Schriftgut folgender Organisationseinheiten:

Stabsamt (78 Bde, 1925-1941, dabei Rundschreiben, Tätigkeits- und Lageberichte); Führungsamt (40 Bde, 1930-1939, dabei Korrespondenz Scheels 1937-1939, Vorgänge in Personalsachen); Amt für Wissenschaft und Facherziehung (51 Bde, 1932-1939, mit Sachgebieten Allgemeines und Schulung. Naturwissenschaft, Rechtswissenschaften, Brauerei, Landwirtschaft, Forstwissenschaft); Amt für Presse und Propaganda (41 Bde, 1933-1939); Kulturamt (19 Bde, 1925-1939, vor allem betr. Studententage, Langemarckfeiern, auch kirchliche Angelegenheiten); Wirtschafts- und Sozialamt (13 Bde, meist in Haushaltsangelegenheiten, 1933-1939); Amt für politische Erziehung (164 Bde, 1931-1939, mit Sachgebieten Kameradschaftserziehung, Landdienst, Reichsleistungskampf, Tagungen, Reichsführerschule, vor allem über einzelne Lager); Außenamt (6 Bde, 1933-1939, vor allem betr. auslandsdeutsche Studenten); Sportamt (4 Bde, 1934-1938); Amt Recht und Gericht (3 Bde, auch mit Disziplinarvorgängen); Studentenwerk (9 Bde, 1933-1937); Amt Studentinnen (51 Bde, 1930-1940, vor allem Tätigkeitsberichte von Gruppen der ANST, Arbeitsgemeinschaft nationalsozialistischer Studentinnen); Amt für Arbeits- und Ausgleichsdienst (19 Bde, 1933-1938). Schließlich gehören hierzu noch einige Akten über die Beziehungen zu anderen studentischen Verbänden (9 Bde, 1923-1939) und eine Sammlung von "Feldpostbriefen“ einzelner Hoch- und Fachschulen an Studenten im Wehrdienst.

Ein dritter Teilbestand enthält die Überlieferung über den Reichsleistungskampf der Studenten beim Reichsberufswettkampf (1935-1941, überwiegend bis 1939). Er umfaßt Akten über die Durchführung im allgemeinen und zu den einzelnen Jahren (Vorbereitung. Themenstellung, Auswertung) und 724 eingereichte Arbeiten u. a. aus den Themengruppen: Volkstumsforschung, Auslandskunde, Musik und Feiergestaltung, Raum und Siedlung, Deutsche Naturerkenntnis, Deutsches Rechtsleben, Deutsche Wirtschaftsgestaltung, Bauerntum und Ernährungsfreiheit, Deutsche Energieversorgung, Deutsches Frauenschaffen.

Sehr umfangreich war die publizistische Tätigkeit (BA, Bestände NSD 32 und 454, und IfZ). Regelmäßig erschienen: „Die Bewegung. Zentralorgan des NSDStB“, ab 1940: ,Zeitung des deutschen Studententums, Organ der Reichsstudentenführung“" (seit 1931). - „Der Deutsche Student. Zeitschrift der Deutschen Studentenschaft“ (1933-1939), - 
„Deutsche Studentenzeitung. Kampfblatt der deutschen Studenten“ (1933-1935). - .Verordnungsblatt des NSDStB“ (ab Dezember 1936 „des Reichsstudentenführers“, 19361944). - „Sieg der Idee. Führerorgan der Studenten GroBdeutschlands“ (bis 1944). „Geist der Zeit. Wesen und Gestalt der Völker" (1937-1944, vorher „Hochschule und Ausland. Monatsschrift für Kulturpolitik"), das Organ des Deutschen Akademischen Austauschdienstes. - „Die Studentische Kameradschaft“ (1937-1938). - „Der Kameradschaftsführer. Führungsblatt für die Kameradschaften“ (1944). - „Die Fachgruppe. Organ des Amtes Wissenschaft und Facherziehung der Reichsstudentenführung“ (1940-1942). - „Mitteilungen und Bekanntgaben des Soldatendienstes des Reichsstudentenführers“ (1944). - „Die ANST-Gruppe“ (1938-1939). - „Die musische Erziehung. Richtlinien und Mitteilungen des Kulturamtes“ (1939-1940). - „Der Altherrenbund. Amtliches Organ des NS-Altherrenbundes" (1938-1943) und "Nachrichtenblatt für die Amtsträger des NS-Altherrenbundes“. - „Nationalsozialistische Studentenkorrespondenz" (NSStK, 1931-1933) und „Studenten-Pressedienst“ (StPD, ab 1937). - „Kultur und Wissenschaft im Ausland" (1941-1942, NfD).

Neben Einzelschriften wie Dienstanweisungen, Studienführem, Tätigkeits- und Tagungsberichten, der Disziplinar- und Ehrenordnung und berufskundlichen Publikationen gab es als Reihen die „Junge Wissenschaft" (5 Bde bis 1939), die „Kriegsschriften der Reichsstudentenführung“ (7 Hefte bis 1941), die „Auslandskunde für die Kameradschaften“ mit 96 Heften und die „Beiträge zur auslandskundlichen und außenpolitischen Schulung der Kameradschaften des NSDStB“" (6 Hefte, 1940-1942).

Lit: H. W. STRÄTZ: Archiv der ehemaligen Reichsstudentenführung in Würzburg. 1967. - GUIDES to German Records. vol. 20. S. 12-24, 36-43. - SCHRIFTEN ZUM STAATSAUFBAU 18. 1938. - G. ARMINGER: Involvement of German students in NS Organisations. 1984. - G. J. GILES: Students and National Socialism in Germany. 1985. - Ders.: Die Verbändepolitik des Nationalsozialistischen Deutschen Studentenbundes. 1982.

\subsubsection{Gaustudentenführungen und Hochschulgruppen}

Ebenso wie auf Reichsebene ist auch hier Schriftgut von DSt und NSDStB nicht deutlich zu unterscheiden. Die Tätigkeit von Gauführungen ist ohnehin nur durch wenige Akten der Gauführung Baden (KA, in Best. 465d, 20 Bde, 1933-1944, davon 10 Bde betr. Altherrenschaften, 1937-1944, an allen badischen Hochschulen, Reste von Korrespondenz), Aktensplitter der Gaustudentenführung Bayreuth (BAM), Personalunterlagen der Gaustudentenführung Hessen-Nassau über Kameradschaftsführer an den Hochschulen (WI, in Abt. 483, 1939-1944, dort auch Rundschreiben der Reichsstudentenführung 1943-1944) und die „Niedersächsische Hochschulzeitung. Gauorgan des NSDStB und des NS-Dozentenbundes Süd-Hannover-Braunschweig“ (1935-1938, IfZ) dokumentiert; für Hamburg ist eine Unterscheidung von Schriftgut der Gau- und der Studentenführung der Universität kaum möglich (von der Gaustudentenführung jedoch 2 Bde, 1927-1937, HH, in Best. 614-2/5 NSDAP).

Die Überlieferung der DSt und des NSDStB an den einzelnen Hochschulen ist z. T. als Ergebnis der Tätigkeit des Würzburger Instituts gegen Kriegsende - auf folgende sowie beim NS-Altherrenbund auf den Hochschulring an der Hochschule für Lehrerbildung Esslingen (LB, Best. PL 521, 12 Bde, 1938-1942) beschränkt:

Technische Hochschule Aachen

WÜ, in Best. III 8.0.3

Der Bestand (ca. 35 Bde) enthält Verordnungs- und Nachrichtenblätter (1937), Korrespondenz mit der Gaustudentenführung Köln-Aachen (1937-1944), Personalfragebögen 
(1 Sammelband mit weiteren. 1935-1938. D, in Best. RW 23), Abstammungsnachweise. Personalakten gefallener Studenten und Unterlagen über Maßnahmen bei Kriegsausbruch, Betreuung von Wehrmachtangehörigen und das Studium von Luxemburgern (1942).

Universität Frankfurt

WÜ, in Best. III 8.0.3

Lediglich Arbeitsberichte (1933-1934), Akten über den Altherrenbund, das Tagebuch einer Studienfahrt nach Prag (1941) und das ,Mitteilungsblatt der Hochschulgruppe des NSDStB" (Mai 1941) sind vorhanden.

Universität Gießen

UGI

Nur wenige Aktenreste - auch des NS-Dozentenbundes - befinden sich in Schriftgut der Hochschule.

Universität Hamburg

WÜ, in Best. III 8.0.3

Überliefert sind (ca. 100 Bde, 1933-1944, mit Teilprovenienzen Studentenring 1933, Amt für Volkskultur 1934) Satzungen. Rundschreiben, Semesterberichte, Personalunterlagen. Feldpostbriefe und Akten über Korporationen, Arbeits-, Land- und Fabrikdienst, Studentinnen, Kundgebungen, Schulung, Lager, Heime, Werbung, Auslandsbeziehungen.

Technische Hochschule Hannover

H, Best. Hann. 320 IV Ein Teilbestand DSt (13 Bde) enthält u. a. Rundschreiben und „Hannoversche Hochschulblätter" (1933-1935), Semesterberichte (1937-1938), Namenslisten (1933-1938). Akten über Korporationen (1933-1934) und den Kampfausschuß gegen Schmutz und Schund (1933). Weitere Rundschreiben und Monatsberichte, Mitgliederlisten, Richtlinien für Feiern (1938) sind als Provenienz NSDStB zusammengefaßt (18 Bde). Gesondert überliefert ist Schriftwechsel mit dem Rektor (3 Bde, 1933-1937), mit der Reichsstudentenführung und der Reichsleitung des NSDStB (13 Bde, 1932-1938). Als Teilprovenienzen sind ausgewiesen das Außenamt (13 Bde. u. a. betr. Grenzlanddienst, Patenschaft für Riga 1930-1934, Werbung für Studium in Österreich und Danzig 19341936, Betreuung von Ausländern), das Amt für politische Erziehung ( $8 \mathrm{Bde}$, dabei Rundschreiben 1933-1935, Gauschulungslager Rittmarshausen 1935). Amt für Arbeitsdienst und Werkjahr (4 Bde, 1931-1936), Amt für Kameradschaftserziehung (10 Bde, 1933-1939, mit Dienstplänen und Diensttagebüchern von Kameradschaftshäusern) und (mit insgesamt 9 Bden) die Ämter für studentische Wirtschaftsfragen (19331934), für Studentinnen (1933-1938), für Wissenschaft (1934), für Aufklärung und Werbung (1934-1937), für Studentenkampfhilfe (1937) und das Sozialreferat (19351937).

Universität Kiel

$\mathrm{SL}$, in Abt. 456

Überliefert sind nur Aktensplitter (mit Tätigkeitsberichten und Mitgliederlisten) der Kreisleitung Nord und der Kreisreferentin Nord für Studentinnen des NSDStB (4 Bde, 1933-1934).

Universität Köln

UK

Die Akten (34 Bde. 1933-1938) betreffen u. a. den Studentenschaftsführer selbst (3 Bde), die Ämter für Arbeitsdienst (1934-1935) und für praktische Volkstumsarbeit (1933-1934), den Verkehr mit dem Bereich West der Reichsstudentenführung bzw. der 
Gaustudentenführung Köln-Aachen und anderen regionalen Organen der Studentenschaft (13 Bde), Personalangelegenheiten (8 Bde, auch von Professoren 1935-1936, politische Gutachten 1935-1937) und die Studentenkampfhilfe.

Universität Tübingen

UAT, Bestände 169,320

Das Schriftgut der Studentenschaft wurde 1945 absichtlich vernichtet bis auf einen Band mit politischen Beurteilungen von 134 Dozenten und Assistenten (1934-1940), ferner ein Typoskript über die zahlenmäBige Entwicklung des NSDStB (ca. 1939), einige Vorgänge des Studentenführers (1933-1940) und 4 Faszikel der Gruppe Tübingen des NSDStB (1933-1940).

Universität Würzburg

WÜ

Der Bestand (134 Bde, 1933-1939, vereinzelt bis 1944) enthält an allgemeinen Unterlagen (31 Bde) u. a. Verzeichnisse der Studierenden, Rundschreiben der DSt und der Reichsstudentenführung, Schulungsmaterial, Unterlagen über Studententage, von der Studentenführung (25 Bde) Schriftwechsel mit Rektorat, Kultusministerium, einzelnen Korporationen, Tätigkeitsberichte, Akten über Disziplinarverfahren u. a. gegen jüdische Studenten und wegen kommunistischer Betätigung, über Wahlen und Reichsleistungswettkampf. Als Teilprovenienzen sind vertreten das Organisations- und Personalamt (5 Bde), die Ämter für Arbeitsdienst (14 Bde), Landdienst (2 Bde), für studentischen Einsatz (6 Bde), Leibesübungen (3 Bde), Presse bzw. Aufklärung und Werbung (6 Bde), das Wehr- (3 Bde), Außen- bzw. Grenzland- (12 Bde, dabei Akten über Volkstumsarbeit in Siebenbürgen, Bessarabien und dem Banat, Studium von Ausländern und im Ausland, Korrespondenz des Kolonialreferats) und Fachschaftsamt (11 Bde, u. a. der Fachgruppe Kulturwissenschaft und des Fachausschusses Katholische Theologie), das Verbindungsreferat zu SA und NSKK (5 Bde), mit wenigen Akten der Ehrenausschuß, das Referat Volks- und Raumforschung, das Referat Gas- und Luftschutz, der Unterausschuß für Stipendien und Vergünstigungen, die Arbeitsgemeinschaft Studentengeschichte und die ,Aktion wider den undeutschen Geist" (mit schwarzen Listen von Büchern). Gesondert überliefert sind von der NSDStB-Hochschulgruppe (25 Bde) u. a. Anordnungen, Mitgliederlisten, Schriftwechsel mit und Berichte von Kameradschaften und der ANST, Akten über Langemarckfeiern und -spenden (2 Bde, 1929-1935) und über den Deutschen Studententag in Würzburg 1939.

Lit.: Vgl. die Angaben zu den einzelnen Hochschulen im Abschnitı 4.5. zu Würzburg F. GOLÜCKE: Das Kameradschaftswesen in Würzburg von 1936-1945. 1982. - P. SPITZNAGEL: Die Machtergreifung der Nationalsozialisten an der Universität Würzburg. 1982.

\subsubsection{Nationalsozialistischer Deutscher Dozentenbund (NSD.-Dozen- tenbund)}

Von der Reichsamtsleitung unter dem Reichsdozentenführer, dem Münchener Mediziner und Honorarprofessor Walter Schultze, die personell mit der Leitung der Fachschaft Hochschulen im NSLB verbunden war, blieb kein Schriftgut erhalten. Vorhanden sind lediglich Rundschreiben des NS-Dozentenbundes (1935-1937, BA, in Best. NS 20) und sechs Reichstätigkeitsberichte des Auslandsamtes der Dozentenschaft der deutschen Universitäten und Hochschulen (April 1939-1942 September, BA, in NSD 46). Von den Veröffentlichungen liegen die Ehren- und Disziplinarordnung (1934), die „Mitteilungen des NS-Deutschen Dozentenbundes" (Jg. 1, 1938, bis 5, 1942) und der "Informationsdienst der Reichsdozentenführung“ (Jg. 1, 1938) vor. Bis 1940 sind 22 
Hefte der Schriften der Wissenschaftlichen Akademie des NSD.-Dozentenbundes der Christian-Albrecht-Universität Kiel nachweisbar. Von den Dozentenbundsführungen an den einzelnen Hochschulen sind nur in Köln Rundschreiben, Korrespondenzsplitter und einzelne Fragebögen und Mitgliederlisten, Presseausschnitte (UK, 6 Bde, 1933-1938. 1943), aus Marburg politische Auskünfte über Dozenten und Assistenten (WI, in Abt. 483, 3 Bde M-Z, 1934-1938) und in Tübingen Reste von Akten im NachlaB Rupprecht Matthäi (UAT 257) und im Schriftgut des Anatomischen Instituts (UAT 174) vorhanden, dessen Direktor Robert Wetzel bis 1944 Dozentenführer war.

Lit.: V. LOSEMANN: Zur Konzeption der NS-Dozentenlager. 1980. - R. WETZEL: Die wissenschaftliche Akademie Tübingen des NS-Dozentenbundes. 1941.

\subsection{Angeschlossene Verbände}

Für die von Hitler als solche bestimmten angeschlossenen Verbände war jeweils ein zentrales Amt der Partei zuständig, dessen Leiter auch an der Spitze des Verbandes stand, so daß eine Trennung des Schriftguts nicht möglich ist. Das gilt auch für einen Teil der betreuten Organisationen, wie Deutsche Studentenschaft (oben 9.3.6.1), Deutsches Frauenwerk (oben 9.3.5.1) und Reichsbund der Kinderreichen (oben 9.1.13), nicht für den Deutschen Gemeindetag (oben 2.1.1.2.1). Von dem vom Reichssportführer (oben 2.1.1.1) betreuten NS-Reichsbund für Leibesübungen, über dessen Tätigkeit und nationalsozialistische Schulungsarbeit die Zeitschriften „Der Dietwart“ (ab 1935), „Volk und Leibesübungen“, „NS-Sport“ (mit „Deutsche Turnzeitung“) und der Pressedienst „DLR-Mitteilungen“ (ab 1936) informieren, wie auch vom Deutschen Siedlerbund, den das DAF-Heimstättenamt beaufsichtigte, ist kein Schriftgut überliefert. Unberücksichtigt bleibt die Überlieferung von der Partei als unpolitisch angesehener Organisationen wie Reichskriegerbund, Reichsluftschutzbund und Reichskolonialbund.

Lit.: H. BERNETT: Der Weg des Sports in die nationalsozialistische Diktatur. 1983.

\subsubsection{Deutsche Arbeitsfront (DAF)}

\subsubsection{Reichswaltung}

BA, Best. NS 5

ZStA, Best. 62 DAF 1 und 2

Von den meisten der in Berlin ansässigen (1942) 21 Ämter und 16 Fachämter für einzelne Berufszweige der Zentralverwaltung der DAF und den mit ihr verbundenen 6 weiteren Ämtern der NS.Gemeinschaft "Kraft durch Freude" blieb nichts oder nur wenig erhalten. Der Rest verteilt sich auf folgende Provenienzen:

Adjutantur Ley (ZStA).

Die Akten (9 Bde, 1933, Korrespondenzpartner H-L) enthalten fast ausschlieBlich Eingaben an Ley und daraus erwachsenen Schriftwechsel mit den Reaktionen Leys auch in seinen Funktionen als Präsident des preußischen Staatsrates und als Abgeordneter, Partei- und DAF-Angelegenheiten; darunter sind auch Vorgänge betr. Schutzhaft eines Sozialdemokraten, Entlassungen aus dem öffentlichen Dienst aus rassischen Gründen, antisemitische Übergriffe in Neermoor/Ostfriesland, Verweigerung der Anwendung des 
Etbgesundheitsgesetzes durch die Heil- und Pflegeanstalt Saffig bei Andernach, Wirtschaftsfragen; Eingaben und Vorschläge zur Arbeitsbeschaffung und private Korrespondenz mit Kriegskameraden, Studien- und Berufskollegen der IG Farben Leverkusen.

Zentralbüro mit untersteliten Fachämtern

In Koblenz sind nur einzelne Schreiben und Rundschreiben Leys und von den Fachämtern, die zur Betreuung der Betriebe in den verschiedenen Bereichen der Wirtschaft und des öffentlichen Dienstes bestimmt waren, Akten des Fachamtes Freie Berufe (12 Bde, 1939-1943, ZStA 4 Bde, 1935-1938, mit Tätigkeits- und Reiseberichten, Rundschreiben) und Aktensplitter anderer Fachämter (10 Bde), in Potsdam folgende Teilbestände vorhanden;

Fachamt Energie, Verkehr und Verwaltung: u. a. Stellungnahmen zum Sofortprogramm zur Sicherstellung der laufenden Produktion in der Rüstungswirtschaft 1945, Sitzung des Reichsverkehrsministers mit den Werkstättenbereichsleitern im März 1945, Personal- und Sozialangelegenheiten (11 Bde, 1937/40-1944/45);

Fachamt Der Deutsche Handel: Rundschreiben, Liquidation des Gesamtverbandes Deutscher Handwerker, Kaufleute und Gewerbetreibender, Gehaltsabrechnungen für Mitarbeiter (4 Bde, 1934-1939);

Fachamt Nahrungs- und Genußmittel: Mitteilungen und Rundschreiben verschiedener Dienststellen, außer Kraft gesetzte Verträge, ProzeBangelegenheiten (3 Bde, 1936-1937); Fachamt Textil: Berichte über Buch- und Kassenprüfungen bei der Reichslehrweberei Langenbielau 1942, Kurzarbeiterverhältnisse in der Lederhandschuhherstellung (2 Bde, 1942,1945);

Fachamt Chemie: Urlaubsordnung, Reichsberufswettkampf 1937 (2 Bde, 1937);

Fachamt Druck und Papier: Karneval- und Festartikel-Industrie, Entgeltbestimmungen (2 Bde, 1932-1937).

Noch geringer ist die Überlieferung der Fachämter Eisen und Metall, Landwirtschaft (später Hauptabteilung I des Reichsnährstandes) und des Wehrmachtsamtes (ZStA) wie des Amtes Heer und von Entscheidungen der Ehren- und Disziplinargerichte (1936) in Koblenz.

Personalamt (ZStA)

Überliefert sind (ca. 90 Bde, 1933-1942, vorwiegend 1936-1941) Einzelfallakten mit Beschwerden, Eingaben, Disziplinar- und strafrechtlichen Verfahren von hauptamtlichen Funktionären und von Angestellten der DAF und ihrer Einrichtungen.

\section{Amt Information (ZStA)}

Die aus dem geheimen Nachrichtendienst der NSBO und der NSDAP hervorgegangene Zentrale des Spitzeldienstes der DAF firmierte zunächst als Amt Abwehr, zeitweise als Abteilung Vermittlung des Organisationsamtes und von Oktober 1934 bis zum Übergang ihrer Funktionen auf Gestapo und SD, mit denen schon vorher eine enge Zusammenarbeit bestanden hatte, Anfang 1938 als Amt Information (Vorakten des SD-Hauptamtes im BA, Best. R 58, oben 2.2.1.2.6). Der Teilbestand enthält folgende Akten:

- Meldungen über Widerstand gegen das Regime, vor allem der KPD, aus den Gauen Düsseldorf (2 Bde, 1934), Groß-Berlin und Danzig (1 Bd, 1933-1937), Halle-Merseburg (1934), Hessen-Nassau (1934), Koblenz-Trier (1934), Köln-Aachen (1933-1934), Kurmark (1933-1934), Süd-Hannover-Braunschweig (1933-1934) und Thüringen (19331934, alle jeweils $1 \mathrm{Bd}$ ). 
- Widerstand einzelner Organisationen: Kommunisten, im Reichsgebiet insgesamt (1 Bd, 1935-1937) und (1 Bd je Gau, hauptsächlich 1935-1936/1937) in den Gauen Baden, Bayerische Ostmark, Danzig, Düsseldorf, Essen, GroB-Berlin, Halle-Merseburg, Hamburg, Hessen-Nassau, Köln-Aachen, Kurhessen, Magdeburg-Anhalt, Mainfranken, Mark Brandenburg, Mecklenburg-Lübeck, München-Oberbayern, Ost-Hannover, Ostpreußen, Pommern, Sachsen, Schlesien, Schleswig-Holstein, Süd-Hannover-Braunschweig, Thüringen, Weser-Ems, Westfalen-Nord, Westfalen-Süd, Württemberg-Hohenzollem sowie in der Auslandsorganisation der DAF (1936-1937), ferner der Roten Hilfe und des Kommunistischen Jugendverbands (2 Bde, 1935-1937 bzw. 1936), Sozialdemokratie und Gewerkschaften (je 1 Bd, 1935-1937) und von einzelnen Personen im gesamten Reichsgebiet ( $1 \mathrm{Bd}, 1937$ ) und in den Gauen (jeweils $1 \mathrm{Bd}$, 1935-1936/1937 bzw. 1938) Baden, Düsseldorf, Essen, Franken, GroB-Berlin, HalleMerseburg, Koblenz-Trier, Köln-Aachen, Kurhessen, Mainfranken, Mark Brandenburg, München-Oberbayern, Ostpreußen, Pommern, Rheinpfalz-Saar, Sachsen, Schlesien, Schleswig-Holstein, Schwaben, Süd-Hannover-Braunschweig, Weser-Ems, WestfalenNord, Westfalen-Süd, Württemberg-Hohenzollern.

- Informationen und Lageberichte über die Arbeiterbewegung im Ausland, Protesterklärungen der ausländischen Arbeiterbewegung (2 Bde, 1935-1937).

Andere Akten betreffen die Liquidation der 1933 zerschlagenen Gewerkschaften (4 Bde, 1935-1938), die Überwachung von einzelnen Wirtschaftsunternehmen (2 Bde. 1935-1938) und der DAF selbst (7 Bde, 1935-1938, mit Vorgängen über die Vertrauensratswahlen 1935 (1 Bd) und die kommunistische Zersetzung, 1936-1938).

\section{Amt Soziale Selbstverwaltung (ZStA)}

Zu diesem Teilbestand gehören Handakten (5 Bde, 1936-1940) von Dr. Theo Hupfauer (bis 1943 Leiter des Amtes und des Kriegshauptarbeitsgebietes II des Zentralbüros), ein Rest von Schriftwechsel (1-3 Bde) der Abteilungen Vertrauensrat (1936-1939, mit der DAF Gauwaltung Schlesien), Arbeitsbedingungen (1939), Schriftum und Fachversammlungen (1937-1941, u. a. Handakten von Dr. Hans Lande) und Ausrichtung (19381939). Den Hauptteil bilden Akten der Abteilung Leistungskampf (ca. 215 Bde, zum größten Teil 1938-1941, in Einzelfällen 1937-1943) mit Fragebögen und ergänzendem Schriftwechsel über einzelne Betriebe, die sich am Leistungskampf der deutschen Betriebe beteiligt haben, in folgenden Gauen: Baden (2 Bde), Bayerische Ostmark (10 Bde), Berlin (9 Bde), Danzig-Westpreußen (4 Bde), Düsseldorf (7 Bde), Essen (8 Bde), Franken (1 Bd), Halle-Merseburg (1 Bd), Hamburg (6 Bde), Hessen-Nassau (2 Bde), Kärnten (1 Bd), Köln-Aachen (3 Bde), Kurhessen (4 Bde), Magdeburg-Anhalt (2 Bde), Mark Brandenburg (5 Bde), Mecklenburg (7 Bde), Moselland (12 Bde), München-Oberbayern (1 Bd), Niederdonau (1 Bd), Oberdonau (5 Bde), Ost-Hannover ( 7 Bde), Ostpreußen (14 Bde), Pommern (6 Bde), Sachsen (1 Bd), Schlesien (1 Bd), Schleswig-Holstein (7 Bde), Schwaben (1 Bd), Steiermark (14 Bde), Sudetenland (6 Bde), Süd-HannoverBraunschweig (10 Bde), Thüringen (1 Bd), Tirol-Vorarlberg (2 Bde), Weser-Ems (17 Bde), Westfalen-Nord (9 Bde), Westfalen-Süd (1 Bd), Westmark (18 Bde), Wien (5 Bde), Württemberg-Hohenzollern (1 Bd), Auslandsorganisation der DAF (1 Bd).

\section{Zentralstelle für die Finanzwirtschaft der DAF (BA)}

Die Akten, die den Hauptteil der Koblenzer Überlieferung bilden, betreffen die Verwaltung des überwiegend den rechtmäßigen Eigentümern entzogenen Vermögens der DAF, vor allem Grundstücke (2 982 Bände, 1934-1945, dabei auch Grundbesitz in den 
Niederlanden), Barackenlager und Wohnschiffe für Arbeiter (90 Bde mit Einzelfällen. 1940-1945), Hypotheken (359 Bde, 1934-1944), Darlehen für Handwerker, Siedlungen und Erfindungen (39 Bde, 1934-1944), das Gemeinschaftswerk der DAF, in dem ehemalige Verbrauchergenossenschaften und deren Beteiligungen zusammengefaßt waren (12 Bde, 1941-1945, mit Geschäftsberichten) und die Treuhandgesellschaft für die wirtschafilichen Unternehmungen der DAF (90 Bde, 1934-1945, dabei Akten über den „Deutschen Ring“ und andere Versicherungen, die „Neue Heimat" und weitere Bauund Wohnungsgesellschaften, Verlage und Buchhandlungen, die Stettiner Vulkanwerft und niederländische Firmen).

Von den übrigen Hauptämtern und Ämtern sind in Koblenz durch Aktenreste vertreten:

Wirtschaftsamt (14 Bde, 1935-1938, u. a. betr. Einzelfälle von Juden in der Wirtschaft 1935),

Amt für Berufserziehung und Betriebsführung (7 Bde, 1938-1942, mit Berichten, Gutachten, Handakten über kaufmännische Berufe),

Amt für Arbeitseinsatz (11 Bde mit Schnellbriefen betr. Fremdarbeiter, 1941-1943 Juli),

Frauenamt (4 Bde, 1941-1943) und

Amt für Rechtsberatungsstellen (6 Bde, 1940-1942),

in Potsdam

Hauptamt für Handwerk und Handel (Best. 62 Ha 3, 8 Bde, 1934-1937, dabei Schriftwechsel über Boykott jüdischer Geschäfte durch örtliche Dienststellen der NS-Hago 1935),

Hauptamt NSBO (Best. $62 \mathrm{Ha} \mathrm{4,} 3$ Bde, 1934/35-1938, u. a. über Binnenschiffahrtsund Reichsautobahnangelegenheiten) und mit jeweils nur einem Band oder Druckschriften das Schulungsamt, Presseamt (Pressestimmen zum deutsch-italienischen Sozialversicherungsabkommen 1941), Sozialamt (u. a. über Auseinandersetzung mit dem Reichsarbeitsministerium über Sozialversicherung 1933), Reichsheimstättenamt (Fragebögen aus den Gauen 1937) und das Amt für Arbeitsführung und Berufserziehung (Jahresbericht 1935 der Reichsschule für Ingenieure in Gelsenkirchen).

Forderungen von Gewerkschaftlern an die DAF auf eingezogenes Vermögen sind im Schriftgut der Reichsfeststellungsbehörde (oben Abschnitt 3.2.4.3) dokumentiert, die Rückerstattung von Vermögen der Gewerkschaften und Konsumgenossenschaften nach 1945 ergibt sich aus den Unterlagen der dafür in der britischen Besatzungszone eingerichteten Prüfungsausschüsse (BA, Best. Z 36).

Aus der Tätigkeit des Generalbaureferenten der DAF sind Bauzeichnungen und Risse vorhanden (BA, Best. Plan 88). Akten des Stadtbaubüros der DAF in der Stadt des KdF-Wagens befinden sich im Stadtarchiv Wolfsburg (389 Bde, 1938-1944).

Ein Protokoll über eine Tagung der Reichsarbeitskammer 1935, 47 Berichte der Forschungsstelle für internationale Gewerkschaftsfragen des Amtes Information (19351936) und einige Berichte des Heimstättenamtes (1940-1942) und von KdF (1934) sowie der NSBO (1933) sind im Hauptarchiv der NSDAP (NS 26) überliefert, der „Gesamtrechenschaftsbericht" Leys zum 30. Januar 1943 als Drucksache „Nur für den Dienstgebrauch“ (BA, NSD 50). Umfangreiche Korrespondenz mit der DAF vor allem über Fragen der Berufsausbildung, ferner der Sozialversicherung und der Ausländerbeschäftigung enthalten Akten der Sozialwirtschaftlichen Abteilung der Reichsgruppe Industrie (BA, Best. R 12 I, überwiegend 1937-1944). 
Mit dem laufenden Schriftgut ist offenbar auch das Zentralarchiv der Deutschen Arbeitsfront vernichtet worden, das 1935 innerhalb des Arbeitswissenschaftlichen Instituts errichtet wurde, neben dem "gesamten erledigten Schriftgut" der DAF vor allem beschlagnahmte Überlieferung der Gewerkschaften und Arbeitgeberverbände auch aus besetzten Gebieten aufnahm und dessen Umfang der Bericht des Instituts über die Zeit von 1935 bis 1942 mit ca. 300000 Aktenbänden angab. Dasselbe gilt für die damals dort vorhandene Sammlung von Unterlagen über ca. 5000 deutsche Industrie- und Handelsunternehmungen (Firmenarchiv), das dorthin von der NS-Hago übernommene „Reichsbezugsquellenarchiv" über ca. 170000 Firmen und das "Tarifarchiv", während die Zeitungsausschnittsammlung in das ZStA gelangt ist und aus dem Archiv der Reichsarbeitskammer dort vor allem Protokolle von Tagungen von Gauarbeitskammern (6 Bde, 1936-1940) überliefert sind.

Ersatzuiberlieferung ist reichlich in Publikationen der DAF, ihrer Ämter und Unterorganisationen vorhanden (ca. 1000 Bde im IfZ, weitere BA, NSD 50, 4 Bde auch ZStA). Als Tageszeitung erschien wenige Jahre ab 1933 ,Der Deutsche“, für Weisungen ab 1935 das ,Amtliche Nachrichtenblatt der Deutschen Arbeitsfront und der NSG 'Kraft durch Freude”“. „Arbeitertum. Blätter für Theorie und Praxis der NSBO“ wurde ab 1933 als „amtliches Organ der DAF“ fortgesetzt, „Schönheit der Arbeit“ warb für Verbesserungen am Arbeitsplatz. „Der Aufbau“ wandte sich an die Allgemeinheit, „für das schaffende Auslandsdeutschtum" gab es „Der Auslandsdeutsche“ (bis 1938 „Der Deutsche im Ausland“, im BA Jg. 1940-1943). „Der Querschlag“ (1937/38), „Volksgesundheit“ (Jg. 1938-1939), „Der Deutsche Techniker“, „Jungvolk am Bau“, „Die Deutsche Gaststätte“, "Theater, Film, Varieté“ und andere, insgesamt ca. 50 „fachliche Schulungsblätter", die von den Fachämtern herausgegeben wurden und vielfach frühere Verbandszeitschriften fortführten, waren für einzelne Berufsgruppen bestimmt, „Der Arbeitsinvalide. Mitteilungsblatt für die Alten der Arbeit" für Rentner und „Schaffende Jugend“ für Berufsanfänger. „Schulungsmaterial“ wurde regelmäßig unter wechselnden Titeln (u. a. „Die DAF-Schulung“, 1936-1940, „Arbeit und Wirtschaft“, 1940-1943) verbreitet.

Pressedienste waren die „Deutsche Arbeits-Korrespondenz (DAK)“ (ab 1933) und „Die DAF im Spiegel der Presse“ (ab 1936). Weiter gab es den „Kalender der Deutschen Arbeit“ (1934-1943), „NS-Sozialpolitik“ (ab 1933, später ,Monatshefte für NSSozialpolitik“, mit Beilage „Der Vertrauensrat"), nur für den Dienstgebrauch bestimmte „Betriebs-Informationen“ (ab 1939), den „Informations-Dienst des Geschäftsführers der DAF“ (1943-1944), die „Rednerinformation“ (Einzelnrn. 1938-1944), einen „Lagerführer-Sonderdienst“ (1940-1944), „Richtlinien für Werkscharen“ (1941-1943), „Die Frau am Werk“ (Jg. 3-4, 1938-1939). Andere Schriften befaßten sich mit den Reichsberufswettkämpfen und der Ehren- und Disziplinarordnung (von 1936 mit Verfahrensordnung für den Obersten Ehren- und Disziplinarhof und die Gaugerichte, IfZ).

Herausgeber von eigenen Schriftenreihen und Einzelschriften waren das Amt „Schönheit der Arbeit", das Amt für Berufserziehung (u. a. ,Monatsspiegel der fördernden Berufserziehung" und zahlreiche Arbeitsunterlagen aus Verwaltung und Justiz), das Fachamt „Eisen und Metall“ (vorhanden u. a. 5 von 12 Nrn. „Steigenung der nationalen Produktionskraft“ ab 1939) und das Amt „Handel und Handwerk“ (Hauptamt NS-Hago, u. a. Sozialpolitische Schriftenreihe), für „Arbeitshefte“ das Amt des Siedlungsbeauftragten (später Heimstättenamt mit dem Deutschen Siedlerbund als betreuter Organisation). Auf „Wehrfront. Mitteilungsblatt der Abteilung Wehrmacht“ (Jg. 2, 1934/35) folgte im Krieg „Die KdF-Truppenbetreuung“. 
Von der NSG „Kraft durch Freude“ stammt auch die Reihe „Lebensformen der Volkstumsarbeit“", und sie setzte Veröffentlichungen der NS-Kulturgemeinde fort („Volkstum und Heimat. Rüstzeug für nationalsozialistische Volkstumsarbeit und Volkswerdung“, 1934-1942, „Die Kunst im Dritten (ab 1939: Deutschen) Reich“ (1937-1944).

Die „Jahrbücher des Arbeitswissenschafulichen Instituts“ der DAF (1936-1940/41) sind als Nachdruck, in einer Mikrofiche-Edition seine Periodika zugänglich: „Arbeit, Volk und Staat", 1935-1939; "Neue Internationale Rundschau der Arbeit", 1941-1944; „DAF-Rohstoff-Dienst“, 1937-1944; „Wirtschafts-“ bzw. „Wirtschafts- und Sozialberichte“, 1936-1944; ebenso sind von ihm herausgegebene bibliographische Übersichten und hunderte von Denkschriften und Gutachten zur Sozial- und Wirtschaftspolitik (bis 1944) verfügbar.

Die Öffentlichkeitsarbeit der DAF wird ferner durch 185 Plakate der Reichs- und einzelner Gauwaltungen und $61 \mathrm{KdF}$-Plakate dokumentiert (BA). 34 DAF-Filme (BAFilmarchiv) dienten der Propaganda im allgemeinen (z. B. „Arbeiter heute“, 1935, „Deutsche Arbeitsstätten“, 1940), berichteten von Erfolgen im Wohnungs- und Siedlungsbau (z. B. „Alltag in einer Siedlung“, 1942) und vom WeltkongreB für Freizeit und Erholung (1937), warben für das „KdF-Schiff Wilhelm Gustloff“ und Reisen nach Italien (1938) oder behandelten Ausbildung und Tätigkeit in einzelnen Berufen.

Lit.: SCHRIFTEN ZUM STAATSAUFBAU 3/4, 5, 27/28. 1935-1939. - V. KRATZENBERG: Arbeiter auf dem Weg zu Hitler? 1986. - R. SMELSER: Rober Ley. 1989. - SOZIALSTRATEGIEN der Deutschen Arbeitsfront. Teil A: Jahrbuicher des Arbeitswissenschaftlichen Instituts. 5 Bde - Teil B: Periodika, Gutachten und Veröffentlichungen des Arbeitswissenschaftichen Instituss. Microfiche-Ausgabe. 1987. - R. GIERSCH: Zu Rolle und Funktion der Deutschen Arbeitsfront im staatsmonopolistischen System der faschistischen Diktatur in Deutschland. 1976. - Ders.: Die .Deutsche Arbeitsfront“. 1981. - T. SIEGEL: Rationalisierung statt Klassenkampf. 1988. - U. ZUCHT: Das Arbeitswissenschaftliche Institut und die Nazifizierung der Sozialwissenschaften in Europa, 1936-1944. 1989. - U. GEUTER: Das Institut für Arbeitspsychologie und Arbeitspädagogik der Deutschen Arbeitsfront 1987. - U. REIFNER: NS-Rechtsberatungsstellen und die Rechtsberatung der Deutschen Arbeitsfront. 1981. - VERSORGUNGSWERK des Deutschen Volkes. 1985. W. BUCHHOLZ: Die nationalsozialistische Gemeinschaft „Kraft durch Freude“. 1976. - L. v. Z MOYER: The Kraft durch Freude Movement in Nazi Germany, 1933-1939. 1977. - K. H. BOCK: Wachstum aus wilder Wurzel. 1982. - M.-L. RECKER: Die Grobstadt als Wohn- und Lebensbereich im Nationalsozialismus. 1981.

\subsubsection{DAF-Gauwaltungen}

Die Überlieferung der Gauwaltungen besteht vor allem aus folgenden vier Beständen:

Gauwaltung Bayerische Ostmark (Bayreuth)

BAM, Best. M 30

Der umfangreiche Bestand (ca. 800 Bde) enthält Jahresberichte der Gauwaltung und der Kreiswaltungen (35 Bde, 1934-1942), Unterlagen über Organisation (81 Bde, 19381941) und Personalentwicklung (76 Bde, 1934-1942) und Überprüfung der Kreis- und Ortswaltungen (64 Bde, 1935-1937), Bilanzen und Kostenübersichten der Kreiswaltungen (83 Bde, 1933-1941) und sonstiges Kassenschriftgut (18 Bde, 1935-1943), dokumentiert die Tätigkeit der Gaurechtsberatungsstelle (45 Bde, 1934-1944) und die sozialen Verhältnisse in einzelnen Unternehmen, u. a. durch Ergebnisse von Besichtigungen und Betriebsfragebögen (8 Bde, 1933-1945) und durch Teilnahme am Leistungskampf der deutschen Betriebe (31 Bde mit ca. 4000 Einzelfallen, 1935-1944). Geringeren Umfang haben die Korrespondenz des Gauwalters (2 Bde, 1934-1936) und des Revisionsobmanns der NSBO (1933-1934) und Akten u. a. über Reichsberufswettkampf (5 Bde, 1937-1939), Teilnahme an Veranstaltungen am 1. Mai und anderen nationalen Feiertagen und Reichsparteitagen (5 Bde), über den Reichstreuhänder der Arbeit (1937-1940), die 
Reichsbetriebsgemeinschaften (5 Bde, 1936-1943), Ehren- und Disziplinargerichtsbarkeit der DAF (1940-1944), Schulung (1942-1943), „Kraft durch Freude“ (1936-1942), die Volkswagensparaktion (2 Bde), Beschwerden aus der Bevölkerung (1934-1936), Korrespondenz mit Kreiswaltungen (13 Bde, 1933-1942). Akten der Kreiswaltung Regensburg (104 Bde) befinden sich noch im BA.

Gauwaltung Hessen-Nassau

WI. in Abt. 483

Überliefert sind einige Unterlagen der NSBO (1931-1934), Anordnungen und Rundschreiben (8 Bde, 1935-1942), Akten über Personalangelegenheiten (Allgemeines und Einzelfälle, 7 Bde, 1934-1943), Werkscharen (6 Bde, u. a. bei der Opel A.G. Rüsselsheim, 1936-1938), Rechtsberatungsstellen (4 Bde, 1934-1942), Berichte der KdF (19361941), Zeitungsausschnitte über das „Rhein-mainische Siedlungswerk“ (1933-1943). Den Hauptteil (28 Bde, 1934-1942) bilden Urteile (1937-1942), Ermittlungsakten, Korrespondenz und Gnadengesuche aus der Ehren- und Disziplinargerichtsbarkeit. Als Ergänzung sind Akten der Kreiswaltungen Frankfurt, Wetzlar und Wiesbaden und von sieben weiteren, außerdem von den Kreiswaltungen Bergstraße und Offenbach (DA. Best. N 1) vorhanden.

Gauwaltung München-Oberbayern

MSt Neben wenigen Organisationsunterlagen, Vorgängen des Gauheimstättenwerks (19431945), Berichten über drei Betriebe (1940-1943), Sammlungen von Tarif- und anderen Bestimmungen für die Gaubetriebsgemeinschaften Bau und Steine und Erden ( 3 Bde, 1928-1942) sind hauptsächlich die Akten über die Teilnahme von 169 Firmen in 78 Orten (über München nur ein Sammelband) am Leistungskampf der deutschen Betriebe (1937 bis 1943 mit Fragebögen, politischen Beurteilungen, Ergebnissen von Besichtigungen, Angaben über Produktionsverhältnisse und Sozialleistungen, Bildern) vorhanden. Außerdem enthält der Bestand Aktenreste der Kreiswaltung Berchtesgaden-Laufen (10 Bde, 1934-1943, u. a. über Veranstaltungen und einzelne Firmen) und von fünf weiteren Kreiswaltungen (6 Bde und Kleinbildnegative von Betrieben und Veranstaltungen im Kreis Miesbach), Rundschreiben (1935-1942).

Lit: WIDERSTAND UND VERFOLGUNG in Bayern. Bd. 2. 1975. S. 114-136.

Gauwaltung Schwaben

A

Vorhanden sind Unterlagen (insgesamt 28 Bde und Einzelvorgänge) über Funktionäre und Mitglieder, einzelne Industrie- und Handwerksbetriebe, Tagungen (u. a. der Arbeitskammer Schwaben 1936-1937), Reichsberufswettkampf, Aktion „Schönheit der Arbeit“. Als Ergänzung liegen Akten der Kreiswaltungen Memmingen, Augsburg, Günzburg, Marktoberdorf, Nördlingen, Sonthofen und von neun weiteren Kreisen yor.

Nur splitterhaft ist die Überlieferung aus folgenden Gauen:

Baden-ElsaB: „Gaubriefe“ 1936-1937 (KA, Best. 465 d), dazu Ergänzungsüberlieferung der Kreiswaltungen Freiburg (4 Bde, noch BA), Zabern (26 Bde BA, weitere $10 \mathrm{KA}$ ) und Kehl (8 Bde, 1938-1943, Nationalarchiv Paris, AJ 40).

Hamburg: Nur Mitgliedskarten für ausländische Arbeiter der Organisation Todt und Personalunterlagen über 539 ausländische Mitarbeiter in Lagern (ISD Arolsen).

Koblenz-Trier: Kassenbelege der Ehren- und Disziplinargerichtsbarkeit der DAF, 1940 1943 (KO, Best. 662,7). 
Kurhessen: Lediglich Berichte der Kreiswaltung Bad Hersfeld über Arbeitslager 19421944 (Nationalarchiv Paris AJ 40) und Stellenkartei derselben 1938-1941 (MR, Best. $327 / 1)$.

Mainfranken: Personalvorgänge (WÜ, Best. III 8.0.1, 3 Bde, 1933-1942, außerdem Akten von 11 der 14 Kreiswaltungen).

Süd-Hannover-Braunschweig (H, Best. Hann. $310 \mathrm{I}$, betr. NS-Musterbetrieb in Helmstedt 1939-1944, Feldpost für eingezogene Mitglieder 1940-1941).

Weser-Ems: Akten betr. Schuldenregelung (OL, Best. 320, 19 Bde, 1940-1943) und betr. Statistik 1934, Sozialgewerk Bremer Handwerker 1939-1944, seit 1944 von DAF übernommen (HB, Best. 7,1066, 20 Bde).

Westfalen-Nord: Unterlagen aus 53 Verfahren $(3 \mathrm{Bde}$ ) vor dem Ehren- und Disziplinargericht Bielefeld-Halle der DAF (1937-1943, nur Beschuldigte mit Anfangsbuchstaben $\mathrm{H}$, I und J), u. a. wegen Abtreibung, Arbeitsuntreue, Vorbereitung zum Hochverrat, Homosexualität, Unterschlagung von WHW-Geldern) und einige Aktensplitter der Gauwaltung in der Teilüberlieferung der Gauleitung im StadtA Bielefeld, ferner (MS) Akten der Gaufachschaft Volkspflegerinnen (10 Bde, 1936-1944) und Splitter (u. a. Aufstellung von Werkwachtverbänden im Kreis Lüdinghausen 1942-1945) sowie Monatsbilanzen von 9 Kreisverwaltungsstellen 1937 im Schriftgut der Reichswaltung (BA, Best. NS 5).

Württemberg-Hohenzollern: Rundschreiben (auch des Gauheimstättenamtes und der Abteilung Werkscharen), Vorgänge über Personalangelegenheiten, Reichsberufswettkampf, Ehren- und Disziplinargericht (LB, Best. PL 515/0, auBerdem einzelne Akten der Kreiswaltungen Göppingen, Heidelberg, Ludwigsburg, Öhringen-Künzelsau, Ulm, Waiblingen).

Diese Überlieferung wird ergänzt durch einzelne Tätigkeitsberichte und Mitteilungsblätter der Gauwaltungen Baden, Bayerische Ostmark, Essen, Franken (auBerdem Gau-Ausgabe der Zeitschrift „Kraft durch Freude“ 1934-1941), Hessen-Nassau, Moselland und Saarpfalz/Westmark (IfZ), und für die Gauwaltungen Düsseldorf, Essen, Köln-Aachen, Westfalen-Nord, Franken und Mainfranken ist Korrespondenz mit staatlichen Stellen in deren Akten (D, DT, WÜ, N) nachgewiesen. Bereits 1946 wurden zwei leitende Mitarbeiter der DAF-Gauwaltung Köln-Aachen vom Landgericht Köln wegen Ermordung eines 1945 bei ihnen beschäftigten Hitlerjungen, der sich der Dienstpflicht entziehen wollte, verurteilt (JUSTIZ UND NS-VERBRECHEN Nr. 002).

Lit:: SCHRIFTGUT der NSDAP. Teil 1. S. 215-221, 230-233: Teil 2. S. 146-149; Teil 4, S. 338-346.

\subsubsection{NS-Volkswohlfahrt (NSV)}

\subsubsection{Reichswaltung/Hauptamt für Volkswohlfahrt BA, Best. NS 37}

ZStA, Best. $62 \mathrm{Ha} 2$

Im Koblenzer Bestand betrifft eine Sammlung von Rundschreiben und Anordnungen (58 Bde, überwiegend ab 1935) alle Arbeitsbereiche, darunter Wohlfahrtspflege und Jugendhilfe (6 Bde, 1937-1942), Hilfswerk ,Mutter und Kind“" (6 Bde, 1937-1942), NSSchwesternschaft (8 Bde, 1935-1944), Ernährungshilfswerk (5 Bde, 1937-1944), Winterhilfswerk (4 Bde, 1936-1944), ferner Volksgesundheit, Finanzverwaltung; eine kleinere Sammlung (ISD Arolsen) bezieht sich vor allem auf Tuberkulosehilfswerk, Reichsadoptionsstelle und Jugendhilfe (1937-1943). Akten sind nur über Grundstücke auBerhalb des Gebietes der heutigen Bundesrepublik vorhanden. Berichte über Jugendhilfe (1937), 
Einsatz in besetzten Gebieten (1940-1944) und nach Luftangriffen (1941-1945) sowie über das Kriegswinterhilfswerk (1942-1943) befinden sich nebst dem Manuskript einer Geschichte der NSV bis 1934 im Hauptarchiv der NSDAP (NS 26).

Der Potsdamer Teilbestand enthält Akten des Sekretariats des Hauptamtleiters Hilgenfeldt (7 Bde, 1935-1944), Handakten von Eva v. Schroeder über die Wiederaufnahme des Verfahrens im Pommerschen Brandstifter-ProzeB von 1931 (9 Bde, 1933-1944), Akten des Propagandaamtes bzw. des Amtes Werbung und Schulung (3 Bde, 1935-1941), u. a. über den Sondereinsatz in Belgien und Frankreich (1940-1941) und über NSV in Österreich (1938), der Hauptstelle Organisation, Stelle Statistik (1933-1935/39) und verhältnismäßig viele Personalakten.

Veröffentlicht wurden zahlreiche Einzelschriften mit Richtlinien und Dienstanweisungen für die verschiedenen Einrichtungen (Winterhilfswerk, Hilfswerk ,Mutter und Kind“, Emährungshilfswerk, „Adolf-Hitler-Freiplatz-Spende“, Kindergärten, NSSchwesternschaft), mit Werbung für Spenden und Berichten über Erfolge (dabei „Statistik der NSV und des WHW", ab 1936). Neben einer Schriftenreihe (16 Hefte, 1937-1943) gab die NSV den „Nationalsozialistischen Volksdienst“ (1933-1944), einen "Frontdienst" (ab 1939) und die Monatsschrift für den deutschen Volksgenossen "Ewiges Deutschland“ (ab 1931, mit Jahrbüchern 1939-1942) heraus und führte die „Deutsche Jugendhilfe“ und die „Monatsblätter für Straffälligenbetreuung und Ermittlungshilfe" fort. Außerdem gab es noch einen „NSV-Presse- und Bilderdienst", den "NSV-Propagandadienst", den "Informationsdienst für die soziale Arbeit der NSV“ (ab 1938) und einen vertraulichen "Sozialdienst", „Rundbriefe" für Kindergärtnerinnen. Kranken- und Gemeindeschwestern und für Jugenderholungsheime (1938-1944).

Lit.: SCHRIFTEN ZUM STAATSAUFBAU 2. 1939. - H. VORLÄNDER: Die NSV: Darstellung und Dokumentation. 1988. - U. MANN. E. REIDEGELD: Die nationalsozialisusche „Volkswohlfahrtsplege”. 1987. - E. HANSEN: Nationalsozialistische Volkswohlfahr, kommunale Fürsorge und konfessionelle Wohlfahrtspflege im deutschen Faschismus. 1989. - F. TENNSTEDT: Wohltat und Interesse. 1987.

\subsubsection{NSV-Gauwaltungen}

NSV-Gauwaltung Baden

KA, Best. $465 \mathrm{~d}$ Der Bestand (ca. 230 Bde, weitere 3 Bde Nationalarchiv Paris) enthält das Nachrichtenblatt (1934-1935), Dienstvorschriften und Rundschreiben (9 Bde, 1937-1944), Tätigkeitsberichte und Statistiken (40 Bde ab 1935, vor allem nach Kreisen 1943-1944), Personalvorgänge (14 Bde, mit Beurteilungen, 1937-1944), Akten u. a. über Winterhilfswerk (12 Bde, 1934-1944), Finanzverwaltung und Bauten (11 Bde, 1936-1944, dabei Heranziehung jüdischen und kirchlichen Vermögens, 1940-1942), Ernährungshilfswerk und NSV-Küchen ( 9 Bde, 1938-1944), über Unterbringung, Versorgung und Verpflegung von Umsiedlern, Rückwanderern und Flüchtlingen sowie von Evakuieren aus Luftkriegsgebieten, insbesondere Westfalen-Süd (38 Bde, 1938-1944), Einrichtung von Kindergärten (5 Bde, 1933-1944), Jugendhilfe, -erholung und -fürsorge (36 Bde, dabei Einzelfälle der Betreuung jugendlicher Strafgefangener, 1936-1943), Müttererholungswerk und Gesundheitsvorsorge (9 Bde, 1936-1944), NS-Schwesternschaft (9 Bde, 1936-1944), Werbung und Schulung (10 Bde, 1937-1943).

Lit.: REPERTORIEN des Generallandesarchivs. AbL 465 d. 1974. S. 30-58. 
NSV-Gauwaltung Mainfranken

WÜ, in Best. III 8.0.1

Die Aktenreste (32 Bde, 1933-1945) betreffen u. a. Wohlfahrtspflege und Jugendhilfe, Hilfswerk „Mutter und Kind“, Winterhilfs- und Ernährungshilfswerk (1933-1942), Vermittlung von Adoptionen, Werbung.

NSV-Gauwaltung Westfalen-Nord

Vorhanden sind neben Rundschreiben (18 Bde, 1935-1945), Organisationsunterlagen (28 Bde, 1930-1945) und Tätigkeitsberichten (20 Bde, 1935-1945) Akten vor allem über Kindertagesstätten und -gärten, deren Personal und seine Ausbildung, die Übernahme konfessioneller Einrichtungen (ca. 460 Bde, allgemeines und Einzelfälle, dabei 7 Bde Rundschreiben der Reichsleitung, 1934-1943). Ebenfalls relativ gut ist die Überlieferung über die Mutter- und Säuglingsfürsorge (ca. 100 Bde, 1934-1945), die Jugendfürsorge (ca. 100 Bde, 1936-1945, davon 55 Bde über einzelne Adoptionen) und den Einsatz von NS-Schwestern in der Gemeindepflege (87 Bde, 1935-1945, mit Rundschreiben der Reichsleitung) und Personalangelegenheiten von Volkspflegerinnen (36 Bde, 19351945), ferner über Gesundheitsfürsorge und Erholungsheime (140 Bde), Kriegseinsatz (55 Bde, vor allem Betreuung von Umsiedlern und Evakuierten), Überwachung und Übernahme konfessioneller und privater Fürsorgeeinrichtungen (25 Bde, 1935-1944), Haushalts- und Familienhilfe (34 Bde), Obdachlosen-, Asozialen- und Gefangenenbetreuung (7 Bde) und Einsatz des weiblichen RAD bei der NSV (1936-1939).

Lit.: A. zu CASTELL RÜDENHAUSEN: ..Nicht mitzuleiden. mitzukämpfen sind wir da." NSV im Gau Westfalen-Nord. 1981.

Die Überlieferung der übrigen Gauwaltungen beschränkt sich auf Aktensplitter aus Bayreuth (2 Bde, BAM), Hessen-Nassau (Akten der Kreiswaltungen AlsfeldLauterbach, Wetterau, Offenbach, DA, Best. N 1), Kurhessen (Gaustatistiken 1933 . 1945, Mitgliederkartei Kreis Hersfeld, MR, Best. 327/1), das NSV-Mitteilungsblatt München-Oberbayern (1936-1939, MSt) und einige Vorgänge aus Schwaben über WHW und Personalien (A, mit Ergänzungsüberlieferung in Akten eines NSVKinderheims und der Kreisleitungen Memmingen, Augsburg, Günzburg, Marktoberdorf, Nördlingen, Sonthofen und in geringerem Umfang von 10 weiteren Kreisleitungen). Die der Württembergischen Zentralleitung für das Stiftungs- und Anstaltswesen übertragenen Aufgaben der Gauwaltung Württemberg-Hohenzollern sind in deren Akten dokumentiert (Abschnitt 2.1.2.2.4). Für die Gauwaltungen Düsseldorf, Essen, Köln-Aachen, Franken und Mainfranken ist Korrespondenz mit staatlichen Stellen in geringem Umfang in deren Akten (D, DT, WÜ, N) nachgewiesen.

Lit.: SCHRIFTGUT der NSDAP. Teil 1, S. 199; Teil 2, S. 133; Teil 4, S. 315-318. - P. ZOLLING: Zwischen Integration und Segregation - Sozialpolitik im "Dritten Reich" am Beispiel der "Nationalsozialistischen Volkswohlfahrt" (NSV) in Hamburg. 1986.

\subsubsection{NS-Kriegsopferversorgung (NSKOV)}

Vom NSDAP-Hauptamt für Kriegsopfer in München, das ebenso wie den angeschlossenen Verband NSKOV der Reichskriegsopferführer Hanns Oberlindober mit Sitz in Berlin leitete, ist kein Schriftgut überliefert. Aus der publizistischen Tätigkeit liegt die Zeitschrift „Deutsche Kriegsopferversorgung“ (ab 1932, mit Fachblatt „Der Kriegsblinde" bis 1943) vor.

Der größte Teil der spärlichen Überlieferung aus dem nachgeordneten Bereich stammt von der 


\section{Landessiedlungsleitung West}

und ist in Akten des Arbeits- und Sozialministeriums von Nordrhein-Westfalen (D, Best. NW 6) enthalten. Es handelt sich dabei um das Bauprogramm und allgemeine Bestimmungen zum Volkswohnungsbau mit entsprechendem Schriftwechsel (7 Bde, 1933-1942) und über die Durchführung von Bauvorhaben in Essen und in 18 weiteren NSKOV-Siedlungen in der Rheinprovinz und in Westfalen (ca. 160 Bde, 1933-1944).

Die übrigen noch vorhandenen Akten der NSKOV sind bei den Gauwaltungen Baden (KA, Best. 465 d, 3 Bde, 1937, 1942-1944), Köln-Aachen (D, Best. RW 23, 27 Bde 1941-1944, dabei allgemeines 5 Bde, 1937-1939, Verleihung des Verwundetenabzeichens, 1940-1944, Fürsorgemaßnahmen, vor allem Gewährung von Renten in Einzelfällen, 18 Bde, 1940-1944), München-Oberbayern (MSt, 5 Bde, mit Rundschreiben 1935-1944, Beitragsabrechnungen 1944, 16 Bde Schriftwechsel der Kreiswaltung Traunstein in Einzelfällen, 1920-1944), Westfalen-Nord (MS, Ortsverband Herford, 29 Bde, 1936-1944, mit Rundschreiben der Gauleitung) und Württemberg-Hohenzollern (LB, Best. PL 518, Rundschreiben 1939-1940) entstanden. Für die Gauwaltungen Düsseldorf, Essen, Köln-Aachen, Franken und Mainfranken ist Korrespondenz mit staatlichen Stellen in geringem Umfang in deren Akten (D, DT, WÜ, N) nachgewiesen.

Lit.: WIDERSTAND UND VERFOLGUNG in Bayern. Bd. 2. 1975. S. 147-149. - SCHRIFTGUT der NSDAP. Teil 1, S. 201, 203: Teil 2. S. 136: Teil 4, S. 323.

\subsubsection{NS-Deutscher Ärztebund/Hauptamt für Volksgesundheit}

Die zentrale Überlieferung beschränkt sich auf einen Tätigkeitsbericht für 1939 bis 1942 im Hauptarchiv der NSDAP (BA, Best. NS 26), die Zeitschrift „Ziel und Weg“ (1931-1939, dann „Die Gesundheitsführung“ bis 1945), einen Informationsdienst des Hauptamtes (ab 1942) und Einzelschriften „Für Mutter und Kind“). Ergänzungen enthalten staatliche Akten (u. a. des Reichsgesundheitsführers, vgl. Abschnitte 2.1.1 und 2.1.2.2.3). Von regionalen Gliederungen sind wenige Vorgänge aus Baden (KA, Best. 465 d, 2 Bde, 1941-1944) und Bayreuth (BAM, 7 Bde, 1937-1945) vorhanden.

Lit: M. H. KATER: Die „Gesundheitsführung“ des deutschen Volkes. 1983. - A. ZAPP: Untersuchungen zum Nationalsozialistischen Deutschen Ärztebund. 1979.

\subsubsection{NS-Rechtswahrerbund (NSRB)}

\subsubsection{Reichsrechtsamt}

BA, Best. NS 16

Aus dem von Reichsleiter Hans Frank ebenso wie die Akademie für Deutsches Recht als Konkurrenz zum Reichsjustizministerium aufgebauten und in Personalunion mit dem NSRB geführten Amt blieben nur wenige Akten erhalten (insgesamt 109 Bde). Sie betreffen $u$. a. allgemeine und organisatorische Angelegenheiten (10 Bde, 19341945, mit Anordnungen), Personalien (22 Bde Sammel-, 29 Bde Einzelpersonalakten), Schulung und Berufsförderung (10 Bde, 1938-1945, mit Handakten des Staatssekretärs Klemm), Mitgliedschaft im NSRB und seiner Sterbegeldversicherung (13 Bde, 19361945), Vermögen und Haushalt (27 Bde, 1935-1945). Vom Amt für Rechtsbetreuung ist der Jahresbericht 1941 vorhanden (Hauptarchiv der NSDAP, NS 26).

Der "Deutschen Justiz" des Reichsjustizministeriums entsprach als "Zentralorgan" des NSRB die Zeitschrift „Deutsches Recht“ (ab 1931), der ein „Mitteilungsblatt“ des NSRB (ab 1935) beigefügt war, neben dem es noch „Vertrauliche Mitteilungen des 
Reichsrechtsamtes“ gab (ab 1936); 1939 wurde sie mit der vom Deutschen Anwaltverein bzw. der Reichsgruppe Rechtsanwälte herausgegebenen "Juristischen Wochenschrift" vereinigt. 1936 erschien erstmals ein "Jahrbuch des deutschen Rechtsstandes". Das Reichsrechtsamt führte die Zeitschriften „Deutsche Verwaltung“, „Deutsche NotarZeitschrift" und „Der deutsche Rechtspfleger" und die Berichterstattung über die Reichstagungen fort, die an die Stelle des Deutschen Juristentages getreten waren. Weitere Publikationen waren „Die nationale Wirtschaft“ (12 Jahrgänge, 1933/34 bis 1944), ,Jugend und Recht“, "Mitteilungen des Vereins Deutscher Amtsanwälte“, das "Jahrbuch für nationalsozialistische Wirtschaft", „Nationalsozialistische Leithefte für ein neues deutsches Strafrecht“ (1936) und die Ehrengerichtsordnung von 1937.

Lit: SCHRIFTEN ZUM STAATSAUFBAU 8. 1935. - R SCHMID: Erinnerungen an den NSRechtswahrerbund. 1954. - C. SCHUDNAGIES: Hans Frank. 1988.

\subsubsection{Gauwaltungen des NSRB}

Nur wenig ist von ihrem Schriftgut erhalten. Am umfangreichsten sind Personalunterlagen (Karteikarten, Fragebögen u. dgl.) der Gauwaltung Baden-Elsaß (KA, in Best. 465c, ca. 180 Bde Sammelakten, 1933-1944, 6 Bde, u. a. über Berufsförderung und Zusammenarbeit zwischen Justiz und Partei, 1933-1942, noch im BA, Best. NS 16) und Akten des Bezirks Altona im Gau Schleswig-Holstein mit Berichten, Rundschreiben, Beurteilungen, Vorgängen über Mitgliedschaft, Schulung, Maßnahmen gegen Juden (HH, Best. 614-2/6, 51 Bde, 1933-1937, z. T. bis 1940).

Im Bestand der Generalstaatsanwaltschaft beim Oberlandesgericht Hamm (MS) befinden sich Handakten der Gaufachgruppenleiter des Gaus Westfalen-Süd, Generalstaatsanwalt v. Steinaecker und Oberlandesgerichtsrat Roebling, u. a. über Strafrechtsreform und Stellung der Richter (20 Bde, 1934-1939). Die 1934 bei den Amtsgerichten eingerichteten und den Gaurechtsämtern nachgeordneten Rechtsbetreuungsstellen, in denen Anwälte eine nebenberuffiche Auskunfts- und Beratungstätigkeit ausübten, werden durch Akten der Rechtsberatungsstelle Medebach dokumentiert (MS); sie betreffen Organisation, personelle Besetzung, Dienstanweisungen, Berichterstattung, Fortbildung und Einzelfälle (93 Bde, 1934-1938).

Von der Gauwaltung München-Oberbayern sind Rundschreiben und Schriftwechsel, Tätigkeitsberichte, Programme, Personalbögen (insgesamt 9 Bde, 1933-1944) sowie fortgefürte Akten des Landesverbandes bayerischer Referendare (5 Bde, 1929-1942) vorhanden (MSt), vom Gaurechtsamt vor allem über Rechtsberatung (4 Bde, 19371940); sie werden ergänzt durch Korrespondenz des Gaurechtsberaters, des Münchener Oberlandesgerichtspräsidenten Walter Stepp, u. a. über Veranstaltungen, Vortäge, Tätigkeit in Zivilsachen und Beamtenorganisationen in Akten des Oberlandesgerichts (4 Bde, 1943-1944). Einige Personal- und Organisationsvorgänge der Gauwaltung Württemberg-Hohenzollern sind ebenfalls überliefert (LB, Best. PL 518, 4 Bde und 42 Einzelschriftstücke, 1933-1943); von derselben Provenienzstelle liegen Akten über Rechtspfieger und Notare mit Vorakten von Berufsverbänden (5 Bde, 1928-1939) vor.

Lit.: WIDERSTAND UND VERFOLGUNG in Bayem. Bd. 2. 1975. S. 145-146. - SCHRIFTGUT der NSDAP. Teil 1, S. 192: Teil 2, S. $128 \mathrm{f}$. 


\subsubsection{Reichsbund der Deutschen Beamten/Hauptamt für Beamte}

BA, Best. NS 40

Die Überlieferung beschränkt sich auf wenige Akten über Personalangelegenheiten insbesondere in Verbindung mit ReichsverteidigungsmaBnahmen (5 Bde, 1937-1942), Rundschreiben der Gaufachschaft Reichssteuenerwaltung Hamburg (1933-1936) und im Hauptarchiv der NSDAP (NS 26) zusammengestelltes Material über Gründung und Auflösung des Reichsbundes (1930-1943) sowie Teile der Mitgliederkartei (im BDC). Der Film ..Das Buch der Deutschen“ zeigt die Herstellung einer Prachtausgabe von "Mein Kampf“ und Übergabe durch den Reichsbeamtenführer Neef an Hitler als Geschenk zum Geburtstag 1936 (BA, Filmarchiv). Als Publikationen sind die NS-Beamtenzeitung (mit 10, z. T. von gleichgeschalteten Verbänden übernommenen Fachausgaben u. a. für Verwaltungs-, Justiz-, Finanz-, Post- und Eisenbahnbeamte, 19331942), „Die Brieftaube“ zur Betreuung einberufener Mitglieder (ab 1939), der „Deutsche Beamten-Kalender" (ebenfalls mit unterschiedlichen Ausgaben für einzelne Fachschaften), der "Almanach der Deutschen Beamten“ und das „Beamten-Jahrbuch. Wissenschaftliche Monatsschrift für das Deutsche Berufsbeamtentum“ (1934-1939), ferner das „Mitteilungsblatt des Reichsbundes der Deutschen Beamten“ (ab 1935) überliefert. Als Einzelveröffentlichungen erschienen $u$. a. beamtenrechtliche und beamtenpolitische $\mathrm{Ge}$ setze, Verordnungen, Erlasse (5 Bde, 1937-1941) und Richtlinien fur Propaganda und Schulung (3 Bde, 1936-1939). Reste von Schriftgut der Gauämter für Beamte sind nur für Württemberg-Hohenzollern vorhanden (LB, Best. PL 517, 7 Bde mit Rundschreiben und Propaganda).

Lit.: H. MOMMSEN: Beamtentum im Dritten Reich. 1966.

\subsubsection{NS-Lehrerbund (NSLB)}

9.4.7.1 Reichswaltung/Hauptamt für Erzieher $\quad$ BA, Best. NS 12

Der noch nicht endgültig erschlossene Bestand (ca. 1500 Bde ohne die Karteien) enthält einen wesentlichen Teil des in Bayreuth unter den Amts- und zugleich Gauleitern Hans Schemm (bis 1935) und Fritz Wächtler entstandenen Schriftguts. Darunter befindet sich Korrespondenz Wächtlers (1936-1943), eine Sammlung von Anordnungen und Tätigkeitsberichten (20 Bde, 1930-1944), allgemeine Korrespondenz mit Gauwaltungen (26 Bde, 1932-1937), Berichte u. a. der Gauwaltungen Essen, Franken, Hamburg und Kurhessen (1935-1937), Denkschriften und Vorschläge aus allen Bereichen des Erziehungswesens. Material über Aufgaben und Leistungen des NSLB im Krieg (1941 bis zur Einstellung der Tätigkeit 1943) liegt im Hauptarchiv der NSDAP (NS 26) vor (auch Rundschreiben 1940-1942). Weitere Akten der Reichswaltung sind mit denjenigen der Gauwaltung Bayerische Ostmark (BAM, M 30, 1930-1944, u. a. betr. KLV, Berufsund Fachschulen, Schülerfahrten, Tbc-Hilfe, Kassensachen und Hypotheken) überliefert. Im übrigen sind folgende Abteilungen im BA-Bestand mit Akten vertreten:

Abt. Organisation (11 Bde, 1932-1938, u. a. betr. Tagungen, Grenz- und Auslandsangelegenheiten).

Abt. Erziehung und Unterricht (30 Bde, 1933-1940, insbes. betr. sozialpädagogische Berufe, Zeitschrift „Der Kindergarten“, ferner Verhältnis zu den Kirchen, Angelegenheiten der Landschulen und der Tanzlehrer). 
Abt. Schrifttum mit Rundschreiben, allgemeiner Korrespondenz und Tätigkeitsberichten (8 Bde, 1933-1943), Korrespondenz mit Verlagen (18 Bde, 1930-1939), Akten über Jugendschriftum (19 Bde Schriftwechsel 1933-1936, 97 Bde Begutachtung einzelner Publikationen) und -zeitschriften (19 Bde). Begutachtung pädagogischer Schriften und Lehrmittel (48 Bde).

Abt. Presse und Propaganda (ca. 100 Bde, 1934-1943, dabei Stimmungsberichte aus den Gauen 1935-1937, Rundschreiben der Reichspropagandaleitung 1935-1940, Pressearchiv 1927-1943, Akten der Schriftleitungen „Der Deutsche Erzieher“, 1938-1944, und "Nationalsozialistisches Bildungswesen“ und über Lehrmittelausstellungen).

Abt. Wirtschaft und Recht mit Akten über Haftpflicht-, Rechtsschutz- und Unfallversicherung (19 Bde mit Vorakten des Deutschen Lehrervereins, 1926-1943), über Verwaltung von Erholungsheimen und anderen Liegenschaften (54 Bde, 1928-1944) und über die Liquidierung von Lehrerverbänden, vornehmlich in Österreich und dem Sudetenland (69 Bde, 1935-1940).

Abt. Kasse und Vermögensverwaltung (92 Bde, 1935-1943, dabei Finanzierung der Kinderlandverschickung 1940-1943).

Die nach Gauen geordnete Mitgliederkartei (240 Bde) ist unvollständig, doch befindet sich im Berlin Document Center eine alphabetische Kartei, die zusammen mit anderen Personalunterlagen über Lehrer und einer Kartei des NS-Dozentenbundes (Fachschaft I des NSLB) Angaben über 491270 Personen (u. a. über Zugehörigkeit zu früheren und zu anderen NS-Organisationen) enthält.

"Rundschreiben der Reichswaltung“ wurden ab 1937 verbreitet. Mit der „Nationalsozialistischen Lehrerzeitung“, ab 1938 „Der Deutsche Erzieher“ (mit Beilagen für die einzelnen Gaue, einzelne Jahrgänge und Nummern für Berlin: „Nationalsozialistische Erziehung“, München-Oberbayern und Schwaben: „Pädagogischer Umbruch“ im IfZ und "Wirtschaft und Recht“) wandte sich die Reichsleitung an alle Lehrer, die Zeitschriften „Die deutsche Volksschule“ (ab 1939), ,....höhere Schule“ (ab 1934), „....Hauptschule“ (ab 1941), „...Sonderschule“ (ab 1934) berücksichtigten die Schularten. Außerdem erschienen die erziehungswissenschaftliche Monatsschrift „Deutsches“ (1933-1936) bzw. „Nationalsozialistisches Bildungswesen“ (ab 1936-1943), „Die deutsche Schulfeier“ (Jg. 1938 IfZ), „Die deutsche Berufserziehung“ (1940-1942 IfZ), „Politische Leibeserziehung“ (ab 1934, 1943 vom Reichserziehungsministerium übernommen), „Bausteine für die deutsche Erziehung“ (ab 1935, drei von 19 Heften IfZ), „Fest-, Feier- und Freizeitgestaltung. Amtliches Mitteilungsblatt der Hauptabteilung Schulung“ (12 Hefte, 1936-1939, IfZ). Für die schulpflichtige Jugend wurden seit 1933 die Schülerzeitungen „Deutsche Jugendburg“ (für die Grundschule) und „Hilf mit!“ herausgegeben.

Lit:: J. WEISS: Nationalsozialistische Schulbuchgutachten im Bundesarchiv Koblenz. 1981. - W. FEITEN: Der Nationalsozialistische Lehrerbund. 1981. - J. ERGER: Lehrer und Nationalsozialismus. 1980. - F. KÜHNEL: Hans Schemm. 1985. - J. HEINSSEN: Das Lesebuch als politisches Führungsmittel. 1964. U. NASSEN: Jugend, Buch und Konjunktur, 1933- 1945.

\subsubsection{Gauwaltungen des NSLB}

Es ist nicht auszuschließen, daß der Bestand im BA außer der Ersatzüberlieferung durch Schriftwechsel mit Gauwaltungen auch noch Schriftgut von diesen selbst enthält; mit Sicherheit gilt das für Akten der Gauwaltung Ausland (23 Bde). In der nach Gauen geordneten Mitgliederkartei (242 Bde) sind die Gaue im späteren Gebiet der Bundesrepublik unterschiedlich vertreten: Baden mit 13, Bayerische Ostmark mit 6, 
Berlin mit 9. Düsseldorf 5, Essen 6. Franken 4. Hamburg 5. Hessen-Nassau 8. KölnAachen 6, Kurhessen 3, Mainfranken 2. Moselland 1 (nur Anfangsbuchstaben G-Z), München-Oberbayern 5. Ost-Hannover 3. Schleswig-Holstein 5. Schwaben 3. SüdHannover-Braunschweig 6, Weser-Ems 5, Westfalen-Nord 8, Westfalen-Süd 7, Westmark 6, Würtemberg-Hohenzollern 9.

Von folgenden Gauwaltungen sind Akten in die Staatsarchive gelangt:

Bayerische Ostmark (BAM, Best. M 30): Korrespondenz Wächtlers, u. a. mit einzelnen Kreiswaltungen. Rundschreiben, Akten betr. Schulungslager und Gauschule Burs Hohenberg, Personalangelegenheiten, KLV (17 Bde, 1938-1944).

Baden (KA, Best. 465 c): nur Rundschreiben (1939-1941) und Personalunterlagen (53 Bde).

Hessen-Nassau (WI, Abt. 483): Akten über politische Überprüfung und Beurteilung von Lehrern (1934-1942), Mitgliedschaftsangelegenheiten (1935-1941), Akten der Kreiswaltung Friedberg (DA, Best. N 1).

München-Oberbayern (MSt): Rundschreiben der Reichswaltung (5 Bde, 1933-1943), Schriftwechsel, einzelne Berichte und Rundschreiben der Gauwaliung im allgemeinen (6 Bde, 1934-1940) und der Reichsabteilungsleiterin für weibliche Erziehung im NSLB, Prof. Auguste Reber-Gruber (14 Bde, 1935-1942, u. a. über die Zeitschrift „NSMädchenerziehung"). Erhebungsbögen über einzelne Schulorte (15 Bde), Personalbögen zur Leistungsschau deutscher Erzieher 1939 (6 Bde), politische Beurteilungen einzelner Lehrer (11 Bde Sammelakten, 1933-1943) und Akten über Organisation (4 Bde. 1928-1942, mit Statistiken und Informationsdienst). Schulung und Tagungen (2 Bde. 1934-1939).

Lit.: WIDERSTAND UND VERFOLGUNG in Bayern. Bd. 2. 1975. S. 137-143.

Weser-Ems (OL): Akten über Überprüfung und Säuberung der Schulbüchereien (5 Bde. 1940-1941), Werbung für ..Hilf mit" (2 Bde, 1939-1941).

Württemberg-Hohenzollern (LB, Best. PL 516, 230 Bde, 1933-1943): Korrespondenz(89 Bde, davon je 5 mit Reichs- und anderen Gauwaltungen und mit Gauleitung und deren Ämtern, 61 mit Kreiswaltungen) und Sachakten u. a. über Organisation. Personalund Haushaltsangelegenheiten (57 Bde), Sozialeinrichtungen (16 Bde). Tagungen und Veröffentlichungen (18 Bde). Schulverwaltungsangelegenheiten (19 Bde). Erziehung und Unterricht ( 9 Bde, dabei Weltanschauungsunterricht), gesellschaftliche Stellung des Lehrers (8 Bde), Mitgliederkartei.

Lit.: G. CORDES: Das Aus für die Lehrervereine in Würtemberg. Gleichschaltung und Zwangsfusion 1933. 1988.

Aus dem Gau Moselland sind Akten der Hans-Schemm-Gauschule Schloß Friedewald (KO, Best. 662,4) vor allem über einzelne Lehrgänge (31 Bde. 1936-1939. u. a. Rasse-, nationalpolitische und Lehrgänge für weltanschauliche Schulung. Musikerziehung und Feiergestaltung) überliefer, aus Süd-Hannover-Braunschweig von der Kreiswaltung Hannover (H, 54 Bde, 1932-1942, u. a. betr. Gleichschaltung 1933-1937, Feldpostbriefe 1942), und die Mitgliederkartei des Kreises Dinslaken (Gau Düsseldorf) liegt in Akten des Sonderbeauftragten für Entnazifizierung in NRW (D. Best. NW 10081129). 


\subsubsection{NS-Bund Deutscher Technik/Hauptamt für Technik}

BA, Best. NS 14

Der kleine Bestand enthält u. a. Allgemeine Verfügungen und Anweisungen des Amtsleiters und späteren Ministers Fritz Todt, seines Nachfolgers Albert Speer und des Leiters des Stabsamtes Karl Otto Saur (16 Bde, 1937-1944), Korrespondenz mit den eingegliederten Berufsverbänden und Gauwaltungen in Mitgliedschaftsangelegenheiten (15 Bde, 1937-1942), Akten über Berufsangelegenheiten von Ingenieuren und Chemikern (15 Bde, 1937-1943), über Redner- und Vortragswesen (8 Bde, 1939-1942) und die Herausgabe der "Technischen Mitteilungen“, "Deutsche Wasserwirtschaft" und "Der Deutsche Baumeister" (mit der Beilage „Heimatpflege - Heimatgestaltung") sowie anderer Veröffentlichungen (25 Bde, 1937-1944). AuBer diesen erschienen noch die „Deutsche Technik“ mit „Mitteilungen des NS-Bundes Deutscher Technik“ (1933-1943), die Wochenzeitung "Rundschau Deutsche Technik“, Mitteilungsblätter und Dienstnachrichten der Fachgruppe Bauwesen und anderer Untergliederungen, einzelne Schulungsbroschüren und Tagungsberichte (z. B. der Reichsarbeitsgemeinschaft Erfindungswesen 1944, von der auch 1942/43 „Nachrichten“, eine „Arbeitsanweisung“ und ein „Taschenbuch für Erfinderbetreuung“ ausgingen). Ein Film würdigte „Dr. Todt. Berufung und Werk" (BA-Filmarchiv, 1943).

Die im Berlin Document Center aus Akten des Hauptamtes gebildeten ca. 20000 biographic files betreffen hauptsächlich die unmittelbare wie die mittelbare Mitgliedschaft durch Zugehörigkeit zum Verein deutscher Ingenieure, zum Verein der Eisenhüttenleute, zum Verein deutscher Chemiker und andere Verbände für technischnaturwissenschaftliche Berufe. Aus den regionalen und örtlichen Organisationen sind nur wenige Splitter der Gauwaltung Schwaben (A, 5 Vorgänge, 1939-1944) und Korrespondenz eines Vorstandsmitglieds der Ortsgruppe Hannover (H, Best. Hann. 320 II, 2 Bde, 1927-1937) nachweisbar.

Lit.: K. H. LUDWIG: Technik und Ingenieure im Dritten Reich. 1974. - F. W. SEIDLER: Fritz TodL 1988. 
